Portland State University

PDXScholar

Dissertations and Theses

Dissertations and Theses

Spring 1-1-2012

\title{
Public Participation in Emergency Management
}

Jason Alexander Rood

Portland State University

Follow this and additional works at: https://pdxscholar.library.pdx.edu/open_access_etds

Part of the American Politics Commons, Civic and Community Engagement Commons, and the Defense and Security Studies Commons

Let us know how access to this document benefits you.

\section{Recommended Citation}

Rood, Jason Alexander, "Public Participation in Emergency Management" (2012). Dissertations and Theses. Paper 333.

https://doi.org/10.15760/etd.333

This Thesis is brought to you for free and open access. It has been accepted for inclusion in Dissertations and Theses by an authorized administrator of PDXScholar. Please contact us if we can make this document more accessible: pdxscholar@pdx.edu. 
Public Participation in Emergency Management

\author{
by \\ Jason Alexander Rood
}

A thesis submitted in partial fulfillment of the requirements for the degree of

\title{
Master of Science in \\ Political Science
}

Thesis Committee:

Bruce Gilley, Chair

Craig Shinn

Ronald Tammen

Portland State University

(C)2012 


\begin{abstract}
With disasters increasing in frequency and costs each year, this study seeks to explore ways greater public participation could assist emergency managers in their mission to keep communities safe. Specifically this study examines the policy process and administrative functions of emergency management to illuminated the benefits and hindrances involved in greater participation. This study conducted a qualitative analysis of governmental documents, disaster case studies, international research, as well as political science and administrative doctrines, to arrive at its conclusions. The results of this study reveal that the public is a largely untapped resource in the emergency management field. Engaging the public dialogically in early policy stages and emergency management phases is essential to successful inclusion for both administrators and communities. Specifically, public inclusion creates expanded knowledge, shared learning, personal responsibility, and increased social capital. Faced with the growing threat from disasters, emergency management can create communities that are both more resilient and sustainable by increasing public participation.
\end{abstract}




\section{Dedication}

This is dedicated to those who have provided unfaltering support as I have chased my dreams. 


\section{Table of Contents}

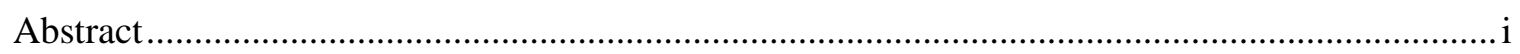

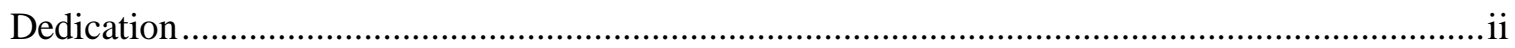

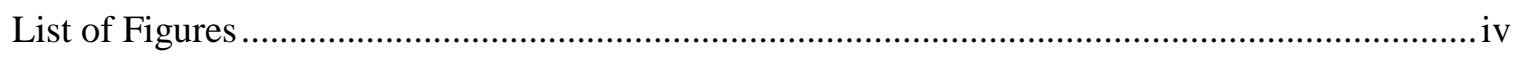

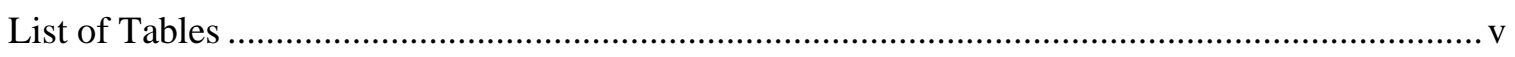

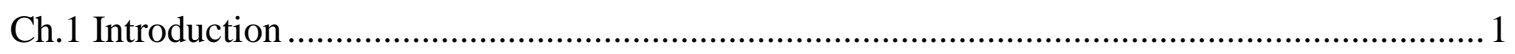

Ch.2 Effective Emergency Management …........................................................................ 18

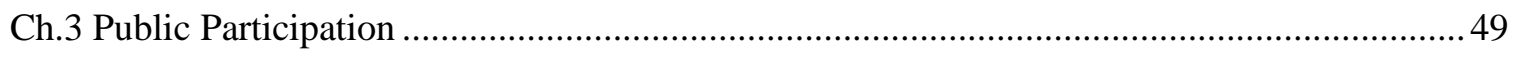

Ch.4 The Public in Emergency Management …..................................................................... 73

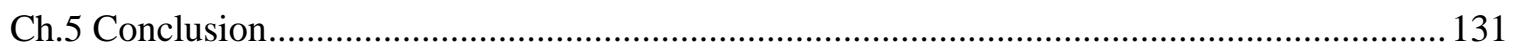

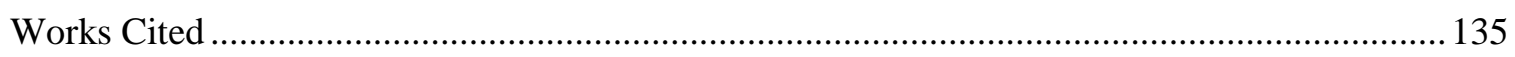

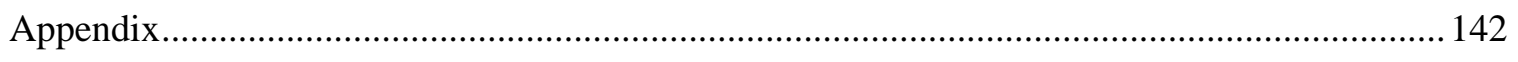

The Public in Portland's Emergency Management.......................................................... 142 


\section{List of Figures}

Figure 1 Core Topics of Hazards and Disaster Research ........................................... 27

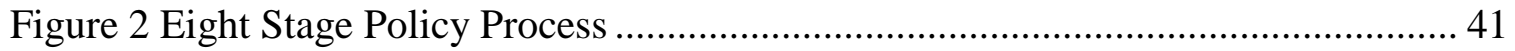

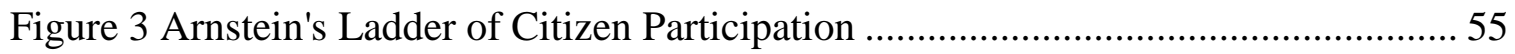




\section{List of Tables}

Table 1 Frequency of Declared Disasters 1953-2011 _................................................. 2

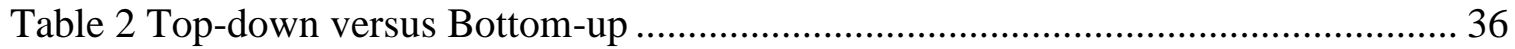

Table 3 Theoretical Participatory Models.................................................................... 58

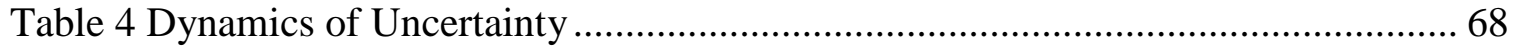

Table 5 Advantages and Disadvantages of Public Participation .................................... 71

Table 6 Recommendations for Public Participation in Emergency Management .......... 134 


\section{Ch.1 Introduction}

\section{Introduction}

The post- 9/11 environment has resulted in a resurgence of the militarized, topdown approach to emergency management. This comes at a time when the nature and number of catastrophic risk events, as well as their complexity, is growing, making this model even more potentially damaging than in the past. While first responders and traditional emergency management functions remain critical, this thesis seeks to reinvigorate interests and action in public participation in the emergency management policy process in order to strengthen the capacity of communities to mitigate, prepare, respond, and recovery from both natural and man-made disasters. The Japanese earthquake of March $11^{\text {th }}$ was the fourth most powerful earthquake in history. The initial disaster rapidly cascaded beyond the abilities of a seemingly well-prepared government. It created nearly 30 -foot tsunami, destroying communities as well as the worst nuclear incident since the 1987 Chernobyl meltdown and is estimated to have led to economic losses of \$309 Billion (United Nations, OCHA, 2011). The human cost stands at an approximate thirteen-thousand confirmed dead, and nearly fifteen-thousand still missing. In contrast to the unpredictability exhibited in the Japanese earthquake, the United States' Hurricane Katrina was understood to the extent that President Bush declared a state of emergency in the region two days prior to the storms landfall. The lack of broad knowledge, community interaction, and preparation led to a worsening of the disaster. The most recent FEMA doctrines on inclusion and collaborative methods, called whole 
community approaches, still lack an institutionalized role for greater public participation (U.S. DHS, FEMA, 2011). Despite advance knowledge and preparations, approximately 1,800 lives were lost and Hurricane Katrina became the most costly disaster in American history.

All disasters have shared the characteristic of being monumentally costly, both in lives and in capital. As the world's nations grow in population size and technical sophistication, the total destructive capability of disasters have also increased. Natural threats can be understood in a continuum including man-made disasters that are chemical, biological, nuclear or technological in nature (Posner, 2004). This continuum has led to the professionalization of those in the field of emergency management, who work to mitigate, prepare, respond, and recovery from disasters.

Table 1 Frequency of Declared Disasters 1953-2011

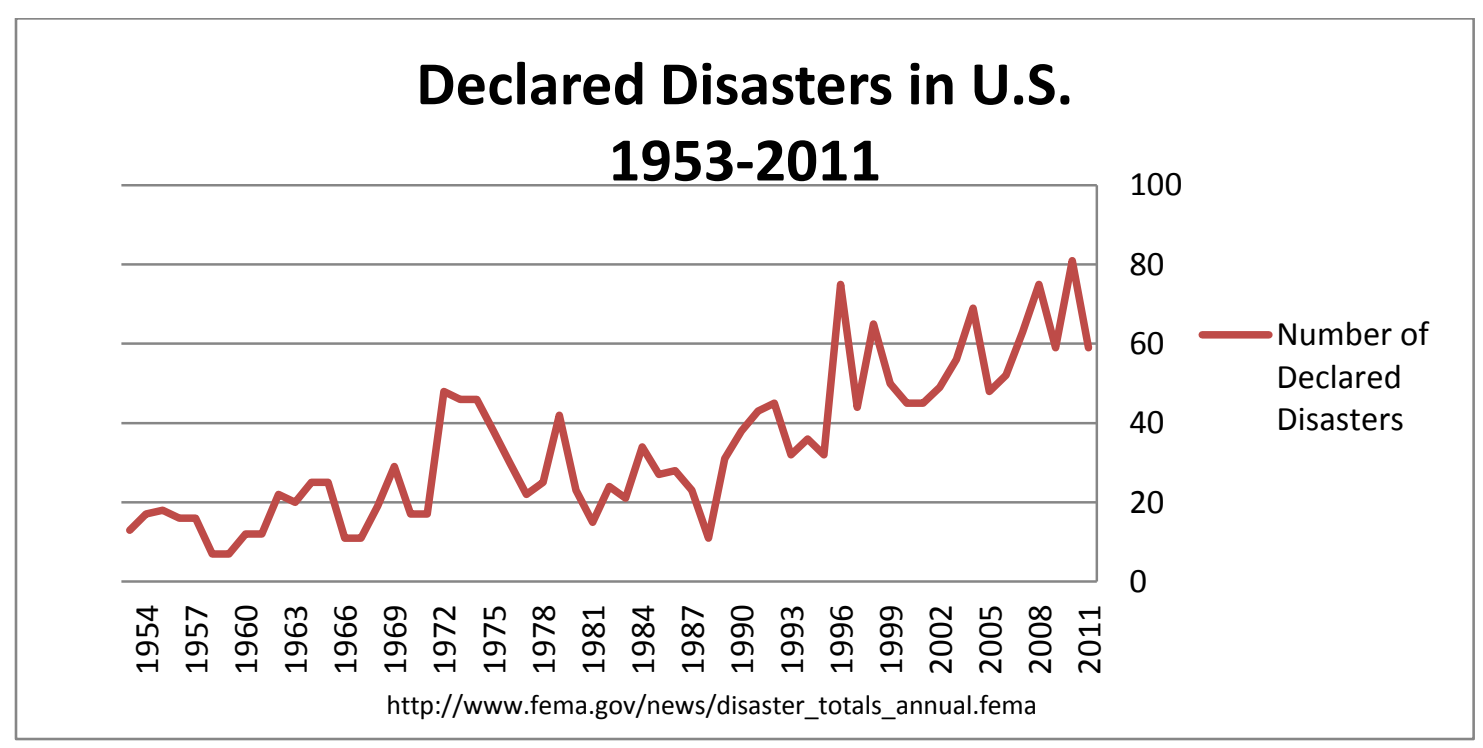


The capacity for destruction and the total-stakeholder effect disasters create fundamentally threaten contemporary society, because disasters, while geographically centralized, have no considerations for political boundaries, administrative processes or carefully laid plans (Edwards, 2009; Bowen, 2008; McInerney and Keller, 2008). Although all disasters are indeed local, the broad interdependences by which societies in developed nations function with, defy the capacities of strictly local emergency planning. With this in mind, the U.S. federal government initiated The Defense of Production Act of 1950 and has since consolidated efforts in the Federal Emergency Management Agency under the Department of Homeland Security (Emergency Management Institute, IS-230A). Based on military hierarchy and top-down management, this organization produces the benefits of rapid and rational decision making at the cost of knowledge depth and a prepared public.

Federal efforts to unify the nation's response to disasters have not just followed a military style of organization, but also a Hamiltonian administrative understanding of issue engagement and policy formation (Sylves, 2008). The Hamiltonian method of issue engagement relies on centralized experts working under performance and evaluative structures to identify, plan, and execute solutions at the governmental level (Sylves, 2008). While this method is excellent for addressing 'tame' problems, such as how to provide a national highway system, it is less apt at dealing with problems of evolving complexity. Disasters present problems that we may identify as "wicked" because of the following characteristics: their nature is not fully agreed upon, context is essential, 
contain moral ambiguities, no immediate or ultimate solutions exist, challenge value systems, involve a myriad of decision-makers and stakeholders, and in a sense the planner has no right to be wrong (Churchman, 1967; Rittel and Weber, 1973). In sharp contrast to the demands of "wicked" problems, Hamiltonian policy approach applies narrowly focused knowledge to clearly classified problems for use of centralized leadership in a closed-decision making system.

While the centralized Hamiltonian approach has been the standard for governmental response to disasters, the Jeffersonian model presents an alternative. Many experts now agree that in the future, the world will face increasingly large natural and man-made threats, only increasing in cost to our communities (Webster, 2005). The centralized approach to dealing with such threats is suitable for some localized situations, but is not as nimble at controlling the cascading effects of large-scale disasters. With costs escalating, budgets shrinking, and authorities strained to the point of collapse; disaster stricken neighborhoods, local communities, and towns end up in the hands of emergent groups of citizens. These groups need to be viewed as neither dysfunctional nor conflictive, but as inevitable and outside the boundaries of planning (Stallings and Quarantelli, 1985). These citizen groups tend to help retain order, provide for the needy, and search for those fallen (Horwich, 1990). One lesson from Hurricane Katrina was when government agencies become inundated, local citizens will organized on their own behalf and come to the aid of their fellow citizens. Rather than conceptualizing the public as obstacles to emergency managers, we must ask, should broad public 


\section{Public Participation in Emergency Management}

participation be incorporated into the policy process and administration to maximize the effectiveness of emergency management?

\section{Statement of Problem}

Major, catastrophic threats facing both the nation and the Portland community are real, but the fact that they are infrequent and unpredictable make dedicated funding, interest, and political movements difficult to manifest. One source of public apathy, not just in emergency management but in many operations of the government, is the essential disconnect the public has with the policy process in general. This indifference to governmental agencies has led to a relatively limited amount of citizen participation in activities encouraged by emergency management, activities that would strengthen the overall resiliency of a community to disasters. When people talk about public participation, they tend to mean voting, but mere voting is inadequate. "Participation" in its Tocquevillian sense, means the community acts on its own behalf to address concerns and solve problems. This process requires a large segment of politically active citizens to work together, which Tocqueville saw as a powerful American quality. Still, Tocqueville was describing America in 1831, well before the centralization and professionalization of the federal government. Since extinguished, the civic republic tradition promoted an active citizenry, face-to-face communications and celebrated average citizen contributions (Morgan, Green, Shinn, and Robinson, 2008). Today, the general public is removed from the policy process; as expertly trained bureaucrats, agencies officials and political actors represent the policy-community, charged with producing policy that best fits into existing systems (Birkland, 2010). This detached policy process has helped 


\section{Public Participation in Emergency Management}

breed not just apathy, but also distrust and resentment towards many state and federal agencies such as Federal Emergency Management Agency (referred from now on as FEMA).

FEMA began as the Federal Emergency Management Agency in 1978, and it has most recently been under umbrella of the Department of Homeland Security. This agency has its roots in Cold War plans to protect against Soviet conventional and nuclear attacks, which is why the organization reflects a military style of hierarchy and communication-- good for battle, but more difficult to apply to untrained civilians during a calamity. Like the military, this federally funded agency uses its grant writing power to promote centralized planning in states seeking funds. As Frances Edwards points out, this degree of central control leaves little room for policy codetermination within states and cities, in turn this disengages creative and pragmatic local problem solving (Edwards, 2009). The fundamental disconnect between the local and the federal governments produce a dysfunction in shared purpose (following orders to receive federal funding versus fulfilling local emergency considerations), just as citizen, disengagement undermines preparedness.

\section{Background and Need}

There are serious problems for emergency managers in establishing consistent connections with the public. Though information campaigns have come a long way since the World Wide Web introduction, they are far from perfect, and the extent to which these efforts have been successful will be explored further in this study. Three primary problems still dramatically affect emergency managing and public safety. First, there is a 


\section{Public Participation in Emergency Management}

lack of awareness by the public of the efforts of emergency managers in their respective communities. Second, the policy process is shaped with input from a relatively small group of actors creating problems in implementation. Finally, the centralized organizational structure of emergency management has prevented it from entering public consciousness.

With a public largely unaware of local agency efforts, and because of Hurricane Katrina, FEMA has become household name with negative connotations. In Portland Oregon for example, knowledge of the Portland Bureau of Emergency Management is sparse, especially considering the unusually high education level (40\% of Portlanders have college degrees) and education's high correlation to social capital (Economic Research Service, 2012; Putnam, 2003). In order to carry out successful mitigation efforts and comprehensive preparedness measures, the public must be both aware and in collaboration with emergency managers.

In addition, a lack of transparency in policy process, beginning with community concerns and ending with an agency enforcing a new tax or law, can entail a dizzying array of political actors, governmental procedures, and closed door negotiations. The policy process at both federal and local levels offer the general public very few areas of participation, usually at the issue emergence and evaluation stages, but there are greater opportunities. Possibly the largest failure to surface during Hurricane Katrina debacle was the absence of coordination between responding organizations, including; local, state, federal governments, nongovernmental organizations, nonprofits, and volunteer 
organizations; resulting in delayed evacuations and the politically disastrous choice to herd people into the Astrodome (Farazamand, 2007). This lack of coordination illustrates a deficit in communication and participation between even the most involved authorities and emergency actors.

The final problem related to public participation and emergency management concerns the organization of administrative functions. FEMA's hierarchical, bureaucratic organization creates a rift in knowledge and interaction between the public and managers. In order to combat this fissure, FEMA has developed and implemented two outreach programs. The first is operated through the Citizen Corps, called the Community Emergency Response Team program (referred to as CERT), is facilitated by local firstresponders, and provides citizens with approximately twenty-four hours of disaster first response instruction, basic equipment and liability protection (CERT Training conducted June 2011). Subsidized through FEMA, this free program is facilitated by local fire departments and emergency medical technicians. The second outreach program is offered by the Emergency Management Institute, and consists of online training programs. While there is no doubt about the value of these training avenues, there are limitations to the overall effectiveness of both, to be addressed in later chapters.

Despite the efforts of both federal and local emergency managers, these three problems continue to hinder the emergency management community in reaching a high degree of community preparedness. This study would like to further understanding of public participation in emergency management by answering three corresponding 


\section{Public Participation in Emergency Management}

questions. First, where are the strengths of public participation and where does it detract from progress on public policy? Second, can we identify areas in the policy process that public input and direction may actually be beneficial to the goals of emergency management? Finally, where in the emergency management community are there areas in policy and administration that are lacking public participation and where its inclusion would be advantageous to the FEMA mission? In light of the changing nature of natural and man-made disasters of all types, the question is how emergency management can be restructured at both the policy-making and policy-implementation stages in a way that brings the benefits of public participation into play while minimizing its shortcomings.

\section{Purpose of Study}

This study seeks to explore ways an increase in public participation could help administrators combat the danger and costs of disasters. More specifically, it asks how public participation could assist public managers within the policy and administrative processes as they work to create more resilient and less vulnerable communities. This study explores the issue internationally, on macro and micro levels across the United States, as well as in the community of Portland, Oregon, which has distinctively active citizenry and various disaster threats (See Appendix).

Today the United States, and cities like Portland, are under threat from natural disasters posing unnecessarily severe impact on citizens, business, and government functions. To prepare for these inescapable and unpredictable eventualities, policies have been based on a Cold War model. This model subordinates the general public and local manager's concerns to those of national importance. In place of locally formed policy, a 


\section{Public Participation in Emergency Management}

centralized federal plan identifies roles, responsibilities, and contingences that require federal manpower and resources. Emergency management's efforts have focused predominantly on centralized planning of response and recovery while overlooking, in many respects, the greatest assets they have against the threat of disasters--a prepared citizenry. Without a broad coalition of public actors, who participate in rather than just being informed of emergency management's efforts, the costs in lives and capital lost to disasters will continue to rise.

In order to draw out areas of emergency management that could benefit from increased public participation, this research explores current and historical foundations of civic collaboration and juxtaposes these findings with current emergency management organizations. To do so, the research engaged in analysis of an array of official government documents including but not limited to; federal, state and city disaster and mitigation plans, Federal Commission reports on Hurricane Katrina, as well as participated in FEMA sponsored activities directly involving citizens. One important element of research on governmental documents requires special mention; there are prominences of federal mandates associated with the requirements of local emergency management grants. In many, if not most states, at least $50 \%$ funding comes by way of the Emergency Management Performance Grant, and demands strict adherence to federal requirements, which will be further detailed in forthcoming chapters. A limitation of this study is the time dedicated to illuminating the elaborate relationships and collaborative 
efforts produced by a number of different actors, including tribes, special districts, the vast regulatory agencies, as well as county and state governments.

Expected outcomes for this study take three different forms. First, this study may provide emergency managers with some useful information regarding the public's potential advantages in implementing disaster mitigation and preparedness policies. Directly related, the second expectation is with the increase in the public participation in local emergency management there will be an increase in social capital that will pay predictable and unforeseen dividends when a disaster does strike a community. Finally, a public active in mitigation and preparedness will be more able to effectively influence policy by motivating political leaders. All three of these expectations would lead to a community less vulnerable to, and better prepared for disasters. A prerequisite of including greater public participation in emergency management is an effective and capacity rich government, from which greater trust and relationships emerge.

This study is primarily concerned with answering the question: what are the optimal levels and areas that could benefit from increased public participation in the policy and administration of emergency management? The question will look at approximately eight stages of the policy process (issue emergence, problem definition, agenda setting, policy formation, legitimation, enactment, implementation, and evaluation) as well as the dynamics of modern bureaucracies to see where opportunities present themselves. The proposal here is that emergency management would be 
strengthened, at local, state, and federal levels, by the adaption of the following bestpractice recommendations:

(1) Explorative Community Workshops based on United Kingdom models that address federal policy monopoly and devolve authority so local input can shape federal policy to a greater degree and communities can help shape policy agendas.

(2) Formative Community Consultations based on New Zealand models that establish balance in policy formation between levels of governance; while helping to recognize interdependencies and enhance policy understanding.

(3) Public Mitigation Sessions based on Indian models that expand disaster education and build partnerships through direct citizen involvement in risk analysis and nonstructural mitigation efforts.

(4) Community Tabletop Exercises based on FEMA prescribed activities extended out to the greater public; engages community members in practical lessons while producing a holistic understanding of threats in managers, administrators, and citizens.

\section{Terminology}

With the understanding that emergency management, policy and administrative studies carry with them terminology specific to their respective fields, this research will now take a moment to define terms that may have ambiguities or contextual notations. The definition of disaster carries with it a few different definitions depending on where you are within the policy process. The first definition comes from the Emergency Management Institute and provides an operational elucidation on when the efforts of FEMA would be initiated: 
"any natural catastrophe... or, regardless of its cause, any fire, flood or explosion, in any part of the U.S., which in the determination of the president causes damage of sufficient severity and magnitude to warrant major disaster assistance" (EMI, IS-230a).

Disasters quantified by FEMA include a numeric understanding that one-hundred deaths, one-hundred injuries, and a minimum of one-million dollars in damages fulfills their standards for a disaster. Finally, the supragovernmental organization of the United Nations defines disasters as any serious disruption of the functions of society to the extent that local peoples, organizations, and government are unable to recover with resources at hand. This study will understand disasters as they emerge in a political process, which reacts to causality figures with policy shaped by fiscal cost/benefit considerations in order to minimize community disruption in accordance with prominent authority's definitions.

Another phrase that may require a further inquiry is public participation. Public participation is the degree to which the general public takes an active role in shaping the policy that makes modern life possible. These activities can range in their requirements of time, effort, and resources from simply voting to running for public office. Sherry Arnstein's “ladder of participation” created in 1969 specifically outlines the levels of involvement the public has in shaping policy; ranging from a maximum of citizen control to the void of citizen manipulation (Arnstein, 1969). The continuum of participation will be explored further in latter chapters to determine optimal levels in particular context. 
Social capital, as defined by Robert Putnam, refers to the material and perceived mutual benefits exchanged between individuals in a densely knit network of shared interest seekers (Putnam, 2000). These connections can be brief or long term; vary in shape and size; can have collective and individual aspects and finally can have negative characteristics. These elements and more shall be fleshed-out as we explore public participation further.

Public policy is typically a governmental reaction to a societal problem that is too large for smaller organizations to adequately handle. Most policy flows through parts of, or all, eight stages of the policy process (explained in detail later). Public policy involves the efforts of actors such as elected officials, legislators, agencies, as well as private business, corporations, nongovernmental organizations, media, and private persons to various degrees. Activities may include organizing disparate individuals, setting agendas, creating goals, balancing costs and benefits, and legitimizing decisions legislatively.

Inseparable from public policy is public administration, which facilitates the implementation side of governmental action, but also actively engages all policy processes. The physical manifestation of public policy denotes the later three stages of the policy process. These actions include, but are not limited to; enactment, implementation and evaluation of policy. Typically, bureaucratic agencies carry out public administration and tend to be focused on efficiency; therefore, they are hierarchical and expert based. The benefits and detriments of 
administrative agencies will be explored as we investigate the policy process and emergency management.

Emergency management operates under a four-phase framework, which will be a central focus of this study. The first phase, mitigation, involves efforts to decrease the initial impact of a disaster. The second phase, preparedness, describes efforts to decrease secondary impact of post-disaster factors such as fire, disease, lack of food, water, and sanitation, which are more detrimental to populations than initial impacts. Third, response describes the short-term organizational efforts of authorities to react to a disaster by applying resources such as medical teams, the National Guard, engineers, and outside assets to help survivors. The final phase, recovery, involves the long-term efforts to rebuild a community.

A final term, resilience, has recently gained prominence in the minds of public managers and describes an especially dynamic community. At its most basic level resilience is a reference to the speed by which a community recovers from adversity or disasters. One definition of a resilient community comes from the Civil Contingences Secretariat of the United Kingdom:

"Communities and individuals harness local resources and expertise to help themselves, in a way that complements the response of the emergency services." (United Kingdom, Cabinet Office, 2009) This brief definition of resilience implies a greater level of understanding that a community, in addition to leadership, needs to possess regarding its own 
capabilities. This means understanding your street, neighborhood, municipalities, and city, not just your country and state. In order for a community to understand its capacity for self-help, it must possess strong internal communication and have some intelligible degree of social capital. Thus, resilience is built from a higher degree of general public participation in social activities and policy processes.

\section{Conclusion}

Disasters are the most serious challenges to the organizational capacity of human endeavors, because they represent uncertainty in three ways. First, they are difficult or impossible to predict. Unlike other problems we face, disasters never surrender the element of surprise and always take the initiative. Second, they do not recognize human boundaries. This means that the differences between levels and locations of government become part of the communication, resource management, and response problem during a disaster. Finally, the impact of disasters can have terrible range. The minimum definition of a disaster rests at one-hundred deaths, one-hundred injuries, and one-million in damages caused by a single event like an earthquake. The cascading Japanese tragedy represents, what many will call, the worst disaster in a generation, and is an important example of the uncertainty of disasters.

The following chapters will analyze the institutions of emergency management and the role the public plays in policy formation. Chapter 2 describes effective emergency management and identifies the key issues. Chapter 3 considers public participation in a policy process, paying attention to the costs and benefits as well as the conditions for success. Chapter 4 surveys the literature and brings together public 
participation in emergency management, considering both the theory and practice of this form of policy process. The final chapter concludes and notes the concrete next steps to increase participation in emergency management. 


\section{Ch.2 Effective Emergency Management}

\section{Introduction}

Emergency management in the United States has been the focus of shifting policy demands and political regimes, producing an institution with subdued initiative, and changing policy directions. The six sections of this chapter will demonstrate an understanding of emergency management and public participation through. First, it will explore the history emergency management as it has evolved over the last 60 years. Second, it will describe emergency management's phases and principles, as well as how they affect the policy process. Third, it will examine policy impetus in shaping recent emergency management trends. The fourth section will explore the dynamics of public administration, and arrive at some conclusions concerning public participation. The fifth section will detail the lack of public participation in policy process as it manifests in eight distinct stages. What will become apparent is a lack of public dialogue, interactions, and participation in all dimensions of emergency management

\section{History}

Governmental disaster response has a long but sporadic history in the United States. This chapter will sketch a brief history of the federal government's attempts to become more involved in disaster management since the 1950's. The emergence of the Cold War fueled fears of nuclear attack, which in turn prompted congress to pass the Federal Civil Defense Act of 1950 creating the Federal Defense Administration. Though limited in size and staff, this new agency had the power to supersede law, marshal federal 


\section{Public Participation in Emergency Management}

resources, and call up personnel during a national emergency, as declared by president and regulated by congress (Cohen and Boyer, 1950). The power of the agency would remain relative minuscule, until disasters of the 1960's created an Office of Civil Defense, a sibling agency in the Department of Defense (referred to as DOD). This new agency commanded far greater funding but also shaped policy in defense interests. It was not until 1978 that the Federal Emergency Management Agency would emerge at the behest of President Carter, consolidating the risk assessing and disaster management interests of 100 federal agencies (Haddow, 2011). Emergency management at the Federal level changed many times-over prior to FEMA, and more changes lay ahead.

The 1980's brought renewed fears of nuclear attack as the Cold War inflamed one final time by a massive arms race between the Soviet Union and the United States. During the Reagan years, FEMA's mission was obscured by concerns of nuclear attack and cleaning up chemical weapons stock piled by the DOD, rather than broad planning for disasters. The agency was in a bureaucratic malaise because funding for technology and growth came from DOD, which in turn controlled agency focus. This changed when President Clinton appointed James Lee Witt as director in 1993. Witt is credited with reviving the agency by refocusing programs on mitigation and risk avoidance, while helping provide customer-centric interactions with communities and organizations (Haddow, 2011). The new relationships between federal and local officials were collaborative in nature, facilitated by citizen engagement, and built long lasting trust and 
respect. This new impetus of FEMA would change as a new administration tackled threats of terrorism.

The massively destructive events of 9/11, and Hurricane Katrina after, had more effect on FEMA than any event $s$ in 50 years of emergency management. Although FEMA showed a relatively strong reaction to the events of $9 / 11$ in organizing resources in both New York and Virginia, the agency would be subordinated under the new Department of Homeland Security (referred to as DHS). Officially opening its doors on January $24^{\text {th }} 2003$, DHS created a bureaucratic net to facilitate greater communication, preparedness and security. In doing so DHS divided FEMA's primary phases, specifically mitigation and preparedness, amongst other agencies, leaving recovery and response as FEMA's primary responsibility (Sylves, 2008). DHS confronted its first great tragedy in 2005 as Hurricane Katrina entered US waters. Despite, elaborate planning, and resource allocation, and an early emergency declaration by President Bush, government response was largely a failure. In fact, Hurricane Katrina took over 1,800 lives, created an estimated $\$ 90$ billion in damages, and has required recovery funds that the Federal government is still providing (Haddow, 2011). The Federal government's response to the hurricane led to a congressional investigation and passage of the PostKatrina Emergency Management Reform Act of 2006. This act reaffirmed FEMA's responsibility for mitigation and preparedness phases, provided organizational autonomy, elevated FEMA within the DHS hierarchy and allowed the opening of ten regional coordination offices (Haddow, 2011). Today, FEMA is still evolving towards meeting 


\section{Public Participation in Emergency Management}

new threats and developing a greater base of knowledge. These efforts have led to broad understanding and reprioritization of the four essential phases of emergency management.

\section{The Four Phases}

Emergency management, as we have seen, has gone through numerous reorganizations and reprioritizations. Currently FEMA operates within the boundaries of four distinct phases; mitigation, preparedness, response and recovery operations. While all phases are essential to the FEMA mission, they are differentiated by allocated resources and by level of community involvement. This section will examine each of these phases and place them on a continuum of organizational focus and public participation. With this continuum in mind, we will be better able to understand areas within emergency management where greater public participation would be beneficial.

The first phase of emergency management, and in many ways connected with the final phase, is that of mitigation. Mitigation can take many shapes, involves all community members to some degree, and can be elaborate or very simple. One very basic definition of mitigation refers to a sustained action to reduce or eliminate risk to individuals and property by the direct effects of an incident (Col, 2007). This basic definition does not address the deeper complexity of analyzing and defining threats to diverse societies. Mitigation thus involves deciding not only what constitutes risk, but also what to do when a risk emerges and how to implement risk-reduction policies (Sylves, 2008). Mitigation necessarily involves long lasting and often permanent measures that can take shape structurally in building codes, zoning, and construction of 
levees. Efforts may be social as well, focusing on educating the public and business in ways to reduce risk by such activities as securing water heaters, bookshelves, and cabinets (EMI, IS-230A). Finally, mitigation involves a wide range of participants outside the emergency management community, such as land-use planners, construction contractors and building officials, business owners, insurance companies, community leaders and average people (Haddow, 2011). One of the largest examples of mitigation is the National Flood Insurance Program legislated in 1968. The legislation provides subsidized insurance for communities in exchange for restricting future development in floodplain areas. A final note on mitigation comes from the Multi-Hazard Mitigation Council, for every $\$ 1$ invested in mitigation activities to reduce disaster loss, $\$ 4$ is saved (Multi-Hazard Mitigation Council, 2005). Mitigation prevents the catastrophic impact from natural disasters, but does not include efforts to protect against secondary threats.

Preparedness represents the second phase of emergency management, and in many ways, it is also the most isolated within the professional community. Preparedness is the state of readiness needed to respond to an emergency, based on planning, training, and exercises (Col, 2007). According to FEMA, this requires assigning responsibility to authorities for emergency actions, resource gathering, as well as planning within a jurisdiction (EMI, IS-235b). As emergency management has evolved, so too have its methods of fine tuning preparedness, including implementing a cycle of preparedness (Bowen, 2008) which aims at defeating false confidence that can sabotage emergency management, while at the same time keeping knowledge cutting edge. For the public 


\section{Public Participation in Emergency Management}

preparedness includes having an emergency plan, a 72 hour kit and being aware of special needs that you will have to address during a disaster, such as medical conditions and especially vulnerable community members. Preparedness efforts aim to minimize the secondary threats the public faces, such as lack of clean drinking water, food and other life sustaining supplies.

The third and most dramatic phase in emergency management is that of crisis response. This phase brings to a head the mitigation and preparedness efforts of the previous two phases and involves immediate actions to save lives, protect property, and meet essential human needs $(\mathrm{Col}, 2007)$. Response is further divided in to five stages; alerting and notification; protecting citizens and property; providing for the public welfare, and finally restoration of essential functions (EMI, IS-230b). These five stages are orchestrated from the Emergency Operations Command (EOC), which provides the logistical, communications, and informational demands which may be required for hours or days depending on the severity of an incident. Central to federal response structure is the National Incident Response System, which requires strict compliance from state and local authorities in order to receive federal grants. One stipulation of this arrangement is that all responders are trained in the Incident Command System (ICS), which details five keys elements (command, operations, planning, logistics, finance) to ensure military style efficiency from all active participates (Haddow, 2011). In addition to this federal organizational structure is the careful diffusion of duties to all officials and responders in every level of government. While the duties of authorities are explicit, there is less detail 
concerning the active role of average citizens. In most cases, the citizenry is provided assistance, instruction, and general updates but has no direct activities within a carefully organized disaster plan.

The final emergency management phase, recovery, represents the culmination of all three previous stages, and in some respects, a new beginning of mitigation. This phase usually starts when threats from both the primary (quake, eruption, and hurricane) and secondary events (unstable structures, levees, and nuclear plants) have been contained. This phase involves actions directed at rebuilding lost residential and business properties, reconstituting the economic base, and repairing and reestablishing infrastructure $(\mathrm{Col}, 2007)$. The enormity of the recovery phase touches the entire community and involves the effort of everyone from emergency managers to homeless victims. This is also the only phase where FEMA recommends developing plans with "full participation and partnership" of the community (U.S. DHS, FEMA, 2011).

Fundamental to recovery are the short-term efforts of returning vital life-support systems to a community, including food, water, electricity, roads, and communications (Sylves, 2008). With the return of vital systems, recovery efforts that may take months or years can begin. These efforts involve redevelopment and improving the original community in a disaster conscious way and influence mitigation efforts, as disaster impacts are still salient to community members. Historically, FEMA has paid an average of $\$ 58$ million per disaster in relief alone, and these numbers are expected to continue rising. Hurricane 
Katrina, according to government estimates, will be the United States' most expensive, with an expected relief pay out of approximately \$100 Billion (Haddow, 2011).

\section{Current Trends in Emergency Management}

Emergency management is not static, and its two current evolutionary trends point in an uncertain direction. The first trend, professionalization of emergency management, is establishing accreditation and qualifications based on a disciplinary focus on case study analysis and inter-organizational structure. The second trend further centralizes federal authority; this stems from military roots as well as political currents that have fundamentally altered the emergency management mission. This section will illuminate the varied ebbs and flows that have shaped the emergency management community, and describe public involvement.

\section{Professionalization}

What was once the role of fire fighters and ex-military personnel on an ad hoc basis, is now transforming into the emergency management profession. Opened in 1994, FEMA's first somewhat limited higher education program has now reached over twohundred certificate and degree programs nationwide. At the core of the new profession, in addition to the four functional phases, are the Principles of Emergency Management (human dimension, areas of responsibility, risk assessment process and methodology, fiscal dimensions, and promotion of emergency management), which are the basic requirements every graduate is expected to understand (Cwiak, 2011). Of all these principles, it is the human dimension principle where we may suspect a focus on greater public involvement. On the contrary, lessons here involve framing disasters, 
understanding social vulnerability, and how to communicate to the public. There is nothing in the principles referring to the larger community in forms other than as clients or potential problems. In other words, the emergency management education program considers the general public a potential problem that needs to be further studied and managed.

The role that any higher education institution plays in the community is twofold. First, it develops, systemizes, and communicates knowledge to those that choose to join its ranks. The second function of a higher education is to promote research, theory building, and abstract thinking on subjects. According to the National Research Council's 2006 report on hazards and disasters, the locus of academic considerations have been dichotomized between hazard and disaster research (National Research Council, 2006). The sub-fields of hazard vulnerability and mitigation are joined by disaster response and recovery studies. Where these two spheres of knowledge converge, the understanding of disaster preparedness emerges (see figure 1 below). The primary resources employed by researchers are the case studies of particular disasters, originally constructed by onsite authorities and other professionals. Research of this kind produces valuable insight into the functioning of agencies and governmental organizations responding to disasters, but lacks abstract understanding of the community at large. This missing knowledge is essential to facilitating the complex understanding of disasters in sophisticated societies that emergency managers are responsible for. Rather than abstractions and theory, many studies cater to "the occupational competition within the 
realm of homeland security" that we see so often as agencies struggle to diversify their funding streams (Sylves, 2008). The final principle of emergency management, promotion of emergency management, evidences this trend. Studies of this kind discuss organizational response efficiency, specifically on skills and the appropriate bureaucrat agencies for different situations. There is little discussion as to whether the organization itself is fully prepared to address the possibility of cascading-disasters as seen in Japan, or who will be there if authorities fail .

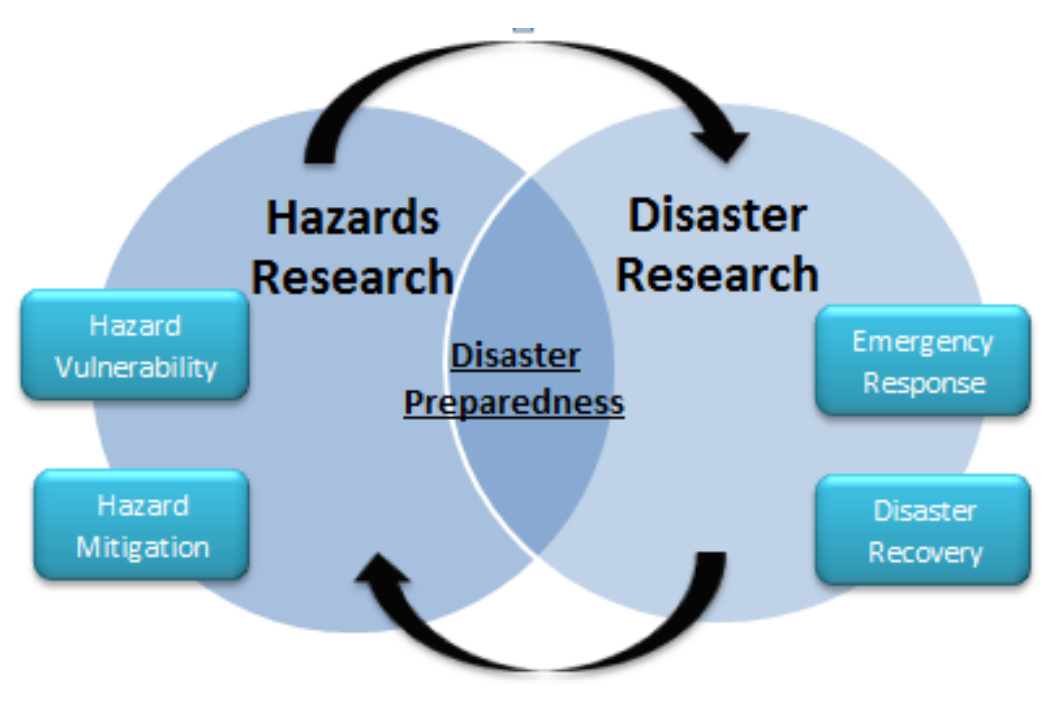

\section{Figure 1 Core Topics of Hazards and Disaster Research}

The Emergency Management Institute provides an enormous curriculum via the internet at no cost to interested parties. The practical implications of the hundred plus classes are not to be discredited, despite their limitations. Specifically, the Professional Development Series, completed by this researcher, exemplifies the over reliance on principle and leadership centric programing (EMI, IS-240a). The seven classes (exercise 


\section{Public Participation in Emergency Management}

design, fundamentals of emergency management, emergency planning, leadership and influence, effective communication, and developing and managing volunteers) that make up this series claim to be a well-rounded set of fundamentals for those in the profession. What may be less apparent is the subtle influence on emergency managers this kind of education may have. Leadership promotion and rigid principles diffuses debate and critical inquiries in the field, laying an unstable foundation for emergency management (Lynn, 1996). This foundation in practice has led to a prominence of false assumptions of preparedness, as seen in Hurricane Katrina, and an inability to adequately deal with change, as seen in the case the of preparedness training of health professionals (Farazamand, 2007; Hoeppener, 2004). Emergency management needs a greater balance between rigid principles and the more fluid understanding of disasters, arrived at through abstractions, theory building, and systemic reviews.

\section{Centralization}

For the great majority of American history, emergency management has been a local affair, organized bottom-up as leadership and communities deemed necessary. This is not the case today, as more power exists at federal level than ever before. Two intertwined but different factors influence this transition from local to federal power. First, the military's role has always been present in response to disasters, where today it is present in many other emergency management phases. Second, the role of federal funding has dramatically dominated the implementation of emergency management policy across the nation. While there are many benefits related to the increases in 
organization and planning capabilities provide by federal involvement, in many ways they create distrust, dysfunction and a lack of citizen preparedness at the local level.

\section{Military Influence}

The Posse Commitatus Act has controlled the role of the military in domestic affairs, since the end of the Civil War Reconstruction era. This act prevents the federal military branches from operating domestically without constitutional or congressional approval, with one exception. The National Guard is a governor's primary resource during times of crisis, and it has served as an umbrella emergency management organization for 28 states that have few disaster threats (Sylves, 2008). The ability to mobilize the National Guard is a considerable power that provides autonomy during incidents at the state and local level, and this has changed. Hurricane Katrina marked a further centralization of federal power, second only to the post- $9 / 11$ reorganization of FEMA under the Department of Homeland Security. Just after the hurricane, President George W. Bush announced his desire for a greater role for all military branches in disaster activities (U.S. DOD, 2005). This followed in 2007 by the passing of the John Warner National Defense Reauthorization, focusing greater mobilization powers in the presidency, at the expense of the governors (Haddow, 2011). Evidence of this centralization was evident in the 2010 Gulf Oil spill, which involved labor and resources from the National Guard, Navy, and Air Force. In terms of manpower and resource allocation, the federal government and the chief executive have succeeded in centralizing power under a narrower set of decisions paths. 
The military, acting at the behest of the federal government, has been more influential in shaping disaster policy than in the past. Since 9/11, DHS has created three interlocking guidelines for local authorities during an emergency. At the top of this network is the National Incident Management System (NIMS), which provides specific details on five key areas of emergency management (planning, communications/information, resource management, command). The fifth point, Ongoing Management and Maintenance, is entirely performed at the DHS and FEMA level (EMI, IS-230a). Connected to and a subordinate of NIMS, is the National Response Framework (NRF). This framework was written for executives, emergency mangers, leaders, and nongovernmental organizations. It emphasizes defining roles for authorities, explaining common discipline and structures involved in emergency management. The final organizational tool, the Incident Command System (ICS), dictates action in a specific crisis area. The ICS outlines specific roles, chain of command, and unitary authority directions. What these plans have three commonalities, they identify no public role, they are completely focused on military style command and control, and compliance is directly tied to federal grant funding.

\section{Grants}

The omnipresence of the military system of command and control combined with greater federal authority in personnel-implementation are imposed through two massive DHS grant programs. The first of these, the Emergency Management Performance Grant Program (EMPG), provided almost $\$ 330$ million dollars in state-matched grants to enhance and sustain emergency management systems in 2010 (Haddow, 2011). The 
second grant program, Homeland Security Grant Program (HSGP) carries vast implications because in addition to comprising seven primary grants, and a multitude of subordinates, this program allocated a total of $\$ 1.2$ billion to states in 2011 (U.S. DHS, 2010). These funds come at the price of compliance with the implementation of NIMS, $\mathrm{NRF}$ and ICS as well as the training, planning and exercise required for maintaining these systems. Compliance imposed from the federal government left very little room for codetermination of policy, and left local authorities scrambling to fall into compliance (Edwards, 2007). In many municipalities, the resources introduced by these grants are the key funding source, for instance the operating expenses for the Portland Bureau of Emergency Management (formerly Portland Office of Emergency Management) totals $\$ 10.3$ million dollars for the $2010-11$ cycle. Of that $\$ 10.3$ million, approximately $\$ 1.7$ million comes from the general fund, while the other $80 \%$ is provided by grants (City of Portland Budget, 2009). This level of federal dominance in funding, unique to emergency management, provides little room for local agencies to act aggressively on behalf of local dynamics.

Emergency managers face disasters riddled with unseen local problems and complications arising from a relatively disconnected policy process. During an emergency, there are three very powerful drivers that exacerbate destruction, poor information processing, isolation during emergencies, and lack of general awareness and preparedness (King, 2000). Emergency management directives centralized at the federal level have created a vacuum in local understanding and knowledge leading to failures 
like Hurricane Katrina. In addition, within local planning efforts there is a growing dependency on federal leadership. These problems are not without solutions, placing greater emphasis on participation at the local level may provide for greater resilience throughout the country.

\section{Conclusion}

The professionalization of the emergency management community and centralization of federal authority represent two powerful trends. The creation of higher education programs and the Emergency Management Institute have succeeded in making available valuable information to communities. Where emergency management has been less successful is in the formation of theoretical, abstract and systemic schools of thought pertaining to the field. This has led to strong structured practice, but inflexibility in the face of disasters. The centralization of authority in emergency management has been carried out with enormous speed over the last decade, at the expense of the public. While military roots have never been far from disaster policies, the level of influence on civilian organization and planning is currently unprecedented. So too is the level of control the federal government wields in funding priorities for its initiatives, frustrating emergency managers such as those in Portland, because they often come with strict stipulations and spending requirements (City of Portland, Strategic Plan, 2010). Taken together, these two trends have provided a successful reconstitution of emergency management, but have done so without the benefit public participation. 


\section{Public Administration}

Public administration represents the last three steps in the policy process (enactment, implementation, evaluation) carried out by teams of experts employed by bureaucracies. The bureaucratic organization is designed to efficiently manage, control, and resolve two variations of large-scale problems (Carr, 2007). The first large-scale problems bureaucracies face are linear in the sense that priorities are relatively clear, ramifications are understood, and interests are addressed, for example, constructing a national highway system. In contrast the second problem type are classified as "wicked" in the sense that uncertain ramifications, moral ambiguities and conflicting interests can produce outcomes worse that the symptoms policy aims to deal with (Churchman, 1967; Rittel and Weber, 1973). To meet these challenges, bureaucracy deploys three essential characteristics; clear managerial methodology, centralized decisions, and the employment of experts. This section will explain how these three characteristics of bureaucratic administration attempt well-reasoned and efficient solutions to problems, without the possible paralysis that could ensue from open problem-solving systems.

\section{Management}

The modern bureaucratic structure, rooted in ancient cultures such as the Roman Empire, blossomed in the post-industrial period. Fueled by students of organization and professionalization such as Max Weber, bureaucracies became responsible for a growing number of societal issues such as healthcare and citizen's economic well-being. The complexity of these issues necessitates the execution of effective management within 
bureaucratic operations. One of the most lucid descriptions of proper managerial order comes to us from the $19^{\text {th }}$ century Frenchmen Henry Fayol, who produced a theory deeply imbedded in our modern culture (Lynn, 1996). According to Fayol, proper management requires emphasis on planning, organization, staffing, directing, coordinating, reporting, and finally budgeting (acronym POSDCORB). The modern bureaucracy uses all these to perform and adds; fixed jurisdictional areas, clearly defined superiors and subordinates, and ridged standard operating procedures (Birkland, 2010). This managerial order creates information streams to leaders so they can make rapid and rational choices. Accountability can be problematic, as levels of understanding in the organization are stratified. As compartmentalized units, no overall understanding of intent and ramifications are presupposed but by a small group of well-informed leaders. Two challenges to this system come in the way of bounded-rationality and dealing with complex concepts like vulnerability. For the manager leading a bureaucracy, choices must be made in a timely manner. This limitation means that many decisions will be made with the understanding that all necessary information is not and never can be accounted for. Vulnerability, understood as elements of our community that will most impacted by disasters, are also those that will be less likely understood by a centralized and distant manager. Understanding these limitations, it serves the interest of managers to expand knowledge in ways attuned to productive demands.

\section{Top-down and Bottom-up}

The decision making model bureaucracies use, a modernized version of Foyal's theory involving the organization, coordinating, staffing, and budgeting of an entire 
organizational structure is called a top-down model, and this section will compare it to the bottom-up model. Drawing from scholarly work, this research narrowed down eight primary emblematic features of the top-down versus bottom-up juxtaposition (Denhardt, 2000; Thomas, 1995; Birkland, 2010; Carr, 2007). The top-down model operates as a closed-system of ascending information and descending commands. This functions to limit scrutiny, isolate relevant data, and boost rational decision-making. Internally, the compartmentalization, divisions of labor, and stratification of hierarchy prevent a comprehensive picture from emerging anywhere but at the top. Individual operators have very little discretion in their interactions with their community, in order to prevent dilution of central leadership's decisions. With clearly defined goals actuated on expertly defined societal groups, leaders take their data and efficiently pass down orders to subordinates for implementation. This decision making process is effective for linear problems, but is problematic when dealing "wicked" problems.

Some problems that emerge prior to, during and after an emergency may be rooted in a top-down policy process. Problems emerging at the local level and stemming from federally dominated policies come in four basic varieties (May and William, 1986). First, the "what next?" syndrome accompanies local agents trying to keep up with federal programs, which have undergone disruptive shake-ups and reorganizations (such as the one done after 9/11 and again after Hurricane Katrina). Second, the "contamination syndrome," describes the distance created between local officials and federal agencies when national efforts go awry or publicly fail. The third syndrome, the "planning 
paranoia" effect develops when planning and professionalization reaches dizzying levels for local leaders. Finally, dependency on federal authorities for plans, resources, and guidance, leads to a lack of self-help initiatives at the local level. These four syndromes result from of central domination of policy process, which in emergency management has proceeded erratically since its inception, with little two-way communication between federal and local communities.

Table 2 Top-down versus Bottom-up

\begin{tabular}{|c|c|c|}
\hline Features & Top-Down & Bottom-Up \\
\hline Transparency & Closed System & Open Forum \\
\hline Discretion & Limited Flexibility & Facilitates Negotiation \\
\hline Direction & $\begin{array}{c}\text { Policy, Directive, Stature } \\
\text { Driven }\end{array}$ & Policy Emerges by Process \\
\hline Mantra & Single Message & Collaborative Messages \\
\hline Tools & Rationality for Efficiency & Shared Interests and Responsibility \\
\hline Interactions & Defined Communities & Communities Define Themselves \\
\hline Goals & Clearly Articulated & Ambiguous and Evolving \\
\hline $\begin{array}{c}\text { Labor } \\
\text { Organization }\end{array}$ & Internal Divided & Shared Implementation Responsibilities \\
\hline
\end{tabular}

Bottom-up decision models, as the table shows, represent a different understanding of how managers operate internally and externally. A bottom-up model does not represent a system; rather it represents a kind of mediated forum where administrators and different interests collaborate. Administrators try to help the community define the parameters of a problem and potential goals. Rather than having 


\section{Public Participation in Emergency Management}

limited discretion, administrators must have the ability to both share information and openly communicate to varying groups. Instead of depending on the rationality of a single executive to maximize efficacy, bottom-up managers illuminate common interests and thus encourage shared responsibility. Administrators take part in the implementation of policy in areas where other parties are unable, thus filling gaps in capacities, openly and transparently. The bottom-up model can be slow, but it addresses a far wider range of considerations, essential when dealing with "wicked" problems.

\section{Hamiltonian and Jeffersonian Approaches}

The priorities outlined by Foyal's theory need the top-down bureaucratic requirement of expert personnel to tackle problems. A bureaucracy confronts informational problems in two primary forms, which have been attributed to two American forefathers: Thomas Jefferson and Alexander Hamilton. As part of the POSDCORB model, those that populate the bureaucracies play a significant role in planning, reporting, and directing of implementation duties. The Hamiltonian approach to this task, seen in most modern bureaucracies, is closely tied to the top-down decision model. Hamiltonian managers understand problems by aligning experts in the specific fields of study with experts of administration, who together define community groups and isolate vital information. These experts eliminate the congestion related to local considerations that can make leadership-centric decisions onerous. Knowledge under this regime operates distanced from the actual incidents, and decisions are held accountable only after-the-fact (Sylves, 2008). Finally, this system focuses on the aggregation of 


\section{Public Participation in Emergency Management}

useful information, utilized by a small group of leaders with access to the entire body of knowledge. Usefulness, in this context, means information both familiar and actionable within the perimeters of the bureaucracy. For this reason, the Hamiltonian model entails an inherent bias towards established powers; vested interests, which are in a position to smother unaligned interests (Morgan, Green, Shinn, and Robinson, 2008). The Hamiltonian model allows decision makers to act rapidly, with trusted information filtered through expert knowledge and free of perceived irrational elements.

On the other side of the spectrum of organizational knowledge, the Jeffersonian model of information management relies on sociotechnical skills to a greater degree than expert knowledge (Sylves, 2008). Managers with these skills first empower the public and draw from them the contextual realities they face in order to meet their needs. In this approach, managers are held to multi-directional accountability during the process, rather than after the policy has either succeeded or failed (Lynn, 1996). Jeffersonian managers are not as reliant on rigidly defined plans because direction is not imposed; rather it is created by wide decision circles. This approach breeds social capital and shared responsibility, bother very important prior to, during and after a disaster.

Understanding the methodological differences in public administration is essential to this study because they represent the dynamics of intergovernmental interaction in our country. At the federal level, obviously, a top-down decision model is in place and Hamiltonian concentration of experts creates plans and imposes them on states, cities, and communities. At the local level, leaders are tasked with mediating concerns and 


\section{Public Participation in Emergency Management}

helping different groups solve their own problems. Rather than expert knowledge, members of the local community apply their thorough but general knowledge collectively to approach policy formation and implementation. Federally top-down decisions are based on filtered data, risk is aggregated across the nation and human life and property is quantified. The local level counterpart perceives the specifics and conditionality of the problem as it pertains to the qualitative understanding of the inhabitants. In many ways, the exclusion of local input in shaping federal policy has created a situation where these two perspectives communicate past one another (Whitford, 2007). This has undercut the effectiveness of emergency management phases; but also prevented social capital development and successful policy creation.

\section{Public Policy}

Emergency management, like all government organizations, is not performing its designated duties in a vacuum. Rather, emergency managers are operating in a complex public policy process that requires some explanation. This section will not attempt the final definition of a highly debated and contentions aspect of American politics, its intent is to show stages, actors and trends that effect emergency management by synthesizing four authoritative works (Birkland, 2010; Anderson, 2010; Jones, 1984; Walters, Aydelotte, and Miller, 2000). This section will describe eight distinct policy stages and place three categorize of actors in them. At the top, those with the greatest influence over the formation of policy are the executive and legislative leaders of government. The middle tier actors represent the bureaucratic managers and agents who advise the first tier 
actors and that help implement policy. Finally, the lowest tier actors are the general, who have many passive but few active roles in the policy process.

To begin with, we can define policy by its essential qualities; it is made in the public's name by government; interpreted and implemented by public and private actors; and finally policy is what government intends to and chooses not to do (Birkland, 2010). Policy can take many different forms, including distributive, redistributive, regulatory, and constituent actions, depending on the desired results (Anderson, 2010). The process by which policy is formed and implemented is the main concern of this section, because we need to identify the characteristics of participation. The eight stages of the policy process are as follows: issue emergence, discussion and problem definition, agenda setting, policy formation, legitimation, enactment, implementation and evaluation. There are many instances where numerous stages are skipped altogether or repeated; the process itself is not necessarily cyclic. 


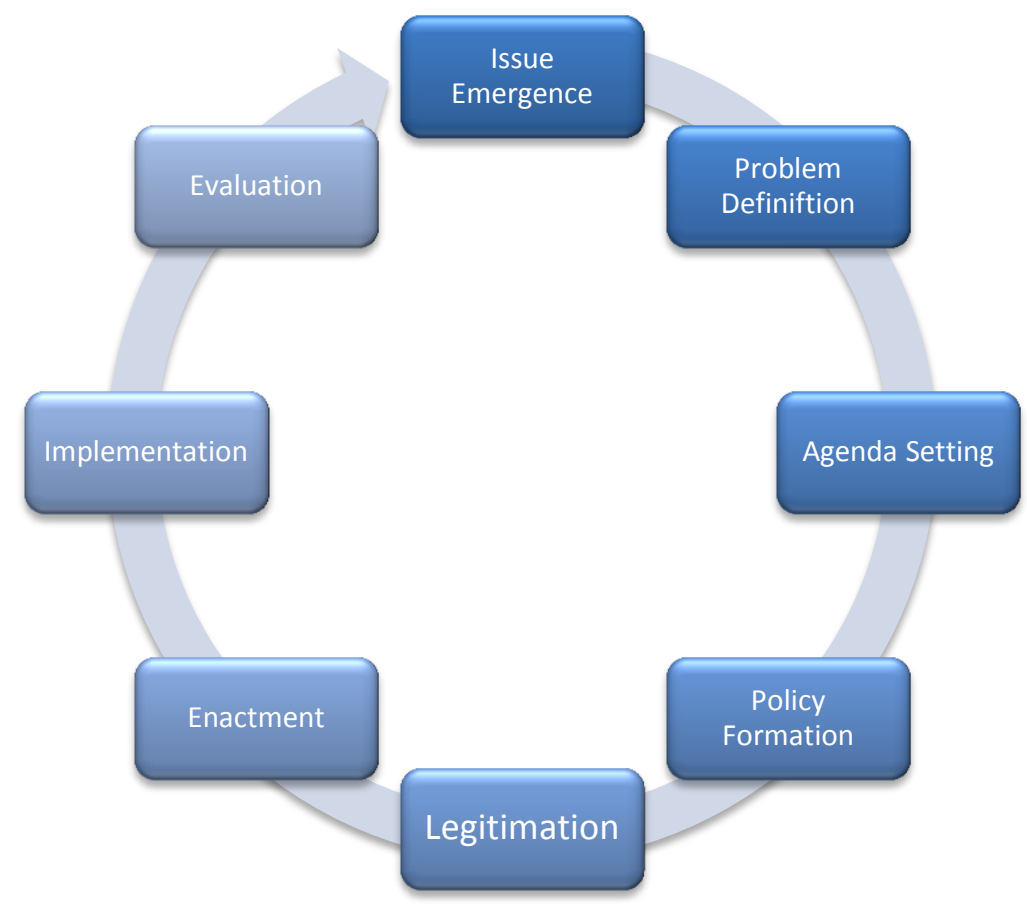

\section{Figure 2 Eight Stage Policy Process}

At the top of the national policy process are those responsible for greatest impact on policy, the executive and legislative branches. For this group the responsibly of agenda setting, formation, legitimation are combined with answering for enactment, implementation and evaluation stages (Anderson, 2010). Specifically, legislature's command of the agenda-setting stage involves great organizational effort, and requires leaders to place parameters on the problem and identify evaluative criteria. The policyformation stage requires leaders to take all considerations and desired results into account in policy construction. The fifth stage, legitimation, occurs when legislatures approve appropriations, denote legal responsibility and direct bureaucratic institutions (Birkland, 2010). Indeed this group of actors has a high degree of influence on all aspects of the policy process. 
The second tier of actors, culminating in bureaucratic organizations, has significant power concerning the enactment and implementation of policy. In the enactment stage, appropriations and laws manifest in the form of an institution or bureaucratic agencies. The implementation stage begins when an institution or agencies implements policy in the form of regulation, taxation and enforcement of those policies. This is not the extent of bureaucratic influence on the policy process; they may also help shape public opinion, define new problems to solve, and cultivate new resource streams (Rourke, 1984). Finally, in the evaluative phase agencies may push back against public and leadership determinations of success or shortcomings of implementation (Jones, 1980). Also during evaluation, agency actors may place blame, co-opt rival bureaucratic actors, and utilize political systems to further goals.

The final tier of actors is the vast and varied public. This group includes business, local leadership, community organizations, media, scholars, and average citizens. While there are examples of this group effecting policy at many stages, their impact is most visible at the initial phases of discussion and debate. The public affects the political response to problems as well as influencing the finally stage of evaluation. In the second policy stage, the public may define the problem in terms of what level of government is responsible and many problems are solved locally. The middle stages in the policy process are largely void of direct and active public participation, as leadership and bureaucratic organizations shape the direction and impact of policy. The urgency and overall consequence of policy, it must be remembered, is also determined by the problem 


\section{Public Participation in Emergency Management}

itself, as the USA Patriot Act of 2001 demonstrates. In reaction to great public fear of terrorism, many leaders who previously stood opposed to greater internal security measures before $9 / 11$, gladly signed the act (Wedel, 2005). After 9/11, public outcry and fear produced a policy window that had not existed, and allowed for a sweeping national effort. Finally, the public may participate in the evaluation of policy and leaders via voting, the initiative and referendum processes, organizing protests or open resistance to the laws or regulations that government may implement.

\section{The Absence of Public Participation}

Emergency managers today base their discipline on four phases and principles drawn from experience with disasters and agency competition. Professionalization and centralization are two current trends of the emergency management community that are increasing their relative power, specialized knowledge and authority at the cost of distancing communities, decreasing transparency and accepting incomplete knowledge. These trends remove emergency managers from the local community and place them in the eight-step federal policy process. As has been described, policy in emergency management is dominated by the executive and bureaucratic agencies. The prime task of agencies such as FEMA is implementing policy, and they have done so by using topdown management models to maximize efficiency. What this chapter wishes to compare to Hamiltonian methodology is a more inclusive relationship with the public at large in order to address "wicked" problems. After all, it is the public that pays the greatest price for errors formed during the policy process. It follows that they should have some 


\section{Public Participation in Emergency Management}

say in policy processes. In order to better understand this proposition, we must construct a far more sophisticated idea of the public and the role it plays.

The details provided about the four phases of emergency management are in no way exhaustive, but they should provide insight into the complexity of disasters. A basic understanding of the players and tasks for each stage should help us construct a model of where the public fits, either as participants in positive activities or as passive recipients of information and orders.

First, a great number of individuals pursuing governmental, business and safety interests actively participate in the mitigation process. The individual citizen plays a passive role as the bearer of costs for codes, building regulations, and zoning for which they have a limited institutionalized role in shaping (town hall meetings and public outreach do provide at least a public sounding board). Preparedness is the phase that the general public has the least institutionalized role. In this phase officials, agencies members and first-responders are highly active in shaping plans, training, and conducting exercises. In relation to official activities, the public is kept at arm's length, only learning of emergency management activities if they seek out information (made more accessible with web-based sources). The third phase, response shows a small increase in institutionalized public participation, but this is still very limited. The Citizen Corps operates the Community Emergency Response Team program, a remnant of the Project Impact program. While this valuable training is available free to the public, according to the Citizen Corps, nationally there are only 1,774 local programs out of the 29,262 
consensus-designated places, or 6\% of U.S. communities (Citizen Corps Councils, 2011;

U.S. Bureau, 2010). This is a very small percentage in a country of 312 million and represents a very low level of public participation in preparedness. The final phase recovery has the highest level of public participation, as communities dealing with recovery leave no resource underutilized.

One critique of the summary of emergency management phases will be that the researcher has ignored the partnerships and collusion with voluntary organizations. Indeed many authorities acknowledge the positive role that volunteers provide, and EMI has an entire unit concerned with managing volunteers. The largest volunteer organization dealing with disaster is the National Organization Active in Disasters (NVOAD), which maintains chapters in every state (nvoad.org). While these organizations are to be celebrated, their role in an emergency needs to be qualified in two ways. First, a disaster is something that, depending on severity, can devastate everything of value for leadership and volunteers, only one of which is expected to perform duties. CERT training emphasized one vital lesson; take care of yourself and your immediate area before you mobilize for larger operations. In a planning scenario, emergency managers must assume volunteers will be part of the impacted group rather than as a resource at their disposal. Second, where volunteers are strong in enthusiasm they are weak is sheer numbers and logistics. According to the federal government, overall volunteer rates are just over $26 \%$, which means they are a small force with no dedicated means of mass mobilization (Corporation for National, 2012). The role of volunteer 
organizations operate on an ad hoc basis and fill in voids in emergency management during recovery phases, but are only marginally involved in forming plans in the other three phases.

The public policy process described above includes many of the stages and actors involved over the course of the proceedings, but not all are necessary. Rather than involving many actors, emergency management institutions have been molded almost entirely by the first tier actors, predominantly by the executive. While this tier includes legislative actors, they have had less ability to significantly impact institutions due to the dispersal of power in their congressional bodies. One rare example of a significant legislative overhaul is illustrated in the 9/11 Commission Report; reporting that Congress's greatest bureaucratic shack-up had happened in 1946 with the Congressional Reorganizational Act, over 65 years ago (National Commission on Terrorist, 2004). Opposed to the diffuse powers of congress, which demands greater temporal resources, the executive branch can act swiftly to reinvent institutions, especially those under its purview. When a disaster strikes a community, the local leaders initiate a chain of command that goes to the state governors and then right to the chief executive of the nation, the president. The decision to provide federal resources is, typically, but not exclusively, held by the president alone. With the president's discretion, authority congressionally approved in 1950, the collective agencies under DHS go into action. While keeping abreast of the situation, the president may increase the resources at an agencies disposal or even interject the US military, as was seen in the 2010 Gulf Oil spill. 
Unofficially, congressional leaders may operate to secure greater relief resources for their constituents or lobby the president to declare a disaster where the necessity is contestable (Sylves, 2008). While congress controls the purse strings, the president has the power to reorder, dissolve, or create new agencies. Choices that an administration makes may reflect larger policy goals or simply serve political ends (Sobel, 2008). In this policy process, the president has an exorbitant amount of power over policy formation. The focus of presidential policy power works in tandem with bureaucratic organizations, who decide how programs are implemented and resources are applied. The role of the general public in policy formation is again limited to the first and last stages of issue emergence and evaluation. Both are determined by the uproar created by the general public and local leaders, which can create greater political pressure. In both cases, tension may influence policy to a small degree as pressure is distributed over large bureaucracies and absorbed by the executive.

FEMA's policy process could be described as driven by a very elite community of experts, bureaucrats and elected officials leading a policy monopoly (Birkland, 1997). This policy monopoly has already been described as highly focused on disaster response and recovery efforts by predominantly distributive administrative tools. Without a thorough understanding of the local environment, this kind of policy drive is problematic to community safety and the FEMA mission. Prior to Hurricane Katrina, the city of New Orleans and the state of Louisiana in general, showed a propensity for graft and corruption and little penchant for disaster resilience (Boettke, 2007). The murky political 
climate, low household incomes, and lack of attractive business environment all undermined the community's ability to mitigate, prepare, respond, and recover from disaster. When FEMA and numerous other agencies initiated their response efforts, despite rather strong first-responder preparations, there was little emergency management permeating the public as a whole. With input from local communities, the problems still plaguing recovery may have been better understood, and adjustments to federal policy could have been made. Centralized policy process may not just hinder, but also hollow, the effectiveness of professional local emergency managers.

\section{Conclusion}

This chapter has shown the historical evolution and administration of public policy involving emergency management. The structures and norms visible today reflect a process isolated from the public. At the same time, it has highlighted evidence about the costs of this lack of public participation and the potential benefits of reversing these tendencies. However, the policy-relevant questions of when and how to incorporate public participation into emergency management in a beneficial and cost-effective way remain relatively unexplored. Diversified preparedness principles are currently receiving greater academic attention, although still discounted in favor of response and recovery by agencies. That said focus is shifting away from larger centralized efforts and back onto the community. What these studies miss is an understanding of where resiliency may be found in efforts to implement greater public participation into the emergency management policy process itself. Before addressing the specific policy process, we must first explore the dynamics of public participation. 


\section{Ch.3 Public Participation}

\section{Introduction}

This chapter will begin by defining the role of the public in the policy process, and describing emergency management interactions. The second component of this chapter will present both the advantages and disadvantages of increased public participation, including the ancillary benefit of social capital. At the core of the proparticipation debate will be the idea that administrators need to focus on the process, not just outcomes of management (King, Felty, and Susel, 1998). The very nature of disasters, as opposed to other public problems, requires a reassessment of wide participatory value in emergency management. For this reason, it may serve the purposes of emergency management to embrace elements from a combination of deliberative and pluralistic participation models where "the content of a form of life...takes into account the generalizable interests of all individuals" in collaborative dialogue (Habermas, 1975). This is the case because of the complexity of the problems disaster pose, ambiguities they reveal, and the total stakeholder effect they may create.

\section{Defining the Public}

Currently there are two contradictory views of the public. One sees the public as a source of problems, and the other the source of solutions. One of these views is ingrained in the foundation of institutional response to disasters. As has been earlier shown, the America that Tocqueville described was one of widespread pragmatic civic association. Over a hundred years later, John Dewey, who identified the "new public," 


\section{Public Participation in Emergency Management}

would eulogize Tocqueville's America. The lost public that Dewey describes contains four essential characteristics. First, it is a group that is impacted, for better or worse, by the externalities of an activity-taking place in society. Second, this group comes together in association and defines the problem for itself. Third, these associations create officers in which the public operates "in and through" on its behalf (Dewey, 1954). Finally, these officers become representatives in the state, tasked as guardians of custom, social understanding and humane ideals. Well short of the full expression of these four characteristics, the 'new public' is detached from the institutions it created and has become less consequential. For many in the emergency management and security communities this is seen as the emergence of a 'nanny society' (Bach and Kaufman, 2009). Reluctant government takes a greater role in public affairs where personal responsibility and interest have fallen sharply. The fundamental misunderstanding Dewey identified is that when bureaucratic organizations are tasked with solving societal problems, their structural detachment contributes the creation of an apathetic and hapless public. This false dichotomy between the public and its managers is not just operationally present, but also promoted through our society, until the public reacts with anger and distrust to government.

The dichotomy between the public and its managers produces, rather than attends to, the visible gulf between one group creating problems and another solving them. This simple disunion communicates through society with growing frequency as centralized power and expert knowledge gain ascendancy. For Dewey, the realm of expert 


\section{Public Participation in Emergency Management}

knowledge is instrumental to the extent that insights are able to translate understanding of a physical condition into a general understanding (Dewey, 1954). Rather than knowledge usage by the few on behalf of the many, knowledge should be something conferred upon by all. Today, we have a public that is simply informed of manager's decisions. Their consent is implied. Media, for the sake of brevity, heeds the messages of public managers, and promotes authorities as solution providers. Media's reliance on public managers as a primary information source obscures very powerful societal problems not addressed by managers, such as the poverty and inequality that increase the destructive potential of disasters (Tierney, Lindell, and Perry, 2001). Finally, a series of publicly directed communications describe the publics subordinated role, solicit it's acceptance of authority, but provides little room for discussion.

John Dewey's definition of the ideal public was in peril or had already passed when he published in the 1950 's. This was due in part to a powerful public management apparatus. The dichotomy that exists between the public and emergency management results from a general managerial trend to favor results over process. This results-based choice is not without merit, and indeed, it has provided a powerful impetus for organizational continuity. This initiative has also helped ferment a profound governmental disconnect from the public. Government, once legitimized by the public's name and built from their ranks, has since become unrecognizably bureaucratized. Though the public was once involved in defining and framing issues, they are now passively provided information via websites, service messages, and alerts. Without 


\section{Public Participation in Emergency Management}

discourse, public knowledge becomes stale and no longer challenges the monopoly of expert opinion. Left to their own accord, the public reacts strongly to problems it understands. In the case of disasters, this is the recovery phase of emergency management. Here, discounting the public deforms the goal of effective policy by placing too much focus on the cure of symptoms (response and recovery), rather than the prevention of the disease (mitigation and preparedness). Importantly, the public is not only defined by the role it plays in the larger policy picture, but also by the varied interests that make up its ranks, which will be the topic of the following section.

\section{Advantages and Disadvantages of Participation}

\section{Introduction}

The public is a very dynamic, diverse, and multidimensional entity, and this diversity can create problems for managers who attempt to rapidly create and implement policy consistently across the entire country. Currently these emergency manager's efforts are greatly magnified by funding from the federal government, but this comes at the expense of local input, essential to the success in implementation of policy. Public participation in policymaking requires a complex blend of considerations; at a minimum balancing stakeholder input and efficiency. This section will first explore the continuum of public participation and then juxtapose two competing theoretical frameworks. Second, this section will address both the positive elements and practical applications of wider participation. In order to address potential weakness in public involvement, the third section will describe its limits. Finally, participation will be explored through the roots of social capital in the community. What will emerge is a picture of public 


\section{Public Participation in Emergency Management}

participation that is neither aggrandized nor debased, and hopefully illuminate places and times where participation can be successfully increased.

\section{Theory}

The role of public participation in the policy process is most commonly associated with the right to choose our leaders or vote on initiatives in our communities. The right to vote has expanded its ranks greatly from its historical roots and today includes the propertyless, young adults, women, and minorities. While the right to vote is a powerful tool, it also represents a very brief and shallow interaction with the larger political and policy system. This section will explore the continuum of participation; ranging from political manipulation to citizen control of political processes. This section will also explore the theoretical and practical considerations involved in deliberative and pluralistic models, and recommend a dynamic model for emergency management.

As members of Dewey's public, citizens are expected to have input into decisions that relate to the welfare of the community. The frequency, purpose, and depth of these inputs are neither consistent nor universal. The participatory ladder, devised by Sherry Arnstein, divides citizen engagement into three basic groupings describing fundamental interactions: degrees of citizen power, degrees of tokenism and finally nonparticipation (Arnstein, 1969). Atop of the eight-rung ladder, citizen control, delegated power and partnership, represent a grouping of maximized participation in the policy process. Citizen control describes a system in which citizens have full managerial power over the policy process. The subordinate group, tokens represent the middle three rungs of 


\section{Public Participation in Emergency Management}

placation, consultation, informing. In these rungs, citizens are able to listen in on leadership discussions and to have a symbolic voice in policy process, but are provided no institutionalized ability to influence policy. At the very bottom of the ladder, the therapy and manipulation rungs, describe participation in Machiavellian terms. Power holders espouse wide-participation when in fact decisions are made for the politically inconsequential public (Arnstein, 1969). Arnstein's ladder, compared to our picture of emergency management, reveals that by and large, the federal government has controlled policy to the degree of public nonparticipation. Local leaders excluded from policyparticipation, in turn relegates the public to an informing degree of tokenism. The domination of federal planning and guidelines were intended to 'cure' the problem of local diversity in dealings of disaster mitigation, preparedness, response, and recovery. At the local level, federal plans have been carried out and the public is provided websites and news to inform them of decisions and plans. This level of public participation is consistent with strong command and control system, but lacks even a semblance of public consultation, advisory or collaborative efforts; placing participation on the minimalistic extreme of the ladder (Thomas, 1995). The ladder implies a kind of deceitful and malicious intent by authorities, but this is not the position this study takes. Rather the lack of participation was intended to maximize rapid implementation of programs across the nation. This effort was largely effective, but problematic for the sustained mission of FEMA to protect the community. The nature of the policy process as it takes shape 
between different interests will illuminate some of the reasons the public has been exclude from emergency management.

\section{Figure 3 Arnstein's Ladder of Citizen Participation}

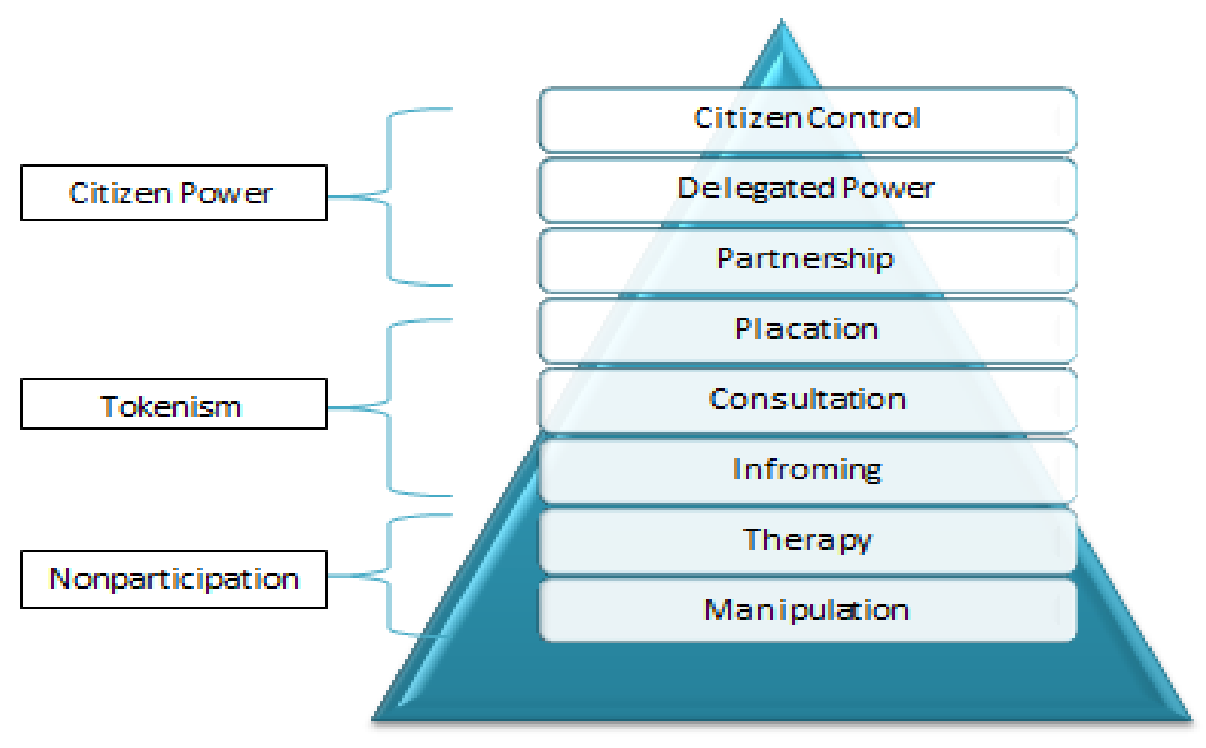

\section{Deliberation versus Pluralism}

Proponents of public participation in the political system come in two definable variations; deliberative and pluralistic. As developer of the critical planning theory, Jürgen Habermas emphasized deliberation and procedure. Countering the emphasis on deliberation is the pluralistic model described by many authorities, including Michael Foucault, who emphasizes contentious discourse between interests seeking power. These two models represent different understandings of how actors interact with one another, how equality is considered, and finally how government should be involved. These three elements will be the focus of the theoretical exploration of public participation to follow.

Deliberative theory is operationally concerned with three challenges to public participation: inept communication between parties, the problems of inequity, and the 
role of authority. According to Habermas, a democratic political system, derived from a self-determining society, should construct policy from the fundamental understanding of all interests (Habermas, 1975). To arrive at this ideal policy, stakeholders need to be engaged in a procedurally deliberative discourse. All stakeholders in this participatory format are to be considered equal in terms of shaping policy. Key to stakeholder equality and consensus is the idea that, at its most fundamental roots, government is not an apt problem solver. This deliberative ideal, defined by procedural communication, is very complex and obviously requires a level of sophisticated information transference that far exceeds those of contemporary capacities. Two practical limitations will undermine the application of deliberative ideas in emergency management. First, there are temporal considerations that emerge between disasters that may happen seasonally or over decades, which require rapid decisions. Second, deliberation requires an enormous amount of mutual understanding between participants. Disaster can strike any or all segments of society, so creating a comprehensive understanding is too large a challenge. For the purpose of this study Habermas's definition is to idealistic and unpractical, but we cannot exclude elements that may help comprise a viable alternative for emergency management.

Pluralism, as represented in the American political system, stands in sharp contrast to deliberative participation in three foundational ways (Silver, Scott, and Kazepov, 2010). First, the pluralistic policy process is primary defined by unscripted and unstructured dialogical struggle between competing interests. Second, recognition of 
imbalances of power is to understand the inherent condition of human power interactions. Imbalances simultaneously provide the impetus for action and temporary resolution of conflict by dominate groups. Finally, government is primarily responsible for shaping the solutions to problems by facilitating the conflicts between interest in a civil and transparent manner. The pluralistic model represents a very contentious method of arriving at policy decisions by rigorously engaged actors, facilitated by government. Pluralism describes conclusions derived from convergences of a "whole order of levels of different types of events differing in amplitudes, chronological breadth, and capacity to produce effect" (Foucault, 1980). While examples of pluralism are abound, one question persists, how is policy shaped when the issue is not rigorously contested? Without the public in the policy process, the contest is between agencies and political leaders. Both the deliberative and pluralistic models of participatory theory provide us with useful and less so elements, so a new model will need to be shaped for emergency management. 
Table 3 Theoretical Participatory Models

\begin{tabular}{|c|c|}
\hline Deliberative & Pluralistic \\
\hline Normative Theory & Normative Theory \\
\hline Stresses Procedure & Stresses Conflict \\
\hline Direct Democracy Focused & Interest Group Domination \\
\hline Deliberation is Key to Success & Dialogue and Debate key is to Success \\
\hline All Parties Equal in Deliberation & Power Inequalities always present \\
\hline Consensus is Goal & Conflicts expose goal \\
\hline Government is not Apt at Solving Problems & $\begin{array}{l}\text { Government Creates Environment for Interests to } \\
\text { Struggle in Civil Manner }\end{array}$ \\
\hline $\begin{array}{l}\text { Procedural Rigidity Reconciles Some Inequalities } \\
\text { but Hides Others }\end{array}$ & $\begin{array}{l}\text { Inequalities Made Conscious by Struggle and are } \\
\text { Left Unresolved }\end{array}$ \\
\hline \multicolumn{2}{|c|}{ Dynamic Participation in Emergency Management } \\
\hline $\begin{array}{r} \\
\text { - Procedure and Conflict Replace } \\
\text { P Public Actors, not C } \\
\text { - Collaboration } \\
\text { - Broad Input, not Consen } \\
\text { - Trade-Offs between Inclusi } \\
\text { Government Facilitates Opennes } \\
\text { - Alleviating Inequali }\end{array}$ & $\begin{array}{l}\text { itive Theory } \\
\text { ith Informal Institutionalized Participation } \\
\text { flicting Interests, are Essential } \\
\text { mphasized over Conflict } \\
\text { s or Dominate Ideas, are Necessary } \\
\text { and Efficiency Taken as Self-Evident } \\
\text { eryone is Allotted Equal Input } \\
\text { Dialogue and Transparent Decision Making } \\
\mathrm{s} \text { is an Element of the Solution }\end{array}$ \\
\hline
\end{tabular}

\section{Dynamic Participation Model}

The limits of the deliberative and pluralistic participation require the creation of a more ample model for addressing the goals of emergency managers. Essential elements of this new model include; collaborative dialogue, equal opportunity for input, and government facilitation of dialogue. First, Nancy C Roberts describes dialogue as involving the fleshing-out of mutual concerns which intern builds relationships (Roberts, 


\section{Public Participation in Emergency Management}

2002). This is less directed and ordered than deliberation, while not involving conflict between interests. Standard rules guiding deliberation and debate are not employed because proper two-way dialogue must operate free of overtly coercive structures and procedures (Roberts, 2002). Each participant is equal in as far as his or her concerns are expressed in relation to the primary topic, with the goal of shared learning. Facilitators establish a primary topic, but the meanings and assumptions are left to the participants to extrapolate dialogically. Rather than dominate-interests groups defining policy, each stakeholder has an equal opportunity to express their position for consideration, without a necessarily equal impact on final policy. Practical communication between individuals, carried out to align goals and interests, can be operationalized in an undominated approach to dialogue (Mantysalo, 2002). The policy process in this regard shifts from essentially contentious to collaborative as participants come to understand mutual interests and concerns. In this theoretical atmosphere, where the ridged roles played by authorities and citizens are dulled, dialogue can widen the knowledge-realm concerning community and individual responsibility. Rather than being inept, as maintained by deliberative theory, government orchestrates public participation processes in four primary ways: issue or situation, administrative systems, administrators, and finally the citizens themselves (King, Felty, and Susel, 1998). Dialogue shapes policy and understanding which is then used by authorities and leaders to construct policy. The current FEMA Whole Community Approach initiated in December of 2011 was constructed from a collage of different methods, including conferences, seminars, 
professional meetings, practitioner gatherings, and official government meetings (U.S. DHS, FEMA, 2011). What is missing, and essential to the effort, is an institutionalized space for dialogue. While gathering information from various sources is important, giving the community a space at the table is the only way to create personal responsibly, social capital, and a prepared community.

The practical playing field of emergency management is where the theoretical idea of dynamic participation colludes with our understanding that no interactions are without miscommunication and error. Both deliberative and pluralistic models contain elements that will dilute the capacity of collaborative efforts to strengthen emergency management policy. Problems emerge from intergroup communication trends, technocratic language, and procedural intolerance. Looking at the citizens themselves, we see institutional barriers that come in the form of authority gatekeeping, formal interaction structure and short-term goal orientation (Beresford, 2005). Barriers such as these are most evident when public participation is interjected into the policy process at disadvantageous stages. The following chapter will clarify wherein emergency management public participation is best suited. Without proper consideration, these barriers will prevent constructive communication, even when the institution has been shaped primarily to facilitate wider participation. For the public to contribute positively to policy processes an understanding of their weaknesses and strengths will require further examination. 


\section{Advantages}

As a blanket concept, increasing public participation in government is not one that this study is prepared to posit. Rather, increases in public participation in certain areas of emergency management and at certain policy stages, will increase overall community safety. Before we can identify where those areas in the emergency management phases and policy process are, we must understand the advantages of public participation. Defined in light of the basic demands of the bureaucratic model, efficiency of rational decisions and quality information, participation offers many benefits. In addition, participation may also sponsor a swell in community engagement in the form of social capital.

Modern society requires information provided by technical, organizational, and scientific experts. With this in mind, the benefits of information provided by public participation must be addressed in relation to disasters. The first advantage emerges when the public is tapped to clarify the ambiguities that define "wicked" problems (Thomas, 1995). These ambiguities include the moral dilemmas that emerge during a disaster, for example whether resources are to be allocated in a utilitarian manner or prioritize for special groups. For those concerned, CERT training was wholly utilitarian, especially as far as triage and treatment efforts were concerned. Second, the public is the only body capable of considering the vast variables needed to arrive at holistic perspective, which is essential when dealing society wide disasters. When utilized, this holistic view has been shown to produce and improve substantive decision quality as well as providing "thick" descriptions of risk (Berele and Crayford, 2002; Horlick and Jones, 


\section{Public Participation in Emergency Management}

2009). The third benefit involves the contextual references that local knowledge maintains, including very specific and up-to-date information as well as broad generational considerations (Innes and Booher, 2010). The fourth informational benefit accrued by the inclusion of the public in policy processes is the emergence of an educated public. As has already been demonstrated, a post-disaster public unaware of the full spectrum of policy options will focus on familiar recovery efforts; at the expense of what maybe the more rational efforts of mitigation and preparedness (Irvin and Stansbury, 2004). Finally, by including all stakeholders into the policy process, managers encourage citizen involvement in the community at large. This can pay unforeseen dividends to policy makers as they look to enact, implement, and enforce directives. The informational benefits noted here are those that emerge from a dialogue between community and mangers, which ultimately lend themselves to greater over all governmental efficiency.

The role of the public in policy process can provide informational benefits to mangers, but there are other situational benefits. First, while the public can clarify ambiguities, it can also break decision gridlocks and mediate powerful interests, as will be explored in chapter 4 (Pearce, 2003). Second, governments may avoid litigation if they share responsibly of decision-making with the public. The third benefit comes in the form of more comprehensive implementation, which manifests from a collective agreement on regulation or laws to be administered. When the public communally agrees, there is less overall resistance to implementation. Another benefit emerges 
concerning the extent to which administrators and politicians are able to appeal to the larger community for support. This may involve administrators mobilizing the public to pressure politicians for greater resources, or politicians mobilizing the citizenry to pressure administrators for greater efficiency. Finally, the government would benefit from an increase in the trust that would emerge with swell in governmental transparency (Irvin and Stansbury, 2004). These five factors are by no means exhaustive, but they do represent areas where the public could benefit bureaucrats' most stringent requirements: efficiently, rational decision-making and quality information.

\section{Social Capital}

Social capital represents an ancillary benefit emerging from a community that contributes to the policy process. This section will begin by defining social capital and illuminating some of its positive and negative elements. Second, this section will explore examples where social capital benefited a community, as well as the where social capital is best vested. Finally, this section will look at where government has failed to capitalize on social capital and how this may be corrected. For any community that goes through growth and change, social capital is a valuable resource, but for those in a disaster it can literally save lives.

At the very heart of the term social capital lay an understanding that social networks have some inherent value for those participating in them. This understanding is closely related to what many call civic virtue, but on a wider more diverse scale. At a general level, these benefits emerge from the trust created through reciprocity, 
information sharing, and cooperation (Sagurao Seminar, 2000). These activities converge in a community, transforming the 'I' mentality to a 'We' mentality. The 'We' represents a more robust, resilient and sustainable social atmosphere, worth further exploring. One element of social capital is the positive effects it may have on the productive value of an association, by helping its members maximize internal resources (such as skills) for the external use on community interests, such as building a library. Social capital can have both individualistic and collective elements, depending on the nature of the problem. Reciprocity too has both individualistic (if you don't come to my wedding, I won't come to yours) as well as general elements (the golden rule for example) (Putnam, 2003). Social capital, because of its nature, is necessarily amorphous and can take on formal and informal tendencies. Obviously, during a disaster, informal and unscripted activities would carry the day, and this is where social capital emerges most beneficially. One final definitional element of social capital is its positive or negative manifestations. While social capital is typically beneficial to those inside the network, it can be detrimental to those outside, as demonstrated by racial and nationalistic groups such as the Klu Klux Klan. Networks can congregate around ethnocentrism, xenophobia, and sectarianism. These negative examples have been the exception, not the rule, in American history. Associations such as churches, bowling leagues, book clubs, cancer support groups, and many more make up social capitals more frequent expression. 


\section{Public Participation in Emergency Management}

While the benefits of social capital may seem obvious to anyone in a tightly networked community, they may seem less so to those in a fragmented body-politic. As we will see in the Walkerton, Canada case study (chapter 4), social capital was essential to the overall disaster resilience of the community (Murphy, 2007). In addition to resilience, studies have revealed that the presence of social capital in the community is strongly correlated to the overall physical and mental health of its members (Schultz, Obrien, and Tadesse, 2008). While the benefits of social capital spread throughout the community, it is at the neighborhood level where relations are at their most influenceable. Social capital is not simply the organic interactions between individuals seeking expression of their interests; in addition, government may bolster social capital. It has been demonstrated that communities can facilitate street level social capital through the institutionalization of neighborhood participation in policy-processes (Kirlin, 1996). One shining example of this comes from the creation of the Office of Neighborhood Associations in Portland, Oregon; described by Robert Putnam as having "helped sustain and encourage the sort of civic activism" that has made the city a bastion for civic engagement (Putnam, 2003). As Putnam notes, the Portland case represents an anomaly in a trend of declining social capital across the nation, and there may be a clear reason for this situation.

The atrophy that we see in the levels of social capital, from the stellar heights of Tocqueville's description to the disengaged levels Putnam describes, is linked to policyprocess disengagement. In what Robert and Janet Denhardt call the "old public 
administration," we see all the hallmarks of a system that effectively kills social capital as it pertains to the establishment of networks (Denhardt, 2000). There is no room in the bureaucratic model for reciprocity; trust is sabotaged by a lack of transparency; flexibility is hindered by limits on discretion; and communication is carefully controlled. The vertical accountability and command structure undermines the horizontal integration of a community. This effectively works against the understanding that communities exhibiting a high degree of social capital are exquisite problem solving units (National Research Council, 2006). At the federal level, there are a number of ways social capital can be bolstered through reforms in institutional transparency, electoral campaigns, and the policy processes (Sagurao Seminar, 2000). While the bureaucratic organization of emergency management has done little to slow the erosion of social capital, local managers have been left with little time or resources to reach out to established associations like those found in Portland neighborhoods.

The role that social capital plays in a community is one that should not be underestimated by citizens or leaders. For emergency management there is an essential lesson, one that was taught in CERT training, that you as a community member will always be the first responder in a disaster. This rather humbling thought should put impetus on efforts to engage the public, but to large degree, it has failed to do so. Social capital is something that is expressed in many shapes, comes in many forms, and requires trust and reciprocity to maintain. What has been on display during the last decade of emergency management restructuring is a fundamental disconnect between reciprocity 
and trust brought on by centralization and bureaucratization. The trend that has undercut social capital can be reversed through a renaissance of government/citizen relations at the neighborhood level, greater local and state input on national policy, buoyed by greater federal efforts at transparency, dialogue, and public participation.

\section{Disadvantages}

Increases public participation may produce numerous, but not insurmountable, challenges to organizational and managerial norms. This section will identify eight essential problems that face any endeavor to include the public in policy. The first disadvantage of more inclusive participation involves the possible subordination of expert opinion to a degree that their advice is all but ignored. While this may seem quite serious, the level of certainty maintained by experts is flanked on three sides by ambiguity in priorities, uncertainty on combination effects, and sheer ignorance involving the unknown-unknowns (Stirling, 2008; Hampton, 2009). With this understanding, both public and experts should have institutionalized roles to challenge uncertainty. 
Table 4 Dynamics of Uncertainty

\begin{tabular}{c|l|l|}
$\begin{array}{c}\text { Knowledge } \\
\text { About } \\
\text { Likelihoods }\end{array}$ & \multicolumn{1}{c}{$\begin{array}{c}\text { Knowledge } \\
\text { About } \\
\text { Outcomes }\end{array}$} \\
\hline Not & $\begin{array}{l}\text { Not Problematic } \\
\text {-Wherstandable Risk } \\
\text { Problematic is an } \\
\text { relatively high } \\
\text { understanding of conditions }\end{array}$ & $\begin{array}{l}\text { Ambiguity } \\
\text {-Where no clear consensus is } \\
\text { available on conditions, ethics, lack } \\
\text { of trust and incommensurable } \\
\text { priorities produce varied advice }\end{array}$ \\
\hline Problematic & $\begin{array}{l}\text { Uncertainty } \\
\text {-Where complexity, human } \\
\text { elements, and transboundry } \\
\text { effects may take effect }\end{array}$ & $\begin{array}{l}\text { Ignorance } \\
\text {-Unanticipated effects, conditions, } \\
\text { gaps, unknowns and general lack of } \\
\text { predictability }\end{array}$ \\
\hline
\end{tabular}

* Andy Stirling, "Science, Precaution, and the Politics of Technological Risk.” 2008 pp.99

A second disadvantage involves the high correlation between the top socioeconomic groups and those that participate in public affairs. While is generally true, the efforts to organize the public on behalf of emergency management have been very minimal. Despite lack of attention, surveys reveal that $64 \%$ of citizens stated they would be willing to engage activities such as the CERT training, if afforded the opportunity (Citizen Corps, 2009). There is obviously a desire among a diverse citizenry to participate in self-help activities. The third problem involves the challenges groups' face reaching consensus with disparate and overly technical information. One critique of consensus involves what is identified as the lowest-common denominator problem. This surfaces when a group of individuals concludes by agreeing on a point where their individual interests are secured without any substantial ground being surrendered, rather than pursuing the most rational choice at the cost a particular view (Coglianese, 1999). 
This problem is reasonable to assume only if a policy is created by consensus without some direction by authorities, a position this study is not positing. Bargaining and collaboration are activities the general public participates in daily, and there is no reason to believe they would suddenly become unwilling.

The next two problems concern the poor policy produced by lack of larger policy objectives and efficiency of policy creation (Sunstein, 2005). The first of these problems concerns public input at the early policy stages, which may produce decisions difficult or impossible to implement by administrators. The answer to the problem is twofold; first greater time is taken early in the policy process as stakeholder views are incorporated with other demands. This produces broader considerations, including understandings of administration, which later facilitates greater implementation efficiency. This stands in contrast to a group of legislators who may rapidly enact policy, with little understanding of the challenges faced by distant administrators. The second problem is the perceived loss of decision control and increased veto points in the policy process. It is the position of this study to increase the capacity for decision quality by increasing the choices provided by a broadened range of considerations (Irvin and Stansbury, 2004).

The final three disadvantages of public participation involve a lack of public sensitivity to temporal, political, and fiscal considerations (Klinke, 2002). This presumes the inclusion of the public, as an ignorant rabble, occurring in a leaderless vacuum, a proposition not made here. Rather, input from the public is garnered and utilized by leaders for optimal policy output. The public consists of disciplined, calculating, and 
responsible individuals who are capable of benefiting policy processes given a measured degree of direction.

\section{Conclusion}

The advantages and disadvantages of public participation in emergency management described here are not definitive, and indeed the dynamic nature of disasters requires flexibility. What is important to understand is that the carefully fortified borders of information and efficiency that bureaucrats hold sacred, can with the right finesse be bolstered by public participation. The disadvantages should not dissuade us from incorporating public participation, but rather offer us glimpses into the specific areas the public can be most potently utilized. These specific areas of policy will be the focus of the ensuing chapters. The inclusion of the public dialogue on policy can also help distill a rich civic environment, one that would pay many dividends to emergency managers during a disaster. 
Table 5 Advantages and Disadvantages of Public Participation

\begin{tabular}{|c|c|c|}
\hline \multicolumn{3}{|c|}{$\begin{array}{l}\text { Public Participation: } \\
\text { Advantages and Disadvantages }\end{array}$} \\
\hline & Benefits & Disadvantages \\
\hline Information & $\begin{array}{l}\text { - Educates Public on importance } \\
\text { of issues } \\
\text { - Clarifies ambiguities of } \\
\text { "wicked' problems } \\
\text { - Holistic perspective } \\
\text { - Greater contextual reference } \\
\text { - Increased Stakeholder } \\
\text { involvement }\end{array}$ & $\begin{array}{l}\text { - Expert/Professional could be } \\
\text { disregarded } \\
\text { - Top Socio-economic groups } \\
\text { dominate } \\
\text { - Lowest common denominator } \\
\text { problem } \\
\text { - May produce poor policy } \\
\text { according to experts }\end{array}$ \\
\hline Efficiency & $\begin{array}{l}\text { - Breaks Decision Gridlock } \\
\text { - Government may avoid } \\
\text { litigation risks } \\
\text { - More Efficient Implementation } \\
\text { of regulation and law } \\
\text { - Greater clout for resource } \\
\text { allocation } \\
\text { - Increase Governmental Trust }\end{array}$ & $\begin{array}{l}\text { - Less efficient early policy stages } \\
\text { - Loss of Decision Control } \\
\text { - Increased Veto Points } \\
\text { - May politically back-fire } \\
\text { - Lack time sensitivity } \\
\text { - Cost/Budgetary concerns not } \\
\text { effectively addressed }\end{array}$ \\
\hline
\end{tabular}

\section{Conclusion}

Public participation is a very contentious phrase in administration, and this chapter has attempted to clarify where it stands in relation to public policy. In order to do so it first compared what John Dewey eulogized as the former public and what he called the 'new' public. Dewey's later description of a largely disengaged and apathetic public is one we well recognize as our own. To remedy this problematic policy situation will require a renaissance in public-government relations both horizontally and vertically. This requires us to understand what participation is, and Arnstein's ladder revealed that currently the public plays a non-participatory role. Two dominate theoretical 
understandings of how the public engages policies were found to be incomplete for the purpose of this study. Drawing from deliberative and pluralistic models, a dynamic model was introduced emphasizing dialogical interactions; based on equal stakeholder positions and facilitated by government for collaborative purposes. Essential, participation needs to be introduced where advantages are most evident, and leave the public out of stages where they would detract from goals, remembering the inclusion of the public in policy processes can bolster social capital. Finally, the public will always bring both advantages and disadvantages to the policy process. Having a vibrant network of neighbors could mean the elimination of an exponentially increasing number of victims during and in the wake of a disaster. This is the case because the public plays one of two roles; either as the victim or as the first responder to aid other victims. The degree to which we can impact which one you will be, depends on where precisely in the emergency management policy process we introduce public participation. 


\section{Public Participation in Emergency Management}

\section{Ch.4 The Public in Emergency Management}

\section{Introduction}

The absentee role of the public in today's emergency management policy process and administration [Ch.2] becomes problematic as we begin to understand the interdependences of social life that disasters disrupt. Adding to the problem, our technological sophistication has increased, as have the frequency and costs of disasters. In reaction to disasters, the federal government has dedicated an enormous amount of financing, organizational knowledge and expertise to defending the nation. Defending is the correct adjective, as the methodology is based on Cold War strategies, and lacks balance with the community. This creates a Federal Emergency Management Agency dedicated to response and recovery, but less interested in mitigation and preparedness, despite public interest (Rossi, 1982). To FEMA's credit, it has taken leaps to professionalize its field, and the billions of dollars it commands have enormous impact in recovering communities. Sadly, pre-disaster efforts such as partnership building and education have been deemphasized. The Whole Community Approach, FEMA's most recent initiative, recommends a number of steps on display in this study: creating a place for the public at the planning table; let public participation lead; build trust through participation; and planning for real situations (U.S. DHS, FEMA, 2011). Fundamentally missing is how local emergency mangers are going to implement, pay-for or find the time for these suggestions without institutional change. Something is missing from FEMA's commitment to mitigation, preparation, response, and recovery; the institutionalized role 
for the public in the policy process and administration of programs.

The role of the general public in the American political system and policy processes has been a contentious topic well before Tocqueville's early $19^{\text {th }}$ century championing. Contrary to the Tocquevillian view, the twentieth century demonstrated a growing trend of public apathy and distrust towards government activities. Apathy and distrust have in part emerged from a policy-monopoly at the federal level. For emergency managers, this apathy and distrust led to a citizenry lacking fundamental preparedness and community-ties to help deal with disasters. To combat a lack of citizen engagement, which leaves the nation more vulnerable, this chapter will look at key areas within the emergency management policy process and administration where public participation could be introduced. First, literature on public participation in emergency management will be surveyed. Second, the policy stages of agenda-setting and policyformation represent opportunities for attuned policy-makers to apply the strengths of participatory dynamics and federal devolution. Third, the administrative emergency management phases of mitigation and preparedness can be expanded to include nonstructural and more collaborative implementation methods. Interweaved with these key areas will be current examples from the United Kingdom, New Zealand and India, where greater participatory involvement exist. These case studies will illuminate recommendations for the greater public participation posited here, in areas where it could most befit our communities and emergency managers. 


\section{Literature on Public Participation in Emergency Management}

The five studies reviewed below will explore the dynamics of emergency management in consideration of the efficiency of, obstacles involving, and implementation of public participation. These mirror the greatest considerations managers have when considering the imposition of additional voices in the policy process.

\section{Efficiency}

\section{Bach-Kaufman}

The study by Robert Bach and David J. Kaufman probes the fundamental disconnect between the general public and emergency planners. In order to create a safer and more secure community, their study shows public mangers (dealing with emergencies) how to reach the public collectively and on a large scale (Bach and Kaufman, 2009). Their study concentrates on public policy actors at the federal, state, and local levels within the continental United States.

In order to suggest a new paradigm in DHS policy, the researchers focused their qualitative analysis on federal initiatives, DHS agency reports and official statements, as well as reports from local politicians and law enforcement. The researchers studied levels of overall public preparedness and post-911 trends in DHS organization to arrive at their conclusions. To illuminate these trends, their study analyzed two DHS directives involving border-security and national strategic preparedness, to find areas that have disenfranchised the general public from greater partnerships. While security is essential, the role delegated to the public in general has been one of passive compliance rather than 
active participation.

While the foci of DHS mangers has been activity in providing policy in the name of security and institutional preparedness, the results of this study highlight some deficiencies. First, it concluded that the dominance of federal level policy-formation and decision-making undermined local authorities' ability to successfully protect communities. Second, the general public was woefully unprepared for emergency situations because local authorities were engaged in federal agency mandates rather than increasing community involvement. In the case of Hurricane Katrina, local authorities followed federal direction on anti-terrorism policy at the cost of natural disaster planning. To rectify this problem, the study suggests a number of recommendations: joint-decision making process, public dialog about risk, establishment of a national directive and institute for preparedness and community preparedness routinization-programs. While these recommendations specifically address the public deficit in emergency management, they are not without limitations, as described in the previous chapter.

\section{Mitchell}

As former FEMA director James Witt noted, "all disasters are local. " Despite this, post 9/11 focus on homeland security has realigned emergency management at the federal level and undercut local partnership (Edwards, 2007). James K. Mitchell's study provides contrast to the trend in leadership centric policies that have emerged since Hurricane Katrina by reintroducing the importance of partnerships to emergency management (Mitchell, 2006). New Orleans provides the setting for this study because of the sheer enormity of the disaster and the fact the despite federal and local authority's 
confidence, plans and initiative; FEMA was rapidly overwhelmed.

In order to flesh-out the problems that seem so numerous in the Hurricane Katrina disaster, Mitchell's study focused on committee and agency documents, insurance industry disaster findings, as well as nongovernmental agency reports that illustrate numerous shortcomings. Mitchell notes eight specific emergency management activities that had been recently consolidated, from more open and transparent methods to more centralized bureaucratic operating models. These consolidated activities include event framing, hazard analysis, emergency reactions, behavior considerations, varied decisionmaking, sources of information, avenues of potential management, and inter-disciplinary openness. In addition, the study brings a brief comparison of United States emergency management with the government responses from China, New Zealand, Canada, and the European Union. The primary concern of this article is to describe the differences in perspectives between broad-national and narrow-community partners, and the effect those perspectives have governmental efforts to address disasters.

This study concludes that current trends in emergency management have removed the benefits of varied partnerships and created four limitations, including; decreased public knowledge about threats, less flexible planning for unforeseen complications, lack of important contextual information on disaster, as well as a narrowing of interpretations of risk, which decreases overall coverage. The reasons for consolidating these areas are clearly important for command and control purposes, but do not adequately address the “wicked” problems faced by emergency managers. These problems are rarely linear, 


\section{Public Participation in Emergency Management}

straightforward or without moral pitfalls. For these complex or "wicked" societal problems, the increase in overall general knowledge about a disaster area and its people are an advantage under-utilized by centralized emergency management.

\section{Discussion}

The efficiency focus that produced a very centralized bureaucratic organization was intended to maximize command and control functions. Command and control functions are appropriate for many problems that government works to solve, but not all. As the above articles have attempted to demonstrate, emergency management could benefit from greater community inclusion in the policy processes. The inclusion of greater general participation at the end of the policy process, while providing local authorities with greater autonomy, will not solve the lack of preparedness in a community. The reason for this, local emergency management is likely to transpose federal command and control systems onto local political systems for response and recovery, thus excluding the general public. Mitchell has a sense of this in his article and thus brings public participation farther upstream, to the point where bureaucratic agents are assessing hazards and dangers faced by communities. While this is a further step in the direction of greater public participation in emergency management, it still does not address the role the public can play in agenda setting, policy formation, and legitimization of policy. These early stages in the policy process have been the subject to controversy, as centralized leadership has focused on security at the expense of other considerations. 


\section{Conclusion}

Mitchell's study comes to one rather straight forward conclusion, "What is most needed is a way of broadening the discourse about recovery and bringing more people into it" (Mitchell, 2005). While the prescription is rather clear, the implications are less so. Since the 9/11 terrorist attacks the reorganization of emergency management under the central authority, DHS, has had detrimental outcomes for FEMA's primary mission. As Bach-Kaufman illustrated the dominance of policy mandates at the federal level undermines local input and collaborative efforts with the community. Mitchell added to this by illuminating the concerns of homeland security, and the need for highly fluid and efficient leadership. Both these authors wish to increase emergency management knowledge by bringing in more players from the community, via closer partnerships and joint decision-making. For Bach-Kaufman, local players need to be involved in guiding the implementation of policy at the local level. This would more appropriately allocate federal resources wastefully used on terrorism prevention for areas with little chance of attack. Mitchell on the other hand, wants to bring diversity to the hazards and risk analysis processes, typical of the mitigation phase of emergency management. These two articles represent different points in the policy stream, Bach-Kaufman at the very end as funds drizzle down to local authorities who must follow federally created and defined policy on response and recovery. On the other hand, Mitchell focuses on the enactment stage (middle of the policy process), and the very beginning of the bureaucratized emergency management mitigation phase. Both have neglected the preparedness phase, which is the most professionally dominated and efficiency focused. 


\section{Obstacles}

Murphy

During a disaster, communities with a high degree of social capital can readily form functional partnerships and even substitute for local authorities, which in turn may increase overall local resilience. The specific question that drives the Brenda $\mathrm{L}$.

Murphy's study is whether social capital can improve community emergency managements' resilience to risks and hazards (Murphy, 2007). Community emergency management, described in this study, is management you would find in low population, homogeneous, and highly networked localities. This definition stands in contrast to policy-isolated and professionalized emergency management you would find in larger cities or operating at the federal level.

To find the correlation between social capital and resilience, the study takes an intimate look at two separate disasters in the province of Ontario, Canada. In the first case, the city of Toronto fell victim to a electrical blackout in 2003, which ultimately affected approximately 50 million people in the eastern regions of the US and Canada. The second case involves the town of Walkerton, which faced an E. coli outbreak in its central water supply. The significance of these two cases stem from respondents' elevated degrees of trust in their communities as well as high frequency of volunteerism and public participation. While the types of disaster and affected populations of the two events are fundamentally different, the cases are commensurable.

In order to investigate the emergencies that beset both Canadian communities, Murphy's study took advantage of a mixed-method survey conducted to research general 


\section{Public Participation in Emergency Management}

emergency preparedness in the wake of an incident. While the principle intent of the original survey was not to investigate social capital, rather general community response, many questions lent themselves to this purpose. In the electrical blackout case study, the researchers conducted a phone survey of 1,203 people in Toronto approximately five months after the outage. In the Walkerton case, the study recorded 104 face-to-face structured-household-interviews, 23 interviews with local authorities/leaders and finally 2 focus group sessions with 12 random community members approximately two years after the disaster. The survey, interviews, and focus groups gathered information on three areas: assessments of the level of preparedness of the communities prior to blackout, direct impact on community members, and finally the impact of community response.

The results of this study reveal a number of points regarding the nature of social capital in relation to emergency management. In general the study illuminated a complex but positive relationship between the presence of social capital and a hazard/disaster resilient community emergency management system. While the natures of the two emergencies were very different, the emergence of citizen partnerships in both was a success factor shaping how the community dealt with problems. In Toronto, media reports told stories of neighborhood barbeques and other such informal gatherings. In the small community of Walkerton (population 5,000), three emergent citizen groups took the reins when local leadership failed. These groups created and facilitated a water disbursement center, handled the collection and disbursement of donations, and lobbied for a full investigation of incident after the fact. The differences in the community 


\section{Public Participation in Emergency Management}

response between these two areas reflect the great differences in demands placed on communities by particular incidents.

\section{Rodriguez, Havidan, Trainer, and Qurarntelli}

Emergency management prides itself on firm planning and efficient execution during the response phase, but the uncertainty of disasters requires leaders to deviate from standard procedure, much like emergent citizen groups. During the 2005 Hurricane Katrina, emergent citizen groups were reported by media to be predominantly chaotic, criminal and antisocial, which has since been proven patently false. In contradiction to many media reports, this study shows ample evidence that most emergent activities in the community were not merely positive, but also took over responsibilities normally assumed by authorities. The word emergent is used in this study to describe "nontraditional or new behavior that deviates from routine or customary norm-guided behavior" and is associated with large organizations, business and citizens alike (Rodriguez, Trainor, and Quarantelli, 2006). The purpose of this study was to dispel the larger media's portrayal of chaos, and replaced it with one illuminating the prosocial activities carried out by citizens, business, and organizations that deviated from conventional norms. Importantly, citizens were the last line of defense, rather than barriers to the FEMA mission.

To complete this survey, the authors used data from the Disaster Research Center at the University of Delaware detailing events transpiring in New Orleans immediately after the Hurricane Katrina. This research is composed of 150 personal interviews with local residents, researcher observations, official interviews, and governmental documents. 
In addition, a single database containing various print and non-print media reports, organizational reports, and informal stories were utilized. For this study the authors analyzed the first-hand personal accounts of residents, which were then confirmed by other sources. This allowed records of personal, business, and organizational interactions to provide evidence contrary to popular reports of anarchy.

The findings of this study provide clues on the behavior of individuals and organizations acting in the face extreme and demanding circumstances. Five organizational levels of description provide a framework for this study. Although not presented in this order, they include joint field office, hospitals, hotels, search and rescue teams, and local neighborhoods. Despite difference in size and capacity, all exhibited emergent behavior in one form or another. The most important for the author's study were those involving local neighborhoods, where they found working class people laboring altruistically for mutual security and survival. Specifically, there was a group of friends who, after evacuating their families, stayed behind to perform rescues and support community members. Much like citizens in Walkerton, these men initially worked alone and eventually formed a loose cooperation with authorities, to provide foodstuffs and other essentials to residents unable or unwilling to evacuate. Right alongside this emergent citizen activity, FEMA unexpectedly established their joint field office in an abandoned mall. In order to bring the mall up to the capacity required of the central hub of nearly all organizations involved, FEMA enlisted the help of contractors, computer networks, and telecommunication engineers. The utilization of the mall was unplanned, 


\section{Public Participation in Emergency Management}

as was the rapid upgrading necessary to maintain it as the joint field office. These two examples of spontaneous and emergent behavior provide us an important reminder that plans rarely survive first contact intact, and obstacles and advantages are often confused with one another. All emergent activities reported in this study are positive, which the authors acknowledge might show bias.

\section{Discussion}

While emergency management has focused on response and recovery capabilities, the building of capacity at the local level through preparedness has been overlooked because the general public is considered an obstacle. According to Murphy, the level of social capital in a community may lead to self-help and organization, rather than what emergency planners usually visualize as a hapless or panicked public. For Rodriguez, the citizenry can be the misunderstood champion of its own cause. Where these articles find agreement is that, any plan, no matter how seemingly sound it may appear, can reach a fracture point. At this point, the apparently disorganized masses that may seem to bog down both the policy process and emergency management phases, actually become a community's last line of defense. In the case of Walkerton, it is very clear that citizens organized themselves to perform many of the functions authorities would have engaged in. In the case of New Orleans, the scale of destruction produced even greater divergence from typical community activities, including requisitioning private property of all kinds for the sake of the community. These two articles demonstrate the dynamic activities of citizens who react positively to situations well outside their normal range of stressors. This adaptability would be beneficial for emergency managers to harness during the 
policy process when bottlenecks and arbitrary decisions can have dramatic affects down the policy stream.

\section{Conclusion}

While leadership and command structures will identify the general public as obstacles to agency goals, the masses represent the last line of defense against the breakdown of society. Public qualities, that include diversity, independence, and ingenuity, may make them both difficult to work with and resilient. The ways citizens respond to emergencies are as varied as the disasters they face. Disasters represent the cusp at which chaos challenges order, and it should be understood that citizens for the most part on the side of order. As such, they should be viewed as assets, not obstacles in the emergency management policy process. An understanding of exactly how and where in the policy process the public best suited to help emergency management could increase positive outcomes.

\section{Implementation}

\section{Pearce}

The policy process and administration in emergency management can be constructed at the local level, using maximum stakeholder input and some federal structural influence. The responsibilities of emergency mangers are made more difficult by the fact that both the public and community planners interests may run counter to emergency concerns. This divergence in interests is not a necessary condition of emergency management in a community; in fact, integration of a plurality of interests can bring great benefits. The purpose of Laurie Pearce's study was to trace out the shared 


\section{Public Participation in Emergency Management}

interests of community planners, disasters managers and the public to show the benefits of their combined efforts in mitigation (Pearce, 2003). The success is illustrated by the policies that were created in a highly seismic and landslide prone area of the Porta Valley, California. The participants included average citizens, city planners, officials, geologists, businesses, and developers. Where at first this group failed in creating successful policy, lessons were learned and sound policy emerged.

This study drew largely from a geologic and planning research conducted by G.G. Mader in 1988. This initial research focused on how communities balance housing growth spearheaded by developers and the highly volatile Sand Andreas fault line. Pearce added to this study by illuminating the public's role in shaping how community planners, experts, and developers reached an agreement by recognizing their shared values. Local policy emerged from the creation of a Geologic Hazards Committee that included diverse expert and lay interests. Pearce identifies the fact that a committee was created to involve the public, as opposed to other limited means of public integration (town halls, focus groups, etc.), as a successful element of this equation.

The findings of this study highlight the success of this community in creating policy sensitive to community planners, disaster management, developers and the general public. Specifically, the general public engaged in discussing the problem; taking political action in creating expert sub-committees; legislating new regulations; ensuring cooperative implementation and evaluating progress. While public and business interests normally resist new regulations and building codes, the openness of this committee 
created a greater understanding of all points of view, and policy was enacted and implemented with abundant support. This study provides an successful example of communities directly benefiting from the general public's inclusion in decision-making. Specifically this article shows that public's integration into policy-process and decisionmaking needs to be properly balanced with other interests and expert opinion and that it makes a difference how and where in the policy process they are included.

\section{Conclusion}

Public managers of all stripes are required to find solutions to complex social problems, and emergency management is no different. To do so they must be efficient and avoid obstacles to sound policy implementation. In contrast to the Murphy article describing public response, Pearce describes public participation incorporated at nearly every stage of the policy process. Where Walkerton residents effectively assumed responsibility for the policy process stages of enactment, implementation, and evaluation, citizens in Portola Valley engaged all eight stages. Besides the four stages mentioned above, citizens were included in shaping the understanding of issues, discussions on problems, taking political action, deciding on an agenda, and passing legislation to deal with the problem. As both cases demonstrate, public input can be beneficially implemented at the local level. For Pearce, there was a significant initial failure by local authorities to properly address the seismic threat, perpetuating the problem. This established a base of failure, just like the water management failure in Walkerton case, from which the public must work from. Initial failure is not a necessary step, if implementation of the public in the policy process is done prior to a disaster. 


\section{Public Actors}

\section{Introduction}

At a general level, we can see that the role of the public in emergency management is discounted, but we need to delve deeper. The public is not a disorganized and quarrelsome group who prohibit sound decisions, as some experts and agents posit. Rather, it contains associations of all sizes, interests, outlooks as well as organizations playing a role in public comprehension, participation, and progress. This section will be concerned with five groups: local elected and unelected officials, academia, media, business, and community associations. These five influential groups share two important characteristics useful for exploration. First, they all have a role in emergency management because of the perceived strengths these actors possess. Second, not all of these actors are used to the fullest of their potential by emergency management. This section will explore each group and help provide a more developed picture of the actors that make up the public described in the previous section.

\section{Elected and Unelected Officials}

While federal political leaders hold enormous power over policy, political leaders at city, municipal, district, state, and regional levels do play an essential role in emergency management. These local leaders are given the compounded responsibly of implementing federal policy in their communities while playing an integral part in its provincial activities. This local connection, which has been interpreted by the majority of national authorities as a source of fault, produces problems as far as the relationship between electoral incumbency and community expectations in two ways. First, it has 
been shown that incumbent political actors will favor short-term solutions (response, recovery) as opposed to long-term solutions (mitigation and preparedness) because these activities are more likely incur political benefits during their terms of office (Olson and Gawronski, 2010). A second study of local political actors shows that public emergency expectations are rarely acknowledged prior to a crisis, but leaders often overreact in response and focus on placing blame during recovery (Boin and t'Hart, 2003). Because of this, the public thinks leaders have more capacity to help than they actually do, and leaders do not have the impetus to engage nationally shaped policy. Local leadership, disengaged from federal policy formation, have failed to communicate and mobilize the public in an effective manner. One method widely hailed as a solution to public disengagement uses "learning moments," instances when leaders act to make an impression on the public about risks and self-help immediately after a disaster (World Bank, 2010; Malhorta and Kuo, 2008). The problem with solutions of this kind is the requirement of a disaster to affect the community in a significant way, something emergency managers are trying to avoid. The passive role assigned to local leaders, as federal policy implementers rather than entrepreneurs, is a powerful underestimation of local elected official's skills and knowledge. Local elected officials have a keen understanding of community dynamics, legal and illicit commerce networks, local custom, demographic characteristics, public and private resources, and importantly a sense of the trust between citizens and government. These local factors become vital 


\section{Public Participation in Emergency Management}

during a disaster, and they should not be suppressed by the imposition of federal level policy.

Unelected officials in emergency management represent the intersection of local political impetus and the federally commanded initiatives. At the local level, unelected officials are tasked with implementing federal policy; they come in two primary forms. First, they may serve at the behest of elected officials as political appointments. These officials will work to intertwine policy initiatives with political policy realities. In addition, appointed officials fulfill the desires of their political patrons, which can often put them in direct conflict with second kind of actors. The second kind of unelected officials represent those that have risen through the ranks of an organization, such as a police or fire department. These officials have a deep understanding of both the organization's traditions and temperaments. How a policy is administered, as well as how policy objectives are balanced against organizational considerations, fall heavy on these unelected leaders. The contradicting views between these two different unelected officials may merely hamper efforts, but may also produce mutually acceptable but poor policy largely ineffective during a disaster.

\section{Social Scientists}

The next groupings of actors contributing to the dynamic of the public are those in social-sciences branch of academia. In the previous chapter, we explored the role of expert knowledge in the physical sciences and administrative disciplines. Here we will explore the role of social scientists. Social scientists at the federal level have been responsible for fundamental additions to emergency management priorities, especially to 
our understanding of social vulnerability (National Research Council, 2006). The National Science Foundation (NSF) is the premier organization dedicated to the pursuit of understanding disasters. Since NSF's inception, the foundation has played a primary role in funding physical science based research in such linked organizations as the National Earthquake Hazards Reduction Program. Playing a relatively minor budgetary role, the Social and Behavioral Sciences Division of NSF has increasingly fought for greater resources to study the human element of disasters. In a few ways they have succeed in playing an important, though discounted, role by exposing the cultural and social impacts of disaster, traditionally obscured by fiscal and physical terms (National Science Foundation, 1992; National Science Foundation, Budget, 2011). The subordinated role that social scientists play is disadvantageous in two regards. First, social scientists are able to apply theory and concepts to practical plans prior to implementation. Importantly, problems unforeseen in previous case studies may be avoided by the inclusion of these elements. Second, the nature of social science emphasizes collaboration and cooperation to enhance productive value (Vigoda, 2002). This characteristic is far more advantageous than a simple state of competition between dominate ideas when dealing with "wicked" problems. Besides bearers of information, social scientists may also be bureaucratic outsiders that can attend to problems and concerns at an unofficial capacity, unhindered by bureaucratic structure and norms (Rourke, 1984). At an official capacity, social scientist may also help form committees that shape the implementation of federal plans at the local level, as seen in the 2005 


\section{Public Participation in Emergency Management}

Portland Mitigation Plan (City of Portland, Mitigation Plan, 2005). While the Portland Mitigation Plan did include the input of social scientists, it needs to be said that the steering committee helped facilitate a federal initiative, not local policy. In addition, five hazard specific sub-committees flanked the steering committee, and those were dominated by physical scientists, administrative experts, and bureaucratic agents. Rather than just helping to implement federal mandates, social scientists could solidify community concerns and facilitate communication with leaders, while helping elected officials and the public take advantage of the skills and knowledge they possess. While social scientists may introduce substantive benefits to emergency management, another group of actors affects the public with the frequency and emotive content of its messages.

\section{Media}

The role of media has traditionally been to inform the community about topics outside their ability to explore. This role persists today, but is disfigured in four primary ways. First, news media has become increasingly biased in favor of elite opinion. This includes institutionalized relationships with government, demonstrated by the White House Press Room. Second, media framing has increasingly ignored historical or contextual information in favor of sensational and emotional content. Third, the topical considerations of news media have centralized to the extent that local news organizations directly repeat or mimic reports carried out by national news networks. Finally, the national news organizations have consolidated into a handful of corporations, facilitating the previous three characteristics (Woodly, 2007). These media developments influenced policy processes, issue framing, problem defining, and agenda setting by restricting 
public knowledge to a narrow set of political perspectives (Irvin and Stansbury, 2004). The value of the old media was in its adversarial position to the establishment. It could take an independent vantage point on a topic while amassing a variety of viewpoints into a single account. An example of the failure to do this emerged during Hurricane Katrina when the media was not able to establish a detached vantage point, and rather took authorities opinions on security concerns and falsely reported that rioting and chaos had been common (Waugh, 2006). This report came despite the fact that reporters, by their later admission, largely never witnessed lawlessness of any kind in decimated areas (Tierney, Bevc, and Kuligowski, 2006). Without separation from a single perspective, minimal contextual reference, and a greater depth of understanding, the media cannot play a positive role in emergency management. As outlined in the numerous emergency management plans and training materials, the media is to be provided a controlled and unrivaled message to prevent it from reporting information that could counter the efforts of authorities (EMI, IS-230a). This controlled message undermines the media's ability to allow public judgment on whether authorities are indeed maximizing their potential until it is too late to change their course of action. On the other side of concentrated business, reflective of big media, small business represents a diverse and important segment of the public.

\section{Business}

The relationship between business and the emergency management community is the most underdeveloped of all public actors. The foremost interaction between emergency managers and business comes in the form of adherence to zoning, building 
codes, work safety measures, standardized building materials, and construction benchmarks. These elements have evolved over more than a century, initiated first by fire fighters who recommended firewalls as simple solutions to unnecessary destruction caused by fires that easily traverse the thin walls between buildings. Today the Institute for Business and Home Safety operates under FEMA to represent corporate insurance concerns (Geis, 2000). This federally directed institute helps shape information on areas at risk from floods, earthquakes, tornados, and hurricanes. The role of business in DHS has been of growing interest, and in 2008 a report on the new "hybrid commercialization process" was outlined for development, production, and equipment acquisition for DHS (Cellucci, 2008). The report reflects a business deal for equipment, but not the kind of collaboration needed to enhance a community's resilience. Locally, DHS has collaborated with private business, specifically Home Depot, to help facilitate greater citizen education for homeowners in New Orleans, in the wake of Hurricane Katrina (U.S. Department of Homeland Security, 2008). Teaching average citizens proper installation techniques and giving advice on prudent materials was done on a very limited basis in a few disaster-affected areas, but not nationally. These two examples show government-business partnerships in their infancy. A truly prepared community will require greater effort.

While any efforts to connect with the business community are commendable, connections are still limited. For instance, while DHS is good at dealing with large corporations, they have left the majority of small business out. In fact, small businesses 


\section{Public Participation in Emergency Management}

are unlikely to have relationships with emergency managers or to have taken any preparedness action (Tierney, Lindell, and Perry, 2001). This is largely due to lack of resources, time and highly contentious views on government intrusion. It is also the case that larger businesses and corporations are more likely to have completed the FEMA recommended Business Continuity Plan, which helps a business avoid risk, respond to crisis, and recover operations more quickly (Haddow, 2010). These facts become compelling when we look at the Small Business Administration's figures showing that non-participating small business account for $99.7 \%$ of all employer forms. Small business actors also employ around half of all private sector employees (U.S. Small Business Administration, 2011). The fact that these businesses are unlikely to participate in simple activities such as fire and evacuation drills, or required managers to know basic first aid, reveals a troubled state of affairs. One could imagine that collaboration between small business and emergency management would reveal local adaptions in commerce, transportation, as well as human capital, which could benefit a devastated community. Not to mention many small business owners are self-sufficient, resourceful, and prone to taking the initiative. Small businesses represent pubic actors deeply connected with the communities and largely unconsidered by emergency managers.

\section{Community Associations}

The phrase community-associations encompasses entities of various sizes, interests, goals and make-up, but essentially involves members of a diverse community coming together to cooperate on a common task. These groups range from Neighborhood-Watch to book clubs and have transcended culture, economic and societal 


\section{Public Participation in Emergency Management}

difference to organize on behalf of an idea or cause. A key association connected to emergency management is the National Voluntary Organizations Active in Disaster (NOVAD), which has achieved federal prominence within the Citizen Corps and plays a small role in every phase of emergency management (NVOAD.org). The Citizen Corps' primary mission is integrating community members and government in order to facilitate greater local involvement in the emergency management. According the Citizen Corps web site, they want to "harness the power of every individual to fulfill this mission," and this researcher agrees that they succeed in the Community Emergency Response Team program (Citizencorps.gov). We can better understand the overall significance of the Citizen Corps, and the community associations it helps organize, through its budgetary appropriations. In 2011, FEMA received $\$ 10.5$ billion dollars from the approximately \$40 billion dollar DHS budget (U.S. Department of Homeland Security, Budget, 2011). Of this $\$ 10.5$ billion dollars, only an approximate $\$ 9$ million dollars were directly allotted to the Citizen Corps. This national agency runs on $.4 \%$ of the total DHS preparedness grant appropriations for states (U.S. DHS, Grants, 2011). To understand where the Citizen Corps stands on the list of FEMA priorities, consider that the majority of grant money is either directly or indirectly tied to security and response initiatives. It must be noted that some, if not many, local Citizen Corps programs receive funding through a combination of alternative sources, thus making the total spent on such projects difficult to track. Although, finding alternative funding means existing personnel are redirected from the staffing efforts of direct public interaction. Focus here on the federal programs 


\section{Public Participation in Emergency Management}

is intended to shed light on priority areas, and those areas that are considered less essential, such as Citizen Corps. The Citizen Corps mission is to harness the citizenry, but resources to engage community associations have tied their hands. Community associations represent a level of intimacy that creates action in the absence of authority, and therefore these public actors are important during a disaster. According to surveys, $49 \%$ of Americans believe their neighbors will be first to come to their aid during an emergency (Citizen Corps, 2009). Unfortunately, due to lack of federal appropriations and commitment to collaborating with groups, it is likely that even if neighbors could come to each other's aid they would be woefully unprepared to significantly help.

\section{Individual Citizens}

The role citizens play in the positive and progressive efforts of emergency managers are miniscule at best. Outside of the five groups described above, the average citizen plays a passive role, not directly engaged in emergency management activities. In a number of ways the average person represents the most difficult entity to approach, and because of this, information campaigns have been used to created interest and build a more knowledgeable community. These efforts have been a secondary consideration, and thus not very fruitful in producing a well prepared citizenry. Programs, such as Map Your Neighborhood developed by Dr. LuAnn Johnson, have succeeded in creating neighborhood groups consisting of 15-20 households cooperating in preparedness (Explore Carbondale, 2012). While this program has been incorporated in a number of emergency management offices across the U.S., it has yet to gain the large fiscal support that efforts of response and recovery enjoy. 


\section{Conclusion}

The public possesses untapped and valuable qualities, largely removed from the emergency management policy process. At the local level, elected officials must balance mandates from the federal government with reactions from a disconnected polity. This has led to misallocated effort and discounted understanding of local conditions provided by political actors. While the physical sciences have been fully embraced by emergency management, the role of social scientists has been minimal. Rather than helping facilitate greater understanding between government, experts and communities; social scientists are relegated to aiding implementation of policy formed at the federal level. Media sources, once slandered as 'muckrakers' for their probing of authoritative power, have acquired elite prerogatives. At the federal level, collaboration between public and private business interests seems to be on the rise, but a small-business community ignored by emergency management slows progress. Finally, community associations are the collaborative partners of the grossly underfunded Citizen Corps. None of these public actors have been fully utilized by the federal government in the task of emergency management.

\section{The Public in Policy Processes}

The introduction of greater public participation in government can bring with it both the benefits and detriments, shown in the previous chapter. Where and when the public is involved takes careful consideration. For the purposes of this section, the eight 
stage policy process will be divided roughly in half between legislative stages and the administrative stages (See Figure \# 2). The first policy stages, which include issue emergence, problem definition, agenda setting, and policy formation will be divided again between areas where the general public are and where they are not included. The issue emergence, and problem definition stages are already influenced by the public, as increasing levels of recovery funding have shown. A knowledgeable public, aware of policy processes and emergency management, which is an ancillary benefit of greater participation, could further aid these two areas. This study posits that agenda-setting and policy-formation stages develop as areas directly benefiting from greater public participation, while imposing the least burden on temporal and organizational concerns. These two stages can both benefit from the greater information base and guidance the public can provide, while not unnecessarily interfering with intricacies of policy activities or how institutions are framed. In both policy stages, greater participation would help return the engaged and attentive public that John Dewey romanticized. This section will explore two policy stages and identify the optimal participation level. Then, it will define a practical methodology that illuminates the benefits of greater public participation.

Emergency management reveals a public no longer permitted to fulfill the four mandatory characteristics (acknowledgement of affliction, association forming, leader selection, representation in state) described by John Dewey. This is not to say that the public is completely obscured from the picture, but its organized inquiry is. Because of what Dewey called an insufficient translation of expert to general knowledge, the public 
reaction surfaces where government and local community disaster interactions are most obvious, during post-disaster recovery (Dewey, 1954). What this means for emergency management, where participation is narrowly concentrated, is that recovery becomes the focal point of public attention. Emergency managers taking steps in mitigation, preparedness, and response have not communicated their activities to the public to the extent value has been established. The public, little aware of emergency management activities, toil in disaster areas and their plight is picked up and disseminated by media who to fail to acknowledge greater context. In this case, the public coalesces around recovery, answered by responsive political leaders with exorbitant resource allotments (Henstra, 2010). The distance between the public and its managers, for the purpose of rational leadership and efficiency, does so at the expense of greater exposure of the public to disaster threats. The public, with only limited knowledge of emergency management efforts produces political focus at the phase with lowest overall return perdollar-spent, at the detriment of mitigation and preparedness activities.

This picture of the public constructed at the federal policy process level, and expressed though FEMA under homeland security is not the only option. As chapter two described, the relationship between FEMA and the public were not always so distant. During the James Lee Witt years (1993-2001) FEMA's partnerships with the public represented nothing short of a "path-breaking institutional innovation that (brought) a wide range of stakeholders into a policy-making apparatus" (Mitchell, 2006). To those looking at FEMA today, the idea of broad stakeholder participation seems far more 
distant than this short temporal reference illuminates.

\section{Policy Process: Agenda Setting}

\section{Introduction}

Currently, agenda-setting is largely defined by professionals in the emergency management community, federal level political actors, and experts in the physical science disciplines who together form a policy monopoly (Birkland, 1997). Agenda setting is the third stage of the policy process, following issue emergence and problem definition. With the nature of the problem ascertained, agenda- setting attempts to identify the unit of measure by which any action will be judged a success or failure. The shaping of criteria is a task that benefits from increases in participation, as potential concerns and interests can be taken into account prior to a policy implementation. With a basic understanding of the unit-of-measure used to weigh criteria, the next step is to generate practical options and theoretical alternatives to initial ideas (Walters, Aydelotte, and Miller, 2000). Here again, the increased levels of participation allow for a greater number of possible options to be weighed against one another. Since emergency management policy has the potential to touch every stakeholder in a community, and indeed future stakeholders, the inclusion of wide concerns is warranted. The inclusion of the public offers managers the benefits of discovering new avenues of action, helps educate the general public on policy processes, and finally will help increase overall legitimation and ease implementation (Walters, Aydelotte, and Miller, 2000). A corollary benefit to the inclusion of the general public in the agenda-setting stage is the 
diffusion of mass medias' problematic role in directing agendas. The following section will examine the emergency management policy monopoly and explore devolution of federal authority.

\section{Policy Monopoly}

The current policy system amplifies, rather than curtailing, the problems that the public has in effectively engaging agenda setting. This is the case because the public often has little technical understanding of exactly what the problem is, and therefore offers a poor definition of it. After a problem has been defined, largely on a technocratic and political level, the actually stage of agenda setting is engaged to solve the issue. In this stage the issue is broken down by the three basic interests involved: systemic interests, policy entrepreneurs, and the mandatory requirements (Anderson, 2010). First, the agenda from the systemic interests are those defined by professionals and experts in whatever issue field the problem has surfaced in, whether it is medicine, meteorology, or engineering. Typically, their recommendations follow accepted frameworks of knowledge and encourage an expansion of previous implementation strategies. They rarely, if ever, advise a radical departure from the status quo. Second, the entrepreneurial interests in a policy monopoly, like in emergency management, typically come in the form of congressionally elected officials, their advisors, and lobbyists. These actors typically advocate for distributive policies bringing greater resources or attention to their constituents, with less concern for potential policy success. Finally, the mandatory requirements are those elements, which must be created to deal with the conspicuous issues emerging from problem definition. In the case of emergency 


\section{Public Participation in Emergency Management}

management, these mandatory elements have been defined by the political impetus produced by sensational media coverage and command and control reactionary functions, producing a distinct emphasis on response and recovery. In order to maximize organizational continuity and the appearance of political responsiveness, the public has been excluded with the reasoning that it acts too irrationally, does not understand costs, and lacks long-term impetus (Anderson, 2010). Claims of this kind are true to a degree, but they are not the main problem. Rather these conditions are symptoms extenuated by the monopolization of policy, notarized in defense of a closed agenda-setting process by those within the monopoly. A closed system is intended to subvert four common traits found at the local county level for administrative, not policy, reasons. First, counties represent greater diversity (urban, suburban, and rural) in interest than do cities. Second, citizens can have greater identification and allegiance with their country as opposed other levels of government because of the diversity. Third, the ambiguous nature of administrative duties mean cooperation is necessary for the success accomplishment goals. Finally, local-to-local cooperation is easily initiated at the county level, compared with higher levels of government (Waugh, 1994). These four characteristics of local policy implementation are considered challenges to federal policy, but represent strengths during a disaster.

\section{Devolution}

The inclusion of the public in agenda setting will help balance the concerns of politicians and bureaucrats while expanding the range of concerns policy tackles. When placed on the ladder of citizen participation constructed by Sherry Arnstein, emergency 
management engages the public somewhere between tokenism and non-participation (Arnstein, 1969). Two programs have defined efforts to engage the public at the federal level. These are the Citizens Corps and the Emergency Management Institute, respectively. While the Citizen Corp has organized the Community Emergency Response Team training, a well-executed program, overall the Corps suffers from underfunding and lack of political attention. On the other hand, EMI has provided the public with a great deal of information free of charge via the internet. While EMI can inform a public, it cannot engage it in dialogue or discussion. With the current state of agenda-setting and public engagement clarified, it is the recommendation of this study that participation increase to the level of partnership between the general public and emergency management at the federal level. This can be accomplished by an increase in local leadership's involvement in national agenda-setting (from its current consultation) to participation levels for national policy. Partnership in the agenda-setting processes means, "power is in fact redistributed through negotiation between citizens and power holders" to clarify the parameters and goals of policy (Arnstein, 1969). At the federal level, this would require devolution of control expressed through grant requirements. Rather than very specific requirements, the government would establish a general policy direction and let the local officials confer on the specifics. The political environment in counties across the nation can provide enhanced administrative avenues in the way of deepened coordination mechanism, real time specific knowledge, and leaders that are already operating on a cooperative level with counterparts (Waugh, 1994). With local 
leadership involved at the federal level, they would develop an understanding of participatory benefits, and engage their own communities more than at present.

\section{In Practice}

The United Kingdom has taken steps to establish a national framework that is both resilient and capable of rapid and uniformed responses. The very progressive Civil Contingencies Act of 2004 replaced former civil defense policy, which, like our own Cold War policy, was active in one form or another since the Second World War. The new policy established a uniformed national response framework, much like the ICS and NIMS (see Ch.2) in the United States, but incorporates far greater local input. Creating resilience at the local level is a larger goal of the UK policy, and they have taken steps to better understand the social, economic, and political problems that hamper resilience (United Kingdom Cabinet Office, 2009). The problems facing efforts to create resilient communities nationwide are the same faced by local leaders and first responders on a daily basis, namely local distinctions in development, education, and trust. With those issues in mind, the national Cabinet Office established a public consultation program so local authorities and professionals could shape the agenda of resilience efforts in their neighborhoods. These consultations, according to Cabinet Office survey, were identified by local leadership as both useful and worthwhile (United Kingdom Cabinet Office, Consult, 2011). Part of the satisfaction local leaders expressed comes from the literal and transparent revisions to policy and plans enacted based on their input.

The inclusion of input from local leadership in national policy has demonstrable benefits, but the United Kingdom's general public has also been engaged in agenda- 


\section{Public Participation in Emergency Management}

setting. The new emphasis in resilience, aided by technology, has led to the creation of open-source software to provide the citizenry with current information and avenues of input. These avenues are represented by government maintained and monitored websites that are essentially interactive and informative maps of a given township, municipality or incorporated area. Online, citizens can provide their perspective, add depth to facts, and help shape new community proposals; transcending the limitations imposed by meetings or town halls (Kingston, 2007). The recent steps taken by in United Kingdom to bolster resilience have had two dynamic effects. First, concerns from local leadership, their bestpractices, and distilled knowledge have been incorporated into national policy. Second, with policy now derived at least partially by local culture, the citizenry has been given access to information and agenda-setting processes in a more accessible manner. The benefits of these inclusionary steps will be the focus of studies for years to come, for now they provide this study's participatory initiatives with a positive direction.

\section{Recommendation}

How participation is enacted will have a large effect on how successful the policy is. Since the goal of greater participation in the agenda-setting stage is to flesh out a higher number of ideas on a topic, we need a more involved method of interaction. While paper and phone surveys can help leaders better understand the mood or general knowledge of the public, they are too shallow for our purposes, as are community forums where leaders shed-light on the bureaucratic and political activities while allowing public comments. What is needed is a dialogue, or a stream of meaning that flows through participating groups, to create new understanding based on shared concerns (Roberts, 
2002). To fully appreciate the complexity of "wicked" problems, three elements must be addressed. First, all participants need to understand and take part in shaping specific goals. Second, all involved must have some shared base of information from which to build ideas. Third, there must be a real and perceived equal opportunity to influence outcome (Fischer, 1993).

The nature of the agenda-setting stage can be understood as a transition from a very wide range of considerations, narrowed through dialogue, to a more operational understanding. Leadership would establish broad rules, objectives and structure, then as a group, more specific guidelines would be decided upon. Contrary to more technical methods, these dialogues could be organized through workshops or planning exercises in the community. A clear example of this took place in late 2009 during the initial phase of the Portland Plan in Portland, Oregon. Planning administrators asked community members for very general thoughts on future policy directions, these thoughts were aggregated and distilled in later phases to create a 25-year plan (City of Portland, Phase 1, 2010). These explorative workshops may take a very informal structure and procedure, yet produce understanding between participants. The goals of proposed emergency management workshops would be threefold. The first goal, to create an emergency management understanding constructed by the local community. Second, workshops facilitate the expansion of leader knowledge, aiding them in shaping specific policy. Finally, these workshops can bolster the social capital of a community and instill social responsibility. Far up the policy stream agenda setting can create foundational bases 


\section{Public Participation in Emergency Management}

from which policy takes form leading to more apt institutions and implementation downstream.

\section{Policy Process: Policy Formation}

Introduction

With the agenda decided and the criteria defined, the policy itself begins to take shape. The policy-formation stage occurs when selected alternatives are weighted against one another and concerns expressed. Four general concerns must be addressed for a policy to be sustainable. First, the policy must be judged on how technically sound it is. Second, the policy must be judged in relation to resource and budgetary considerations. Third, the policy must be politically feasible. Finally, the policy must be judged by its acceptability to the public during implementation (Anderson, 2010). Opposed to the agenda-setting stage, the policy- formation stage must take the general agenda and apply it to the institutional and political currents that will carry it through the remaining policy and implementation processes. While this stage does require greater role for leadership, agents, and experts; their respective concerns need to be balanced against the goals set by the agenda. Minus the public, policy reflects political conveniences and norms of standard operations, as opposed to organizational adaptions maximizing external impact.

\section{Balance}

Within the policy formation stage, there are numerous roles for the general public in making superior policy by balancing interests and knowledge. Leaders, experts and the public as a whole benefit in five ways from public incorporation into policy formation (Walters, Aydelotte, and Miller, 2000). As in the previous stage, the public benefits by 
learning more about shaping policy. The public should be aware of the constraints placed on those shaping and administering policy prior to, not after, its implementation. Second, the public can provide diverse perspectives essential in discovering nuanced differences in policy. Seemingly, small initial conditions of a policy may create greater longer-term problems. The third benefit emerges from the legitimizing role the public adds to policy it helps create, as was seen in the earthquake mitigation in Portola Valley, California (Pearce, 2003). Fourth, the general public can mediate the measures of success between bureaucracies and political actors, who often diverge from one another. This is facilitated by the greater depth of concern they provide, as opposed concentrations on responsiveness, rapid decision making and efficiency. The final benefit of two-way communication is the reduction of misunderstand and the building of trust between the public and leadership, which pays dividends during a disaster.

The focus during policy-formation requires a multitude of considerations including long and short-term goals, as well as organizational and temporal constraints, which are complemented locally by frontline professionals and communities defining details in a way that best maximizes local needs and strengths (Bach, Doran, Gibb, Kaufman, and Settle, 2010). To date, these considerations have been balanced between a relatively small group of interests in the upper echelons of government, creating a dysfunctionally linear institution. Public participation can bring balance to disaster understanding, and help create a safer community. 


\section{Interdependence}

Policy-formation requires increased focus, which reveals greater detail about our interdependences. The requirements that help define the quality of the policy (technically sound, politically feasible, and publicly acceptable) mean the dialogue between interests must be duly calibrated. For this reason, communications need to take a more deliberative format than in agenda-setting, to decide upon a course of action that will most completely address the problem (Fischer, 1993). The same rules of engagement apply from previous dialogues, but topics will address specific policies under specific circumstances. This form of dialogue was visible during a tabletop exercise conducted by the Portland Bureau of Emergency Management's Local Energy Assurance Plan (LEAP), which took place November $9^{\text {th }}, 2011$ (City of Portland, LEAP, 2011). The exercise happened in a large room, with about a hundred persons representing government (TriMet, ODOT, etc.), finance (Banks, Corporations, etc.), and community institutions (universities, clinics, etc.). Key to its success was devising a disaster scenario, in our case we imagined being on day three after an 8.0 on the Richter scale earthquake struck Portland. The groups were broken into their respective interests and guided by emergency managers through a series of questions meant to draw out deeper considerations on potential problems. The results were surprising. Responses ranged from near total unawareness of emergency management goals to understanding that agencies had shared concerns and overlapping responsibilities. The most powerful and moving lesson was how all those involved underestimated the level of interdependence in our community. The format and structure of this exercise is a staple of FEMA's training 


\section{Public Participation in Emergency Management}

program for professionals, and there is no reason that under the right guidance, it could not incorporate a greater range of public actors.

\section{In Practice}

Public participation in emergency management policy formation in New Zealand has taken an even more inclusionary path. Starting in 1996, the New Zealand government decided to engage the community in an effort to establish a more robust emergency management policy. To glean ideas, the government held workshops with local leaders, first responders, volunteer organizations, professional groups, and community associations. From these workshops, it was decided that a new policy needed to be established shaping emergency management so that it could assist communities in achieving their respective goals (Britton, 2000; Britton, 2002). The Civil Defense Emergency Management Act of 2002 enumerated many different policy approaches, but importantly it required and detailed greater public participatory efforts. Specifically, a local emergency management group would be engaged in the national policy formation process. In addition, the local group must provide the general public with notice of any plans that they are currently working on. The level of inclusion does not end there, but any interested parties can submit a comment and be "given a reasonable opportunity to be heard by the body" (New Zealand, 2002). While long-term studies have yet to be completed on the effect of public incorporation in New Zealand, the earthquake that shook Christchurch in February of 2011 will no doubt be the focus of future academics, leaders, and emergency managers. 


\section{Recommendations}

The role of the general public in emergency management policy-formation has changed very little in the last 50 years. Starting in California, the Civil Defense programs in the 1950's completed neighborhood surveys that captured basic information on occupants, contact information and water and natural gas shut off locations (Simpson, 2001). Today the general public plays a similar passive role, albeit greatly more sophisticated, through Geographic Information Systems. With the varied information collected, complex models are created to help emergency managers predict physical, economic, and social impact of disasters. While the data can provide useable information on planning, it cannot directly interact with the population to build capacity. In addition, the system is expensive and requires a high degree of technical sophistication to operate and maintain (Brown, 1996). In order to form policy with multilateral impacts, such as increasing individual preparedness and community reliance through knowledge, the general public needs to be directly and institutionally involved. If emergency mangers simply glean information from communities, there is always the tendency to disregard information which is most administratively incompatible, undercutting efforts like FEMA's Whole Community Approach (U.S. DHS, FEMA, 2011). It is this study's recommendation that the public, citizens at the local level and local leaders at the federal level, participate at the partnership rung of Arnstein's ladder in formative community consultations (Arnstein, 1969). Much like the previous policy step, agenda- setting, members of the community would provide formative input on more narrowly defined courses of action. Specific steps would be prioritize by assemblies and responsibilities 


\section{Public Participation in Emergency Management}

assigned to groups according to ability. Subsequently, leaders end up with a policy agreed on by public with the understanding that political and administrative demands will be later accounted for. Proceeding policy stages of legitimization and enactment are best left to political actors to engage, just as bureaucrats should direct implementation.

\section{Conclusion Policy Focus}

To conclude, this policy focused section will build on some general ideas already presented. The incorporation of a greater participatory role of citizens in local emergency management, and local leadership in federal agenda-setting and policy-formation can provide a number of benefits. Currently our policy processes do not take advantage of the network-power our society has (Booher and Innes, 2002). One step forward would be to engage society in reflecting on its own capabilities, a level of awareness usually established by severe and frequent disaster impacts (Tierney, Liddell, and Perry, 2001). Frankly, public awareness derived from repeated failure is far too costly. Participation does come with costs for policy makers, including increased time requirements and negotiated results. These detriments have been controlled for by the focus on agendasetting and policy-formation stages. These two stages necessitate a transition from broad understanding to narrower policy goals, a function public knowledge can aid. This leaves legitimation and enactment policy stages for political and bureaucratic actors who can most effectively legislate and implement policy. The time lost by incorporating the public in early policy stages, is made up in a more effective and efficient implementation. An increase in public participation in policy formation creates ancillary benefits that emerged downstream in the policy process. 


\section{Emergency Management: Resilience from Mitigation and Preparedness} Introduction

Emergency management builds on the four phases and principles that make up the continuum of understanding disasters. The current organizational and fiscal concentrations have been problematically focused on response and recovery phases. These phases are first-responder centric and politically most conducive to answering public outcry after a disaster has struck. Unfortunately these efforts are not costeffective, as illustrated by a the National Mitigation Council finding that for every one dollar spent on mitigation, four would be saved over response and recovery activities (Multi-Hazard Council, 2005). This becomes increasingly problematic as climate change promises higher-impact events arriving with more frequency, producing more threats to our technologically advanced society. An emerging paradigm in the international emergency management community, put forth in part by the United Nation's International Strategy for Disaster Reduction campaign, is of community resilience. The core of this new paradigm emphasizes community and greater concentration on mitigation and preparedness efforts. This section will explore how greater public participation relates to resilience, and how participation can be applied within the existing phases of mitigation and preparedness.

\section{Resilience}

Community resilience is still evolving as a concept, but it has widened understanding about dynamics between a society and disasters. The definition of resilience is not static, so the definition presented here will be a collage of ideas. First, 
resilience describes a community's ability to have an adaptive capacity to sustain when faced with a disruptive challenge (United Kingdom Cabinet Office, 2009).

Sustainability, adaptability, and capacity are all terms connected to resilience, needing further exploration. Sustainability during a disaster refers the ability of a community to maintain an acceptable level of functioning and structure. In order for it to sustain social structures and function, society must be built from flexible foundations. These foundations allow for pragmatic and fluid course corrections, in other words adaptability (O'Brien, 2006). Essential to the idea of resilience is the understanding that a community has a certain capacity to resist direct and indirect disasters effects. By bolstering awareness, anticipating problems and increasing self-organization, capacity is increased (United Nations, 2007). The final, and most crucial element of resilience, is an understanding of the general public's role. In every definition of resilience, this study noted there is a reference to greater public participation in emergency management efforts. Resilience authorities agree leaders need to embrace far greater collaboration with the public to increase capacity and awareness. In addition, resilience requires the incorporation of a greater number of mitigation techniques into the everyday lives of citizens (Geis, 2000). This of course means altering the daily habits of a community, requiring nothing short of changing the cultural attitudes in society, a daunting prospect (McEntire, 2002). Finally, resilience requires everyone in the community to take more responsibility for themselves and the bonds of interdependence (United Kingdom, Cabinet Office, 2009). A resilient community has mitigated all possible threats, has 


\section{Public Participation in Emergency Management}

prepared down to the individual citizen, possesses flexible and proactive leadership, and enhanced public participation. Resilient communities are the exception in in the United States, but we can bolster the efforts of mitigation and preparedness with increases of participation, steering us in the right direction.

\section{Emergency Management: Mitigation}

Introduction

Mitigation refers to the actions taken by a community to prevent or severely decrease the initial impact from a disaster; such as building codes, land use regulations, and dike construction. By far the greatest mitigation effort concentrates on structural activities, because they represent long-term physical solutions. Non-structural mitigation represents a much smaller effort nationally, but can offer substantial returns. Nonstructural efforts include educating the public, addressing social vulnerabilities, and building partnerships across a community. In order to bolster the effectiveness of nonstructural mitigation, there should be a concerted effort by the government to bring the general public into the fold. Two promising areas in public participation that can positively impact mitigation include building awareness through education and community planning through partnerships. The following section will explore mitigation in reference to education and partnerships.

The current state of citizen engagement in emergency management has been described as primarily informative in previous chapters. Providing basic information in children's primary education and subsequent informational provisions from emergency 


\section{Public Participation in Emergency Management}

management has not adequately bolstered public awareness. Reasons for general public ignorance range from lack of consistent and routinized messages to confusion over which authorities are tasked with what responsibilities. Resilience demands that the public is not just informed about emergency management, but are engaged in dialogue. In order to create a truly disaster resilient community three factors need to be addressed educationally; culture, vulnerability and responsibility (McEntire, 2002). First, we need to change the way our culture thinks about disasters. Today, perspectives on disasters have been conditioned by the National Flood Insurance Program. On a national level, those in need of assistance after a disaster will always be a minority and this minimalizes understanding of impact, and breeds a culture that denies the likelihood of disasters (Moss, 2002). Second, societal vulnerability needs to be understood as those of low political representation; minorities, elderly, and the socioeconomically disadvantaged are most at risk (Bolin and Stanford, 1998). Without awareness of the vulnerable, a greater loss in human life and resources is certain. Finally, people must be educated about the reality of just how much the government will be able to assist them. Personal responsibility is in deficit, as numerous government reports noted the majority of people had dreadfully over-optimistic appraisals of government disaster response capabilities. This section will explore how elements of culture, vulnerability, and personal responsibly can be engaged by emergency managers to produce resiliency through mitigation. 


\section{Education}

Passive and strictly informational public education methods are not adequate to create resilient communities. What is required is a comprehensive approach engaging citizens in their homes, schools, at work, in their community associations and in interactions with government. Currently, citizens are engaged in mitigation activities though a multitude of disjointed agencies. These range from city planners, nongovernmental organizations and the fire department, but there should be a way of engaging the public on a unified front by getting them to participate in issue discussion. One important element leadership and federal policy has misplaced is the idea that our reality, including our hazards and risks, are a social construct (National Research Council, 2006). This is of practical, not just philosophical, concern, as issue salience must be grounded in local custom and understanding. Risk analysis shaping mitigation efforts have often been deterministic, based on technological and expert knowledge, which has reduced the social dynamics of risk into issues of likelihood and magnitude (Stirling, 2008). While generalizable understanding of risk can be communicated by experts and diffused over the internet, for concerns to blossom into resilience in the community they must be incorporated at the local level. Rather than a binary understanding of risk, the public can infuse mitigation understanding with a "thick" description of significance (Horlick and Jones, 2009). This description does not ignore important elements of a community, such as preferred ways of life, trust relations, emotional commitments, and local history. In order to facilitate this understanding, everyone in the community must be accounted for. While the United Nations ISDR 
program recommends engaging children in primary education systems with emergency management lessons, this can only be part of the method of building attitudes, exposing vulnerabilities and instilling personal responsibly (United Nations, 2007). The incorporation of the general public participation into discussion on mitigation strategies and hazard analysis, according to Arnstein's ladder, should be at the partnership level. For mitigation this means including the public as contributing members of the defining and implementation of mitigation strategies, a goal that adds depth to emergency management efforts.

\section{Partnerships}

The second area that requires greater public participation to create resiliency involves the creation of greater partnerships. Partnerships between levels of government, business, experts and the general public all need to be more closely networked to advance mitigation. Partnerships require two different interests to share information, resources, and trust. Despite calls to "build and maintain partnerships," a lack of transparency, flexibility, and local control hamper results (U.S. DHS, FEMA, 2011). In order to capture the value of unique community strengths, non-structural mitigation plans need to be based on a high degree of local concerns. In addition, efforts should be co-supported by grassroots efforts, as opposed to federal mandates (Geis, 2000). Local efforts to address vulnerable populations and attempts to empower the socially marginalized are most effective. Along with greater government partnerships, we need to bring the private sector further into the mitigation conversation. Business can support mitigation in three fundamental of ways. First, they can support FEMA by educating their employees on 
work practices that can mitigate disaster effects, such as job site threats. The Occupational Safety and Health Administration already incorporate elements of this for personal safety, such as the proper storage of explosive and flammable chemicals. Second, business can better understand how their operations may contribute to the severity of a disaster. Chemical processes prominent in high-technology manufactures like Intel Corporation pose a serious threat to the community if not planned (to an extent this is already a requirement of businesses storing potentially dangerous materials). Finally, business can create continuity plans to decrease impact of interruptions in services, aiding recovery in a disaster area.

Another important partnership is between expert and local knowledge holders. These collaborations can fill gaps in quantifiable or qualitative information, clarify uncertainty, and help resolve the challenge posed by unpredictably (Pearce, 2005). Resilience requires that members of the community understand the significance of roles other members play in a disaster. Resilience, through partnerships, also means understanding how each partner can work to mitigate disaster effects. These steps, according to Robert Putnam, taken by emergency managers to facilitate partnerships and communication are also ways in which a community increases its social capital, directly correlated to resiliency (Putnam, 2003).

In Practice

Emergency managers in India have attempted to take a holistic understanding of society, and apply non-structural mitigation efforts to increase resiliency. Two components help shape Indian emergency management; first, broad efforts were 
identified which produce long-term impacts to maximize the return on current activities. Second, poverty alleviation is a necessary engagement when leaders hope to increase community capacity (Joseph and Chakrabarti, 2011). To achieve a resilient community, those that are most vulnerable must be incorporated to a degree that matches their vulnerability. This means that those that are most vulnerable must participate in how the community determines risk. One study was conducted in India to determine the value of risk assessment methods ranging from technically sophisticated to simple and relatively accessible. Findings show that sophisticated methods provided more accurate data, but at far greater cost and with no guarantee that communities would act on the information. On the other hand, the more accessible methods of risk assessment had a greater overall impact on communities. Communities that engaged the citizens in risk assessment were more likely to see those citizens engaging in implementation of mitigation activities (Guragain, 2008). The two-way communication process between leaders and citizens created impetus in the community to self-help by building a shared knowledge about risk and policy processes. The study recommends a blend of technical and simple citizen based risk analysis to maximize both accuracy and implementation. India's efforts to increase community resilience have benefited from the inclusion of the public, both from the standpoint of leaders addressing vulnerability and citizens understanding emergency management objectives.

\section{Recommendation}

Mitigation is a core element of resiliency, thus far overwhelmingly advanced in structural forms by federal policy. A greater emphasis on the non-structural efforts that 


\section{Public Participation in Emergency Management}

work to transform the entire community will be necessary to facilitate transformation, which can be achieved through policies extending emergency management training into primary education. While this will no doubt impact the next generation of community members, we don't have to wait that long. In order to change attitudes, acknowledge vulnerabilities and increase personal responsibilities the public needs to be engaged. One way to do this is provide community members with a place among leaders, emergency managers, and experts at the mitigation table. As partners in collaboration, the general public can expand the base of knowledge, help shape primary concerns, fill gaps in knowledge, resolve uncertainty and most important they can increase their own awareness. The ancillary benefits of participation are increased civic knowledge, personal responsibility, and social capital as well as the creation of new resiliency norms. Collaborative mitigation cannot be carried out unless emergency management reaches out to all members of the community, including average citizens, small businesses, social scientists, and members of marginalized groups. By building avenues of communication between these groups, new strategies and tactics can emerge. A public mitigation session would facilitate greater risk awareness, help shape partnerships, and create norms of resilience. Emergency managers benefit from knowing that mitigation will be more politically feasible, public acceptable and implementable with more concerns addressed during formation. The role of the public in mitigation is important, but it can be extended into the first-responder and expert dominated phase of preparedness. 


\section{Emergency Management: Preparedness}

Introduction

The preparedness phase of emergency management is an area almost completely dominated by leadership, emergency managers, and first-responders. At the core of preparedness is the idea that authorities need to maintain a state of disaster response readiness. In order to do so, plans have been created framing hierarchy, communication, responsibilities, and the breakdown of complex activities into steps. Training and exercising in emergency management techniques are continually carried out to refine the skills of both leadership and first-responders. Plans, training and exercises are essential in a cycle of preparedness, infusing new understandings evolved from evaluative practices (Bowen, 2008). The strength of this focus on leadership and first-responders is the creation of a systemized top-down approach to rapid and uniform disaster response. The great challenge FEMA notes is educating the public on preparedness, and their solutions have come most from in creative marketing schemes. The 2009 Citizen Corps Survey found that only $44 \%$ of American households have created an emergency plan (Citizen Corps, 2009). The significance of this finding cannot be understated; a household plan takes only moments to create and requires negligible resources. Despite these almost nonexistent constraints, the majority of citizens have still not created basic plans. This section will explore how and where incorporating the public into preparedness strategies can bolster the resilience of a community. 


\section{Engagement}

A resilient community takes the time to develop plans, train and perform exercises in emergency management together. Currently, a small group of individuals carries out these essential preparedness functions, while the majority of citizens are excluded. To understand why, we need to establish some understanding of what works in engaging the public in preparedness. There are three established practices (Mileti, 2011), that have helped create preparedness, to which this study would like to add two. First, local individuals who have taken measures to prepare are the best representatives to encourage proactive communities, as opposed to celebrities or federal agencies. Second, individuals need a pragmatic presentation illustrating what behaviors work, how to do them, and simple reasons why they should do them (opposed to scare tactics or overtly technical explanations). Finally, these two factors need to be communicated consistently, repetitively, through varied channels and over a long temporal period to create impact. These three approaches represent a very different approach than has been taken by the federal government and the addition of two more approaches could increase success. These include incorporating the general public in disaster planning sessions and inviting them to participate in emergency exercises.

\section{Planning}

There is a very clear dichotomy between preparedness planning at the leadership level and at the individual level in our community. In fact, most levels of government have participated in some degree of continuity planning, while most households have not. According to FEMA, emergency management planning brings together police and fire 


\section{Public Participation in Emergency Management}

departments, medical services, senior elected officials, public works, health representatives, business, and NGOs (EMI, IS- 235a). These groups plan according to the response framework, assign responsibilities and lay out expectations for participants during an emergency. At the household level, preparedness planning is best represented by the federal governments Ready.gov site. This site has great information on how to make a plan, build a kit, and even how to get involved in your community. The site also connects to social networking sites such as Facebook and Twitter. What this reflects is a passive form of one-way communication that bears no semblance to the diverse and engaging planning process completed by authorities.

Current planning processes have room for, and would benefit from, greater public participation. The planning process described by FEMA has six basic steps: form a collaborative team, understand a situation, determine goals and objectives, develop plan; prepare, review, and approve plan; and refine and execute plan (EMI, IS-235a). This planning process is similar to the larger policy processes that were detailed earlier, especially the understanding the problem and determining goals and objectives stages. Much like the earlier policy agenda-setting and formation stages, the public can help widen understanding, benefit from education, increase implementation speed, create political support, and legitimize efforts. There is another essential element a collaborative effort between the general public and emergency planning groups may provide, the building of pre-disaster plans that are not necessarily post-disaster response based. For example, the most common message emergency manager's voice is the need 
for households to have a plan and 72-hour kit, something few households have. In collaboration with the community, emergency managers could understand why many people have not prepared a kit and help plan out solutions. A 72 hour kits is not cheap, especially during lean economic times, but if a plan was created for individuals to buy incrementally or buy in bulk with agency assistance, it is feasible even for socioeconomically vulnerable groups. Emergency managers are typically focused on outcomes when dealing with the public, but the processes of reaching those goals is also essential to successful preparedness (King, Feltey, and Susel, 1998).

\section{In Practice}

India provides an example of how participation in preparedness can be incorporated into the lives of citizens. India has approximately one-third the territory of continental United States, but with nearly four times the population. In an effort to utilize the human capital, the Indian government has created 169 community-based disaster programs. Not only do the citizens engage in risk assessment, but also they are involved in the planning and exercise activities. Readiness is maintained in villages by drills that test locally-developed plans, which are reevaluated and integrated laterally as well as with higher levels of government (Joseph and Chakrabarti, 2011). India shares the characteristics of cultural diversity with its neighbor China.

A study conducted on the indigenous knowledge of Nepal inhabitants revealed that cultural practices in various regions had deeply ingrained what we would identify as emergency management activities. Researchers studying the culture elements of groups living in hazard prone areas found two key characteristics important for this study. First, 
traditional approaches to mitigation were not only effective, but they had been so ingrained in day-to-day activities that most people did not realize they were prepared for disasters. Second, social structures, relationships, history, and institutional arrangements may be deeply instilled with preparedness considerations, unbeknownst to outsiders (Shaw, 2009). Knowing local characteristics can have a dramatic impact on the success emergency management, something lost at the federal policy level. Preparedness has historically been the duty of every citizen, only recently delegated to professionals. There is still much we can learn from the public's involvement, as India and Nepal have shown, in preparing for disasters.

\section{Recommendation}

Two administrative questions need to be asked (Thomas, 1995); first, is public assistance critical to implementation? Second, do the relevant publics share agency goals? For preparedness, the answer to both is yes. Approaches involving the public in the preparedness planning process can take many forms, and extend well into emergency management exercises. Public involvement in administration has some typical forms, including citizen advisory committees, public meetings and forums. The problem with these approaches is three fold. First, advisory committees are sparsely populated and rarely reflect a complex demographic. Second, public meetings, reaching more individuals, are typically an informational one-way communication. Public officials often unsuccessfully rely upon expert opinion, bountiful statistical data and graphic details to punctuate messages. Third, forums and town halls often perform the catharsis function of airing public frustration to officials without clear policy objectives or 


\section{Public Participation in Emergency Management}

institutionalized accountably. If presented as a goal, change is usually temporally distant or murky in implementation strategies. Opposed to these typical participatory approaches, emergency managers have a method that builds knowledge, fleshes out problems, and engages diverse actors. FEMA recommends the employment of five different styles of exercises: orientation, drills, tabletop, functional, and full-scale (EMI, IS-139a). For the purpose of incorporating the general public, a community tabletop exercise would provide the optimal format for engaging the community. These exercises are adequate because they can involve a large group of people, are relatively inexpensive, involve open-ended discussion, and are facilitator led and narrative based. Tabletop exercises help clarify gaps in communications, responsibilities and knowledge existing between areas of the public and government. The LEAP tabletop exercise, participated in by this research, had no specific questions it was trying to answer. Rather, the intent was to help build questions community partners and emergency mangers could ask themselves and each other about their roles in disasters.

\section{Conclusion}

The public represents a diverse and contentious assortment of groups and individuals, perceived as largely unmanageable. This is exactly why the public has been shut out of emergency management policy processes. It is this study's position that these public characteristics are also the characteristics of a resilient community. The literature reviewed on disasters and participation illuminate the largely untapped strengths of public actors. This chapter has isolated the upstream policy stages of agenda-setting and policy-formation as well as downstream areas of implementation, where the public could 


\section{Public Participation in Emergency Management}

benefit emergency management. Agenda-setting in emergency management has largely been propagated by a policy monopoly at the federal level. This created linear policy inept at dealing with "wicked" problems, in need of a devolution of responsibility and input. Policy-formation too, lacks the essential balance required to create policy that best attends to the dynamic problems policy faces. Without balance, policy denies the vast interdependences that bind a community together, bonds that save lives during response and accelerating recovery. Implementation of under-employed mitigation and preparedness efforts can also benefit from greater participation. Non-structural efforts such as education and partnership building can dramatically bolster mitigation efforts. Preparedness is not a phase to be practiced by first responders alone, as citizens are the true first responders. In this case, citizens need to be engaged and included in planning processes.

Practicing the recommendations posited above, implemented to different degrees across the globe, can contribute community resilience. A resilient community is more able to absorb the initial impact of a disaster through both structural and non-structural mitigation and planning for all stakeholders. A resilient community has engaged the most vulnerable among its members and involved their planning considerations. A resilient community is quicker to respond because citizens have taken measures of selfhelp, and refuse to be victims. Finally, a resilient community recovers more rapidly because it has already established dynamic interconnections described as social capital, deployed in force. Unfortunately, at this moment most communities may only display a 
fraction of the characteristics we would identify as resilient, making them potential catastrophes. 


\section{Ch.5 Conclusion}

For public managers, disasters represent the worst kind of problem, those referred to as "wicked." Policies crafted to combat "wicked" problems face great uncertainty involving ramifications, are ingrained with moral ambiguities as well as often being created in a way that does not benefit (or even harms) those affected by the initial problem. The disaster that struck Japan on March 11, 2011 presented a case of cascading threats initiated by an earthquake, creating a tsunami, and sparking a nuclear meltdown. The United States faced Hurricane Katrina in 2005 with a newly reorganized bureaucratic structure and an early emergency declaration by President Bush. Despite this, Hurricane Katrina is considered by many an epic failure of government, as well as being most costly disaster in American history. These two examples illuminated the boundless unpredictably of disasters and the fact that they affect to a varying extent everyone in a community. Recent policies have denied an active role for the public, and have thus hampered mitigation and preparedness in our communities.

The last decade has provided emergency management with the most rapid changes as it has professionalized, incorporated military organization, and centralized federal dominance at the local level. Administratively these changes have required greater emphasis on managerial norms, top-down decision making and a Hamiltonian informational approach. To accommodate the demands of rapid implementation, the eight stages of the policy process have been monopolized by elite federal actors at the cost of public and local input. Accumulatively these efforts have created a consistent 
national framework for leadership and first-responders, but the public is still woefully unprepared and predictably distrustful.

Incorporating the public requires its careful defining, identification of its characteristics and understanding the advantages and disadvantages of its inclusion. John Dewey recognized an ideal public as one that identified issues facing it and confronted them with positive action; this public is absent today. Local officials, media, social scientists, businesses, community associations, and individuals represent a disjointed and easily subordinated public, as far as emergence management prerogatives are concerned. Brought together in a dynamic-participatory-model, the public can benefit rational decision-making, add depth to knowledge, and bolster resilience through increases social capital. These public attributes are lacking in emergency management policy today. Disasters represent a threat to every stakeholder in a community, without widespread input, a community cannot utilize the totality of its assets.

Careful consideration of where in the policy and administrative stages the public can be positively included is essential to maximizing emergency management's mission. The public can benefit the agenda-setting policy stage through explorative workshops that facilitate greater disaster understanding for communities, leaders, and mangers alike. If included in policy-formation, the interdependencies intrinsic to public life can help balance political and bureaucratic demands that have so far commanded emergency management. Administratively, structural-mitigation can be reinforced in the community by non-structural efforts to increase education and build partnerships. Finally, 
preparedness can reach new heights if the public can be included in tabletop exercises that address specific challenges. The public, if included in the specific policy stages and administrate steps, can positively contribute to an increase in community resilience.

Public participation in policy and administration pose three general challenges to emergency managers. First, public inclusion may increase temporal requirements to the point of inaction. Second, dominate political processes and concerns may be disputed to the point of fracture. Finally, administrative goals of rationality, expert knowledge, and efficiency may be subordinated. Contrary to this understanding, FEMA's mission to protect citizen's lives and property from the effects of a disaster have been hampered by a distanced public. In comparison to other administrative challenges, dealing with disasters necessitates the incorporation of governmental, social, individual, and cultural efforts to decrease costs in lives and property. Challenges posed by the public's introduction require balancing the degree of inclusion with areas in the policy process where benefits are expected. As our society grows in population, social complexity and technological sophistication, the costs associated with disasters have increased, and it is time that our efforts to combat them do as well, by increasing public participation in emergency management. 
Table 6 Recommendations for Public Participation in Emergency Management

\begin{tabular}{|c|c|c|c|}
\hline \multirow[t]{2}{*}{ Policy Stages } & \multicolumn{3}{|c|}{ Levels of Governance } \\
\hline & Local & State & Federal \\
\hline $\begin{array}{l}\text { Agenda } \\
\text { Setting }\end{array}$ & $\begin{array}{l}\text { Explorative Community Workshops } \\
\text { Agenda reflecting community } \\
\text { sensibilities expands policy } \\
\text { knowledge, creates social capital, } \\
\text { and promotes successful } \\
\text { downstream efforts. }\end{array}$ & $\begin{array}{l}\text { State governments, congressional } \\
\text { representatives and governors are provided } \\
\text { impetus and feedback from engaged } \\
\text { communities resulting in greater specificity in } \\
\text { agenda and clearly articulated federal influence. }\end{array}$ & $\begin{array}{l}\text { Policy monopoly at the federal level } \\
\text { devolved, allowing state and local input into } \\
\text { agenda setting. Agenda shaped by } \\
\text { collaborative interests pays dividends in } \\
\text { policy formation and downstream stages as } \\
\text { more concerns are initially considered. }\end{array}$ \\
\hline $\begin{array}{c}\text { Policy } \\
\text { Formation }\end{array}$ & $\begin{array}{l}\text { Formative Community Consultations } \\
\text { Local considerations involving } \\
\text { capacity, social vulnerability, and } \\
\text { culture contribute to broad policy } \\
\text { form. }\end{array}$ & $\begin{array}{l}\text { State characteristics, beyond quantifiable } \\
\text { measures, contribute to leader's ability to } \\
\text { engage federal policy. State political actors can } \\
\text { utilize public support to leverage federal } \\
\text { institutions. }\end{array}$ & $\begin{array}{l}\text { Federal level policy retains technical } \\
\text { soundness and resource accountably while } \\
\text { increasing its political feasibly, and } \\
\text { acceptability to public. Federal resources } \\
\text { diversified over all four emergency phases } \\
\text { increases national capacity. }\end{array}$ \\
\hline Mitigation & $\begin{array}{l}\text { Public Mitigation Sessions } \\
\text { Increase in contextual information } \\
\text { bolsters risk assessment, shared } \\
\text { responsibility and illuminates } \\
\text { importance of partnerships in } \\
\text { collaborative enterprises. }\end{array}$ & $\begin{array}{l}\text { Leaders and managers are provided greater } \\
\text { insight into the dynamics of their communities, } \\
\text { allowing for specific and well-suited federal } \\
\text { assistance on mitigation efforts such as } \\
\text { education, outreach, and building sustainable } \\
\text { norms. }\end{array}$ & $\begin{array}{l}\text { Mitigation efforts developing at the local and } \\
\text { state level offer greater opportunities for best } \\
\text { practices and progressive national policy } \\
\text { development. Federal level cost savings can } \\
\text { reduce deficit spending while maximizing } \\
\text { impact. Political leaders benefit from shared } \\
\text { accountability. }\end{array}$ \\
\hline Preparedness & $\begin{array}{l}\text { Community Tabletop Exercises } \\
\text { With little investment from } \\
\text { managers and leadership, exercises } \\
\text { can engage diverse community } \\
\text { members, build knowledge about } \\
\text { planning, and flesh out potential } \\
\text { problems. }\end{array}$ & $\begin{array}{l}\text { State actors promoting prepared and resilient } \\
\text { communities benefit from accelerated response } \\
\text { and recovery from disasters while lessening their } \\
\text { dependence on federal guidance and resources. }\end{array}$ & $\begin{array}{l}\text { State and local communities familiar with } \\
\text { organizational characteristics complement } \\
\text { federal command and control structures and } \\
\text { more importantly are engaged in self-help, } \\
\text { preparedness, and resiliency efforts. }\end{array}$ \\
\hline
\end{tabular}




\section{Works Cited}

Anderson, James E. Public Policy Making. Boston, MA: Wadsworth, 2010. P. 4-13. Print.

Arnstein, Sherry. "A Ladder of Citizen Participation." Journal of the American Planning Association, 1969, Vol. 35, No. 4, P.216-224.

Bach, Robert and David J. Kaufman. "A social infrastructure for Hometown Security: Advancing the Homeland Security Paradigm." Homeland and Security Affairs, 2009, Vol. 5, No. 2, P.2-13.

Bach, Robert, Robert Doran, Laura Gibb, David Kaufman, and Kathy Settle. "Policy Challenges in Supporting Community Resilience." Presented at London Workshop of the Multinational Community Resilience Policy Group, November 4-5, 2010.

Beresford, Peter and Martin Hoban. "Participation in anti-poverty and regeneration work and research." Joseph Rowntree Foundation, 2005. Web. Oct. 1, 2011.

Berke, Philip J. and Thomas J. Campanella. "Planning for Post Disaster Resiliency." Annals of the American Academy of Political and Social Science, 2006, Vol. 604, P.192-207.

Birkland, Thomas A. After Disaster: Agenda Setting, Public Policy, and Focusing Events. Washington, D.C.: Georgetown University Press, 1997. P. 14-20, 64, 69-71. Print.

Birkland, Thomas A. An Introduction to the Policy Process: Theories, Concepts, and Models of Public Policy Making. Armonk, N.Y.: M.E. Sharpe, 2010. Print.

Boettke, Peter; Emily Chamlee-Wright; Peter Gordon; Standfod Ikeda; Peter T. Lesson and Russell Sobel. "The Political, Economic, and Social Aspects of Katrina." Southern Economic Journal, 2007,Vol. 74, No.2, P.363-76.

Boin, Arjen and Paul't Hart. "Public Leadership in Times of Crisis: Mission Impossible?" Public Administration Review, 2003, Vol.63, No.5, P.544-553.

Bolin, Robert and Lois Stanford. The Northridge Earthquake: Vulnerability and Disaster. Routledge Press, 1998. P. 9-11. Print.

Booher, David E and Judith E. Innes. "Network Power in Collaborative Planning." Journal of Planning Education and Research, 2002, Vol. 21, No. 221.

Bowen, Ashley. "Are We Really Ready? The Need for National Emergency Preparedness Standards and the Creation of the Cycle of Emergency Planning." Politics \& Policy, 2008. Vol.36, No.6, P.834-853.

Britton, Neil R. and Gerald J. Clark. "From Response to Resilience: Emergency Management Reform in New Zealand.” Natural Hazard Review, August 2000, P. 146-160.

Britton, Neil R. "A New Emergency Management for the New Millennium?” Australian Journal of Emergency Management, Summer 2001, P.44-54.

Brown, Mary. "An Empirical Assessment of the Hurdles to Geographic Information System Success in Government." State \& Local Government Review. 1996,Vol.28, No.3, P.193-204.

Carr, Craig L. Polity: Political Culture and the Nature of Politics. Lantham, M.D.: Rowman \& Littlefield Publishers, 2007. P. 156-172. Print.

Cellucci, Thomas. "DHS Global Outreach Efforts: Looking for the Best Technology and ProductsPeriod." U.S. Department of Homeland Security. Washington, D.C. 2008

Churchman, C. West. “Wicked Problems.” Management Science,1967, Vol.14, No.4, P.141-42.

Citizen Corps. 2009. Federal Emergency Management Agency ."Personal Preparedness in America: findings from the 2009 Citizen Corps National Survey." P. 1-91. Web. Dec. 11, 2011. 
Citizen Corps. 2011. Federal Emergency Management Agency. "Citizen Corps Councils Around the Country.“ Web. Dec. 5, 2011.

City of Las Vegas. Office of Emergency Management. Publication Date Not Identified. "Confidentially

Notice: Emergency Plans.” Las Vegas, Nevada Web. Dec. 14, 2011

City of Oklahoma City. Police Home Page. Web. Nov. 12, 2011 at

(http://www.okc.gov/okcpd/divisions/em.html)

City of Portland. 2009. "City of Portland Adapted Budget 2010-11." Portland, Oregon.

City of Portland. Office of the City Auditor. 2010. "Emergency Management: Coordination Limited and

Essential Functions Incomplete.” Portland, Oregon. Web. Dec. 5, 2011.

City of Portland, Bureau of Planning and Sustainability. 2010 The Portland Plan. "Phase I Workshops

Survey Results Summary.” Portland, Oregon.

City of Portland. Office of Emergency Management. 2004. "Portland Natural Hazard Mitigation Plan 2005." Portland, Oregon. Web. Nov. 3, 2011.

City of Portland. Office of Emergency Management. 2006. "Basic Emergency Operations Plan."

Portland, Oregon. Web. Nov. 1, 2011.

City of Portland. Office of Emergency Management. 2010. "2011-2013 Strategic Plan.” Portland,

Oregon. Web. Feb. 7, 2012.

City of Portland. Office of Emergency Management. 2010. "Portland Natural Hazard Mitigation Plan

2010.” Portland, Oregon. Web. Sept. 20, 2011.

City of Portland. Office of Emergency Management. 2011. "Portland LEAP Tabletop Exercise Situational

Manual." Portland, Oregon. Web. Sept. 20, 2011.

Coglianese, Cary. "The Limits of Consensus." Environment. 1999, Vol. 41, No.3, P.28-33.

Cohen, Wilbur J. and Evelyn F. Boyer. "Federal Civil Defense Act of 1950: Summary and Legislative

History." Social Security Bulletin. 1950, Vol. 14.4, P. 11-16.

Col, Jeanne-Marie. "Managing Disasters: The Role of Local Government." Public Administration Review. 2007. Special Issue, P.114-25.

Corporation for National \& Community Service. Volunteering in America. "Number of Volunteers."

Web. Nov. 28, 2011.

Crocker, David A. "Deliberative Participation in Local Development." Journal of Human Development. 2007, Vol. 8, No.3, P.431-55.

Cwiak, Carol. "Framing the Future: What Should Emergency Management Graduates Know?" Journal of Homeland Security and Emergency Management. Vol.8, Iss. 2, 2011, Article 14.

Denhardt, Robert B. and Janet Vinzant Denhardt. "The New Public Service: Serving Rather Than Steering." Public Administration Review. 2000, Vol. 60, No.6, P.549-559.

Dewey, John. The Public and Its Problems. Chicago, I.L.: Swallow Press, 1954. P. 27-47. Print.

Digital Sandbox. “Analysis of FY2011 Homeland Security Grants.” Part.5. Web. May, 24, 2011.

Economic Research Service. "State Fact Sheets: Oregon.” USDA. 2012. Web. Jan. 5, 2012.

Edwards, Frances. "Federal Intervention in Local Emergency Planning: Nightmares on Main Street." State \& Local Government Review. 2007, Vol.39, No. 1, P.31-43.

Emergency Management Institute. Professional Development Series: Independent Study Courses. Couse Numbers: IS-120.a, IS-230.b, IS-235.b, IS-240.a, IS-241.a, IS-242.a. Web. June 2011.

Explore Carbondale. "Map Your Neighborhood-A Program to Bring Your Neighborhood Together." Web. Jan. 5, 2012. 
Farazmand, Ali. "Learning from the Katrina Crisis: A Global and International Perspective with Implications for Future Crisis Management.” Public Administrative Review. 2007. Vol. 67 Special Issue, P.149-59.

Federal Emergency Management Agency. 1997. “Project Impact Guide.”. Web. Jan. 3, 2012. (http://desastres.usac.edu.gt/documentos/pdf/eng/doc13139/doc13139.htm).

Federal Emergency Management Agency. Region X News. 1999. "Multnomah County and City of Portland Join Project Impact.” R10-99-53, Washington, D.C. Web. Nov. 10, 2011.

Fischer, Frank. "Citizen Participation and the Democratization of Policy Expertise: From Theoretical Inquiry to Practical Cases.” Policy Sciences, 1993, Vol. 36. No.3, P.165-187.

Foucault, Michel. Power/Knowledge: Selected Interviews \& Other Writings 1972-1977. Washington, D.C. Pantheon Books, 1980. P. 114. Print.

Geis, Donald. "By Design: The Disaster Resistant and Quality-of-Life Community." Natural Hazards Review. 2000. P.161-80.

Guragain, Ramesh; Ganesh Jimee and Amod Mani Dixit. "Earthquake Awareness and Effective Planning Through Participatory Risk Assessment: An Experience from Nepal." The $14^{\text {th }}$ World Conference on Earthquake Engineering. October 12-17, 2008, Beijing, China.

Habermas, Jurgen. Legitimation Crisis. Boston, M.A.: Beacon Press, 1975. P. 123. Print.

Haddow, George D. Introduction to Emergency Management. Burlington, M.A.: Butterworth Heinemann, 2011. P. 21-172,219. Print

Hampton, Greg. "Narrative Policy Analysis and the Integration of Public Involvement in Decision Making." Policy Science,2009 Vol.42, P.227-242.

Henstra, Daniel. "Explaining Local Policy Choices: A Multiple Streams Analysis of Municipal Emergency Management." Canadian Public Administration, 2010, Vol. 53, No. 2, P.241-258.

Hoeppner, Mary M., Debra K. Olson and Susan C. Larson. "A Longitudinal Study of the Impact of Emergency Preparedness Curriculum.” Public Health Reports. 2010, Supplement 5, Vol. 125.

Holderman, Eric and Ann Patton. "Project Impact Initiative to Create Disaster-Resistant Communities Demonstrates Worth In Kansas Years Later.” Web. Oct. 10, 2011

Horlick-Jones, Tom and Ana Prades. "On Interpretive Risk Perception Research: Some Reflections on its origins; its nature; and its Possible Applications in Risk Communication Practice." Health, Risk \& Society. 2009, Vol. 11, No.5, P.409-430.

Horwich, George. "Disasters and Market Response." CATO Journal, 1990, Vol.9, Iss. 3, P.531.

Innes, Judith Eleanor and David E Booher. Planning With Complexity: An Introduction to Collaborative Rationality for Public Policy. New York, N.Y.: Routledge, 2010. Print.

Irvin, Renee A. and John Stansbury. "Citizen Participation in Decision Making: Is it Worth the Effort?" Administration Review. 2004, Vol. 64, No.1, P.55-65.

Jones, Charles O. An Introduction to the Study of Public Policy. Monterey, C.A.: Brooks/Cole Pub. Co., 1984. Print.

Joseph, Mallika and P.G. Dhar Chakrabarti. "Nontraditional Security Challenges in India: Human Security and Disaster Management." The National Bureau of Asian Research, NBR Special Report \#34, 2011.

King, Cheryl Simrell, Kathryn Feltey, Bridget O'Neill Susel. "The Question of Participation: Toward Authentic Public Participation in Public Administration." Public Administration Review. 1998, Vol.58, No.4, P.317-326. 
King, David. "You're on Your Own: Community Vulnerability and the Need for Awareness and Education for Predictable Natural Disasters." Journal of Contingencies and Crisis Management, 2000, Vol. 8 , No.4, P. 223-229.

Kingston, Richard. "Public Participation in Local Policy Decision-Making: the Role of Web-Based Mapping." The Cartographic Journal. 2007, Vol.44, No.2, P.138-144.

Kirlin, John J. "The Big Questions of Public Administration in a Democracy." Public Administration Review. 1996, Vol.56, No.5, P.416-423.

Klinke, Andreas and Ortwin Renn. "A New Approach to Risk Evaluation and Management: Risk=Based, Precaution-Based, and Discourse-Based Strategies.” Risk Analysis. 2002, Vol.22, No.6, P. 1071-94.

Louisville and Jefferson County Metro Emergency Management Agency. 2010 "Louisville / Jefferson County Emergency Operations Plan” Louisville, Kentucky. Web. Jan.20, 2012.

Lynn, Laurence. Public Management as Art, Science, and Profession. Chatham, N.J.: Chatham House Publishers, 1996. P. 19-30, 51-76, 90-98. Print.

Malhorta, Neil and Alexander G. Kuo. "Attributing Blame: The Public's Response to Hurricane Katrina." The Journal of Politics. 2008, Vol. 70, No.1, P.120-135.

Mantysalo, Raine. "Dilemmas in Critical Planning Theory." The Town Planning Review. 2002, Vol.73, No.4, P.417-436.

May, Peter J and Walter Williams. Disaster Policy Implementation: Managing Programs Under Shared Governance. New York, N.Y.: Plenum Press, 1986. P. 153-156. Print.

McEntire, David A. "A Comparison of Disaster Paradigms: The Search for a Holistic Policy Guide." Public Administration Review. 2002, Vol. 62, No. 3, P.267-281.

McInerney, David and Klaus Keller. "Economically Optimal Risk Reduction Strategies in the Face of Uncertain Climate Thresholds." Climate Change. 2008, Vol. 91, P.29-41.

Mileti, Dennis. "Motivating Public Preparedness.” IAEM Bulletin, 1998, Vol. 28, No. 4, P. 9-12

Mitchell, James K. "The Primacy of Partnership: Scoping a New National Disaster Recovery Policy." Annals of the American Academy of Political and Social Science, 2006, Vol. 604, P. 228-255.

Miyaguchi, Takaaki and Rajib Shaw. "Corporate Community Interface in Disaster Management: A Preliminary Study of Mumbai, India.” Risk Management. 2007, Vol.9, No. 4, P.209-222.

Morgan, Douglas F., Richard Green, Craig W. Shinn and Kent S. Robinson. Foundations of Public Service. Amonk, NY: M.E. Sharpe Inc, 2008. P. 46-61. Print.

Moss, David A. When All Else Fails: Government as the Ultimate Risk Manager. Cambridge, M.A.: Harvard University Press, 2002. P. 23-51, 124-125. Print.

Multi-hazard Mitigation Council. "Natural Hazard Mitigation Saves: An Independent Study to Assess the Future of Savings from Mitigation Activities." National Institute of Building Sciences. 2005. Web. Sept. 5, 2011.

Murphy, Brenda L. "Locating Social Capital in Resilient Community-Level Emergency Management." Natural Hazards 2007, Vol. 41, P. 297-315.

National Commission on Terrorist Attacks upon the United States. The 9/11 Commission Report. New York: W.W. Norton \& Company, 2004. P. 102-103. Print.

National Research Council Committee on Disaster Research in the Social Sciences. Future Challenges and Opportunities. Facing Hazards and Disasters: Understanding Human Dimensions. Washington, D.C.: National Academies Press, 2006. P. 2-31, 65-81, 91-109, 219-233. Print.

National Science Foundation. "NSF 92-1 National Science Foundation Annual Report." 1992. Web. Aug. 12, 2011. 
National Science Foundation. 2011. "Fiscal Year NSF Budget Request to Congress." Arlington, Virginia. Web. Aug, 122011.

New Zealand Ministry of Civil Defense and Emergency Management. 2002. Civil Defence Emergency Management Act 2002. Wellington, New Zealand. Web. Nov. 17, 2011.

O'Brien, Geoff. "UK Emergency Preparedness: A Step in the Right Direction?” Journal of International Affairs.2006, Vol.59, No.2, P. 63-85.

Olson, Richard S. and Vincent T. Gawronski. "From Disaster Event to Political Crisis: A ' 5 C+A' Framework for Analysis.” International Studies Perspectives. 2010, Vol. 11, P.205-221.

Pearce, Laurie. "Disaster Management and Community Planning, and Public Participation: How to Achieve Sustainable Hazard Mitigation.” Natural Hazards. 2003, Vol. 28, P. 211-228.

Pearce, Laurie. "The Value of Public Participation During A Hazard, Impact, Risk and Vulnerability (HIRV) Analysis." Mitigation and Adaption Strategies for Global Change. 2005, Vol. 10, P. 411-41.

Posner, Richard A. Catastrophe: Risk and Response. New York: Oxford University Press, 2004. P. 5-91. Print.

Putnam, Robert D. Bowling Alone: The Collapse and Revival of American Community. New York: Simon \& Schuster, 2000. P. 15-30. Print

Putnam, Robert., Lewis M Feldstein, and Don Cohen. Better Together: Restoring the American Community. New York: Simon \& Schuster, 2003. P. 241-268. Print.

Rittel, Horst W.J. and Melvin M. Webber. "Dilemmas in a General Theory of Planning." Policy Sciences. 1973 No.4, P. 55-69.

Roberts, Nancy C. "Keeping Public Officials Accountable through Dialogue: Resolving the Accountability Paradox." Public Administration Review. 2002, Vol. 62, No.6, P.658-669.

Rodriguez, Havidan, Joseph Trainor and Enrico L. Quarantelli. "Rising to the Challenge of a Catastrophe: The Emergent and Prosocial Behavior following Hurricane Katrina." Annals of the American Academy of Political and Social Science. 2006, Vol. 604, P. 82-101.

Rossi, Peter H., James D Wright, and Eleanor Weber. Natural Hazards and Public Choice: The State and Local Politics of Hazard Mitigation. New York: Academic Press, 1982. P. 85-164. Print.

Rourke, Francis E. Bureaucracy, Politics, and Public Policy. HarperCollins, 1984. P. 11-19, 57, 89-99. Print.

Sadeleer, Nicolas. Implementing the Precautionary Principle: Approaches from the Nordic Countries, EU and USA. Sterling, V.A.: Earthscan. 2007. P. 12-26. Print.

Sagurao Seminar. "The Better Together Report." The Kennedy School of Government, Harvard University. 2000. Web. June 13, 2011.

Schultz, Jennifer, A. Marureen O'Brien and Bedassa Tadesse. "Social Capital and Self-Rated Health: Results from the US 2006 Social Capital Survey of One Community." Social Sciences \& Medicine. 2008, Vol. 67, P. 606-17.

Shaw, Rajib, Anshu Sharma and Yuhio Takeuchi. Indigenous Knowledge and Disaster Risk Reduction: From Practice to Policy. New York: Nova Science Publishers, 2009. Print.

Silver, Hilary; Aland Scott; Yuri Kazepov. "Participation in Urban Contention and Deliberation." International Journal of Urban and Regional Research. 2010, Vol. 34.3, P.453-77.

Simpson, David. "Community Emergency Response Training (CERTs): A Recent History and Review." Natural Hazards Review. May 2001, P. 54-63. Web. June 23, 2011.

Sobel, Russell S., Christopher J. Coyne, Peter T. Leeson. "The Political Economy of FEMA: Did Reorganization Matter." Journal of Public Finance and Public Choice. 2007, Vol. 17, P.49-65. 
Stallings, Robert A. and E.L. Quarantelli. "Emergent Citizen Groups and Emergency Management." Public Administration Review. 1985, Vol. 45, P.93-100.

Stirling, Andy. "Science, Precaution, and the Politics of Technological Risk." Annals of the New York Academy of Sciences. Vol. 1128, P.95-110

Sunstein, Cass R. Law of Fear: Beyond the Precautionary Principle. New York: Cambridge University Press, 2005. P. 37-54. Print.

Sylves, Richard Terry. Disaster Policy and Politics: Emergency Management and Homeland Security. Washington, D.C.: CQ Press, 2008. P. 28-112. Print.

Tierney, Kathleen; Michael Lindell, Ronald W. Perry, editors. Facing the Unexpected: Disaster Preparedness and Response in the United States. Washington, D.C.:Joseph Henry Press, 2001. Print.

Tierney, Kathleen; Christine Bevc; Erica Kuligowski. "Metaphors Matter: Disaster Myths, Media Frames, and Their Consequences in Hurricane Katrina." Annals of the American Academy of Political and Social Sciences. 2006, Vol.604, P. 57-81.

Thomas, John Clayton. Public Participation in Public Decisions: New Skills and Strategies for Public Managers. San Francisco, C.A.: Jossey-Bass Publishers, 1995. Print.

Tocqueville, Alexis. Democracy in America. Chicago, I.L.: University of Chicago Press, 2000. Print.

United Kingdom Cabinet Office. 2011. "Government Response to the Public Consultation on the Draft Cooperation Guidance under the Civil Contingencies Act 2004.” London, United Kingdom. Web. Nov. 10, 2011.

United Kingdom Cabinet Office. Civil Contingencies Secretariat. 2009. "Community Resilience Stakeholder Consultation Outputs.” London, United Kingdom. Web. Nov. 10, 2011.

United Kingdom Cabinet Office. 2011. "Community Resilience Programme.” London, United Kingdom. Web. Nov. 11, 2011.

United Kingdom Cabinet Office. 2011. "Strategic National Framework on Community Resilience." London, United Kingdom. Web. Nov. 11, 2011.

United Nations Development Programme. Bureau for Crisis Prevention and Recovery. 2004. "Reducing Disaster Risk: A Challenge for Development. "New York, New York. Web. Oct 13, 2011.

United Nations International Strategy for Disaster Reduction. 2007. "Hyogo Framework for Action 20052015." Geneva, Switzerland. Web. Oct 16, 2011

United Nations Office for the Coordination of Humanitarian Affairs. 2011. "Japan-Earthquake \& Tsunami Situation Report No. 16." Geneva, Switzerland. Web. Feb. 13, 2012

U.S. Census Bureau. "Statistical Abstract of the United States: 2012." 2012. Web. Feb 3, 2012.

U.S. Census Bureau. “2010 Census U.S. Gazetteer Files.” Web. Dec. 1, 2011.

U.S. Department of Defense. American Forces Press Service. 2005. "Bush Calls for Broader Military Disaster Response Role.” Washing, D.C. Web. Sept. 20, 2010.

U.S. Department of Homeland Security, FEMA. 2011. "A Whole Community Approach to Emergency Management: Principles, Themes, and Pathways for Action." FDOC 104-008-1 December.

U.S Department of Homeland Security, FEMA, Unknown, "New Orleans Metropolitan Area (NOMA) Infrastructure Projects." Web. Jan. 5, 2012.

U.S. Department of Homeland Security. 2010. "Fiscal Year 2011 Budget in Brief." Washington, D.C. Web. Jan. 12, 2012

U.S. Department of Homeland Security. 2008. "The First Year After Hurricane Katrina: What the Federal Government Did.” Web. October 22, 2010. 
U.S. Department of Homeland Security. 2010. “Homeland Security Grant Program 2011.” Web. Jan. 8, 2012.

U.S. Small Business Administration. Office of Advocacy. 2011. "Frequently Asked Questions." Washington, D.C. Web. Dec. 5, 2011.

Vigoda, Eran. "From Responsiveness to Collaboration: Governance, Citizens, and the Next Generation of Public Administration." Public Administration Review. 2002, Vol. 62, No. 5, P.527-40.

Walters, Lawrence; James Aydelotte and Jessica Miller. "Putting More Public in Policy Analysis." Public Administrative Review. 2000, Vol.60, No. 4, P. 349-359.

Waugh Jr., William. "Regionalizing Emergency Management: Counties as States and Local Government." Public Administration Review. 1994, Vol. 54, No.3, P.253-258.

Waugh Jr., William. "The Political Costs of Failure in the Katrina and Rita Disasters." Annals of the American Academy of Political and Social Sciences. 2006, Vol. 604, P.10-25.

Wedel, Janince; Cris Shore; Gregory Feldman; Stacy Lathrop. "Toward an Anthropology of Public Policy." Annals of the American Academy of Political Science and Social Science. 2005, Vol. 600, P.30-51.

Webster, P.J.; G.J. Holland; J.A. Curry; H.R. Chang. "Changes in Tropical Cyclone Number, Fruition, and Intensity in a Warming Environment.” Science Magazine. Sept. 16, 2005, Vol. 309, P. 1844-46.

Whitford, Andrew B. "Decentralize Policy Implementation." Political Research Quarterly. 2007, Vol.60, No.1, P.17-20.

Woodly, Deva. "New Competencies in Democratic Communication? Blogs, Agenda Setting, and Political Participation." Public Choice. 2007, Vol. 134, P.109-123.

World Bank, "Overcoming Behavioral and Institutional Inertia." World Development Report. 2010, Ch.8, P. 321-347. 


\section{Appendix \\ The Public in Portland's Emergency Management}

\section{Introduction}

Emergency managers are tasked with addressing the nonlinearity and ambiguous nature of "wicked" problems, and this thesis provides new ways to approach such predicaments. While the recommendations may seem well outside the current norms of emergency management, foreign and domestic, they are not without precedent. In this appendix, the emergency management community in Portland, Oregon will be considered in light of recommendations for greater public participation. Portland leadership, initially hampered by federal policy domination, has since become powerfully proactive. The first section will examine the cities transition from a limited participatory emergency management focus, to a more holistic and inclusive policy system. The second section will provide a quick comparison of emergency management technological outreach by cities comparable to Portland. This comparison will help place this study's critique of general public participation in emergency management on a practical continuum.

Finally, a former FEMA program called Project Impact will be briefly investigated to establish precedent for federal initiated devolution of emergency management, carried out in Portland. The city of Portland is better protected today thanks to the efforts of emergency managers who have reached out to stakeholders in the community, and there are more to be reached. Compared with other cities, Portland's emergency management agency is alert, attentive, transparent, accountable, and actively engaging new ways to better the community. Finally, the institutional shadow from Project Impact, of which we would be wise to revisit in efforts to increase our community's resilience to disasters (Holderman and Patton, 2010). 


\section{Portland Bureau of Emergency Management, Oregon}

The Portland Bureau of Emergency management (formerly Portland Office of Emergency Management) has been a continually evolving and constantly learning from both stumbles and successes. Established in 2003, PBEM took over the managerial role of emergency coordination traditionally held by the fire and rescue departments. The agency is largely funded by DHS grants [Ch.2] and supports approximately fifteen fulltime positions (City of Portland, Audit, 2010). The agency is responsible for the implementation and coordination of the four-phases of emergency management: mitigation, preparedness, response, and recovery. This section will reflect upon a 2010 agency audit, which revealed a number of concerns, and areas improvement, drawn primarily from two audit objectives. The first objective was to assess the current governance structure to ascertain if they were suitable to provide oversight for emergency management tasks. The second objective was to determine the degree to which the agency had implemented policies affecting planning, training, education, response, and communication. Response to the audit was not just swift, coming in the form of an update mitigation plan, but also expressed the proactive nature of the agency by way of a new strategic plan. The Portland Bureau of Emergency Management stands as a very fine example of how public participation can be brought into governmental agencies, for the benefit of the entire community. The topics of agenda setting, policy formation, mitigation, and preparedness will provide the topical framework by which PBEM will be discussed.

\section{Agenda Setting}

The agenda setting process at the federal level [Ch.2] is one that involves only a marginal degree of public participation [Ch.3]. The repercussions of this, it has been posited, are the problematic implementation of policy for local authorities. The early years PBEM may be a fine example of the problem that emerges from imposing an agenda that is not locally contributed to. The audit of 2010 found that the first years of 


\section{Public Participation in Emergency Management}

the Portland agency were characterized best by two symptoms. First, changes in directorship of the organization were frequent. Second, the agency had failed to establish substantial working relationships with other agencies and partners (City of Portland, Audit, 2010). One could readily understand the conflicts in jurisdiction and perceived power between agencies, only enhanced by a new agency imposed from the federal level. In a letter that prefaced the cities Basic Emergency Operations Plan of 2006, then Mayor Potter described the agencies three goals: to implement National Incident Management System, form committees, and create leadership councils (City of Portland, 2006). This letter was a request to city agency managers for greater compliance and cooperation with the initiatives imposed on Portland through DHS grant requirements. Unfortunately, the mayor's letter was not sufficient in aligning other agencies and community partner's cooperation, and the fledgling emergency bureau struggled.

The problem was ingrained in the top-down command and control focus of the federal plans themselves. At root, the plans were not adequately flexible, preventing the start-up emergency management agency from acquainting itself with essential contextual details required to facilitate collaboration. Despite this the agency did not rest complacently, as both recent mitigation and strategic plans show powerful corrections in behavior. One clear goal of the Portland Strategic Plan of 2011-2013 initiates a holistically integrative planning process (City of Portland, Strategic plan, 2010). This initiative establishes goals and methods to create collaborative planning partnerships with nearly all city agencies, in order develop partnerships. Rather than dictating the agenda of local policy, the plan uses language that describes wider agency partnerships to determine shared goals and objectives. These partnerships also establish mutually beneficial agendas, which in turn increase a policies chance efficient implementation, and long-term success, a lesson PBEM has taken to heart. While this is a progressive step, there is still room for institutionalized public participation. 


\section{Policy-Formation}

Early days of emergency management in Portland reflected a policy-formation process that nearly mirrored the federal processes, one with no public participation. The letter from Mayor Potter, mentioned above, detailed the creation of two advisory committees that helped direct agency development. The first committee consisted of the Mayor, President of the City Council, City Auditors, and key first-responder-agency directors. The second committee was called the Emergency Management Committee and consisted of senior managers from each city bureau. While it is not clear whether this was the case, it is fathomable these two committee efforts were hampered by very divergent ideas, goals and implementation abilities (as elected and unelected interest often do). What the audit noted was a problematic lack of clear parameters and powers assigned to each committee, as well as the fact that their meetings were undocumented (City of Portland, Audit, 2010). A lack of transparency and unclear powers of policy formation and implementation are exactly the forces that form national emergency management policy. This closed system of policy formation excluded not only the general public but also disengaged agencies that could have contributed. Local leadership, without malice, modeled their own committees and leadership after the federal government, which led to very poor performance.

Again the emergency managers in Portland did not entrench themselves in political or bureaucratic positions for their own sake, but rather proactively engaged solutions. Following the audit, PBEM drew from community resources, as opposed to federal, and created a new Strategic Plan for the years 2011-13. The impetus for a new direction in Portland emergency management came from the incorporation of numerous ideas and considerations drawn from the 2010 Portland Audit, Emergency Management Accreditation Program, the Portland Plan, other agencies strategic plans, budget committees, Portland CERT program Steering Committee and importantly from a town hall meeting held in SW Portland (City of Portland, Strategic Plan, 2010). Although all the contributors are noted are essential, by and far the most unusual was the direct 
inclusion of the public. From the town hall meeting, the agency learned that citizens believe preparedness is a matter of having adequate supplies, but lack an understanding on how planning, training and exercises are involved. Although the town hall was largely considered a failure, it did illuminate the lack of basic emergency information held by the public. Policy formation must include considerations from those that may be inadvertently or indirectly involved (citizens), not just authoritative stakeholders (first responders). PBEM took great steps to add participatory depth in the policy formation process, to the benefit of the larger community.

\section{Mitigation}

The 2010 Mitigation Plan pushed the degree of public involvement and risk assessment to the next level. Vulnerability of communities would now be illuminated by three methods; through greater technology, other agencies collaboration, and public outreach. The final approach is most essential for this study, and unlike the vague participatory references found in previous plans, specific details and strategies for the implementation of public participation were presented. These strategies are not just listed out, but factors that will help ensure their success are identified, including information on: prioritization, agencies that are responsible and can help coordinate, potential funding sources, time frames and issues of cost effectiveness and feasibility (City of Portland, Mitigation Plan, 2010). The 2010 Mitigation Plan is the product of a far wider group of individuals than its 2005 predecessor, which is reflected in the desire that the plan comes close to reaching that 'comprehensive' risk assessment goal that was mentioned, but not clearly articulated, by the Portland Audit. The Strategic Plan that followed the Mitigation Plan of 2010 set a new standard by identifying a 'whole community approach' to mitigation. The plan extended emergency management activities into the community and engages very specific groups and vulnerable populations (City of Portland, Strategic Plan, 2010). One problem that emerges is grant funding for PBEM activities, as plans need to be judged by federal guidelines. These guidelines, while broadly useful, are not impregnated with the flexibility that is needed for local implementation. PBEM has 
taken elements of the federal frameworks that work, like command structures, and balanced those that do not with a new emphasis on sustainably and resilience understanding.

\section{Preparedness}

The 2010 Mitigation Plan, once again, revealed a thoughtful and pragmatic approach to creating greater preparedness in Portland. At the heart of the program lay the framework for future planning that deeply incorporated the involvement of city agencies, business and neighborhoods in readiness considerations (City of Portland, Mitigation Plan, 2010). The Strategic Plan that followed would outline even greater levels of public engagement, of which three details will be discussed here. First, as trained disaster first-responders the CERT team members will have greater input in both policy and administrative activities. Second, in addition to general public preparedness activities, households will be targeted with clear information and given low-cost and practical preparedness goals. Finally, community partners such as businesses and neighborhood associations were prioritized as essential participants for preparedness activities (City of Portland, Strategic Plan, 2010). These three steps bring the larger community within an emergency management circle-of-understanding. In the previous chapters the Portland LEAP exercise was presented an unadulterated example of how a agencies and the public can work together for preparedness. The goals of that exercise did not to include arriving at hard conclusions, rather it intended to flesh out questions and illuminate the interdependences in the community. The LEAP program is ongoing, and no doubt will provide valuable information to both emergency managers and the public at large as they collaborate on preparedness.

Emergency management in Portland, as in the rest of the US, was traditionally the responsibly of local first-responders in the fire departments. When the PBEM was established in 2003 it was essentially an agency framed, paid for and directed from federal authorities. This significantly hampered the young agencies ability to garner support, not just from the public, but also from other essential city agencies and 
leadership. Over the course of the subsequent years the professionals at PBEM addressed challenges and critiques very proactively, as opposed taking the position of denial or entrenchment. Agenda-setting and policy-formation was initially conducted by a relatively small group of individuals, but has since opened to the general public to a degree. This has facilitated far greater communication, shared responsibility, and partnerships that span across city agencies, into the private sector and finally engage neighborhoods at a growing rate. Success of mitigation and preparedness activities in Portland should be bolstered, as stakeholders are able to better understand each other's concerns and proficiencies. While there is still plenty of room for the public in Portland emergency management, the steps that have been taken have increased the communities overall sustainability and resilience. How these steps are unique to Portland and from what roots they emerge from will be the topic of the following sections.

\section{Public Information Comparison}

\section{Introduction}

This study has proposed that the levels of public participation in emergency management are critically absent, and that condition has contributed to overall lack of mitigation and low preparedness. Public participation has been placed on a continuum [Ch.3] and measured against more efficiency-focused modes of governance. The conclusion was reached that much of the public's interaction with emergency management is informational, and thus not participatory. While this conclusion is consistent with the findings concerning the small degree of participation in Portland, PBEM needs national comparisons. Although providing the public with information is very distant from active participation, it is none-the-less very important. By far the greatest informational resources available to citizens are provided via governmental websites, and this section will compare PBEM to four other cities along seven measures. The four cities (Louisville, Milwaukee, Las Vegas, Oklahoma) chosen for this comparison were done based on population size, and did not take into account any other variable. This section is intended to anecdotally illuminate the wide range in content 
offered by emergency management departments who received DHS grant funding (Digital Sandbox, 2011). The seven variables include, allowance of feedback, agent contact information, availability of official plans, calendar of events, alerts, news, and finally a citizen involvement section. All emergency management websites had some basic links to FEMA, as well as links to specific threats. All seven measures are present on the PBEM website and the national FEMA site, both of which make for a rather engaging and enlightening experience (www.portlandonline.com/oem/; www. FEMA.gov).

These seven variables help describe the informational context, transparency and governmental dedication to public interactions to bolster emergency management efforts.

Table 7 Emergency Management Website Comparison of Cities Receiving DHS Grants as of 2010

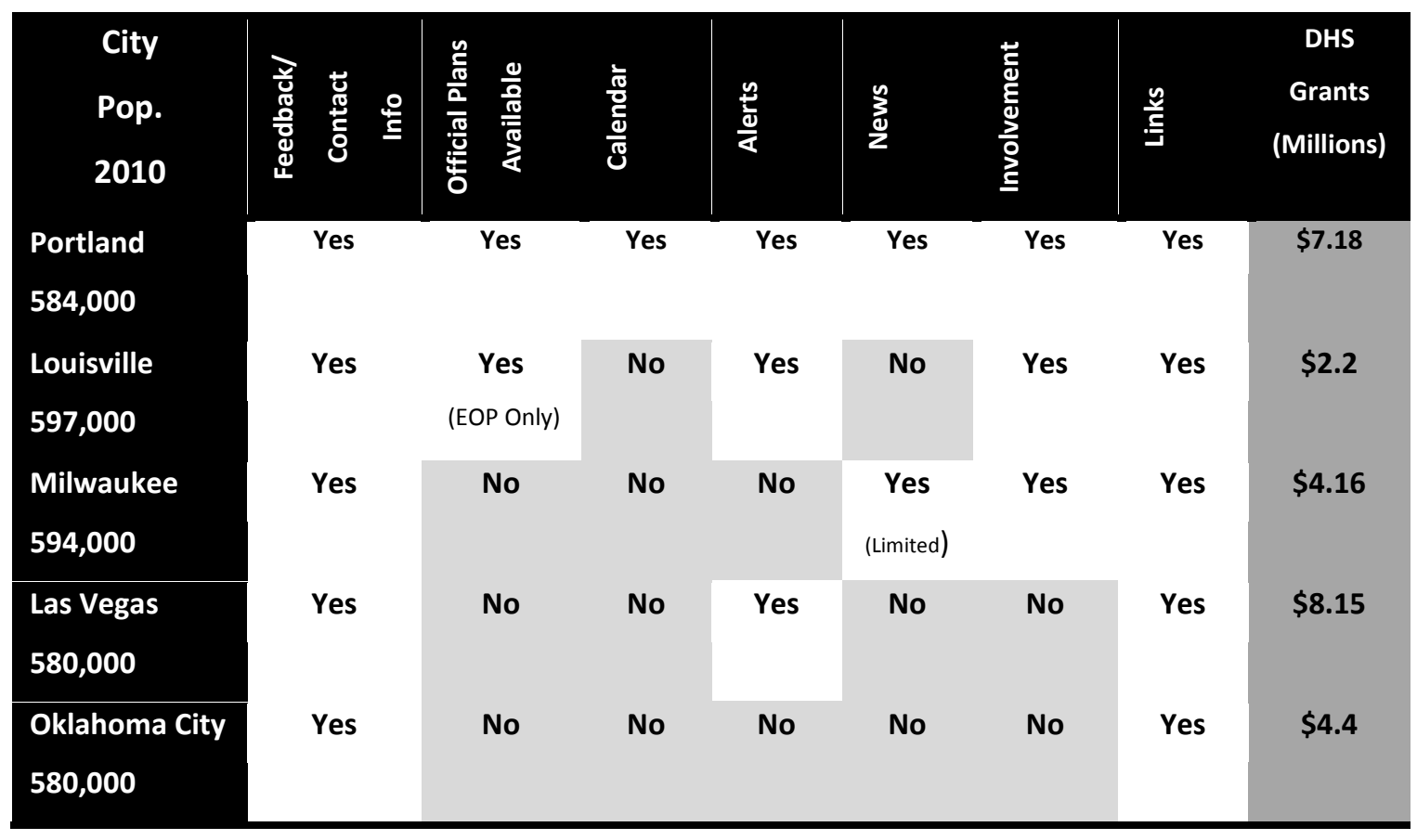

\section{Louisville}

Emergency managers in Louisville, Kentucky are represented by a rather dynamic public website that maintains many of the features found on the PBEM site. Louisville, as of 2010, had a population of approximately 597,000 compared to Portland's 584,000 (U.S. Census Bureau, 2012). The first category of comparison is 
whether the Louisville Emergency Management Office has contact information and has encouraged feedback (Louisvilleky.gov/ema). The website has a clear link to information on individual contacts (names/responsibilities) within the agency but no specific contact numbers or emails for the six employees. In addition, there is only an agency general phone number, with no general email by which comments or questions may be addressed. The second area of consideration involves public access to emergency related plans, including emergency operations plans, mitigation plans, and strategic plans. Louisville has released the city's rather detailed and thorough emergency operations plan. The plan outlines agency responsibilities, communications, hazard analysis, mutual assistance agreements, emergency operations command details, command systems and mass care instructions; just to name a few chapters of this 338-page document (Louisville, 2010). What is missing from the planning in Louisville is a long-term plan to address hazards with a mitigation and preparedness strategy. The third area of inquiry is the inclusion of an agency calendar of events for the public to consult, while there is a link there are no agency activities listed. The presence of an alternative alert system in Louisville, based on text messages, emails, and phones calls, successfully fulfills the fourth measure. The fifth element that is important to have on a website is updated news on agency, weather, and federal activities. The same situation exists in the news section as involved the calendar, there is a link, but it is without content. The sixth category is one that can involve the citizen directly in activities. The Louisville website has numerous informational links as well as links on how to serve on city boards and commissions, but nothing specific to agency engagement or CERT programs. As far as the considerations of this section are concerned, the Louisville Emergency Management Agency website is a reasonably good source of information, offers a degree of transparency, and illuminates the dedicated work of emergency managers. Where the website falters is the lack of event calendars and news, which can be invaluable to citizens who wish to be prepared and participate in community activities. 


\section{Milwaukee}

Emergency managers in Milwaukee, Wisconsin have put together a website that provides substantially less information and opportunity than comparable cities. The Milwaukee Emergency Management and Homeland Security Office is responsible for a population of approximately 594,000 as of 2010, which is slightly less than Louisville but three-thousand more than Portland (U.S. Census Bureau, 2012). As far as the first category is concerned, contacts and feedback, the Milwaukie agency very much succeeds. The agency has general phone, fax, and email information, as well as the phone numbers and email addresses for the five members of the agency (City.milwaukee.gov/OfficeofHomelandSecurity). The second variable to be weighted involves the websites presentation of city emergency plans, in Milwaukee the public is not provided those via the website. The presence of an agency calendar is the third factor considered, and here we find a general city government link but none dedicated to emergency management specifically. The forth element explores the incorporation of an alternate emergency alert system, here again the city is lacking any dedicated system or links to social media sights such as twitter or Facebook.

The presentation of emergency management specific news is an important way of keeping the public up-to-date on activities and threats. While the news is present on the Milwaukee website, it is either very dated (almost a year old) or provides non-functioning links. The finally category detailed here involves links for citizens who want to be prepared or involved. Here the website provides information on personal preparedness as well as links to resources and volunteer organizations such as Citizens and Organizations Active in Disasters. The informational website created by the Milwaukee government represents a decline from Louisville in planning information, transparency, and overall emergency management dedication to public interaction. One cause of this is the splitting of effort between emergency concerns and those of security. Funding from the federal grants come with security spending stipulations, which would explain the combination police office in Milwaukee, as it would keep those funds under the same 


\section{Public Participation in Emergency Management}

roof. Overall, the website is far less successful than Louisville and Portland in providing the citizenry with the information and opportunities they need to mitigate and prepare for disasters.

\section{Las Vegas}

Las Vegas emergency managers are represented by a site reflecting a relatively minor extension of city government. Despite the lacking website, the emergency managers have approximately 584,000 citizens to plan for, an almost identical population to Portland (U.S. Census Bureau, 2012). The website itself provides the very minimum of contact information for the agency, with only an office address, phone number and general email. Agency members and their specific information are not provided. The second variable considered is public access to emergency plans, and Las Vegas is an outlier. While a link to the city's emergency operations plan is presented, what is provided is a notice that state law requires plan to remain confidential (City of Las Vegas, 2011). Contained in the notice is a reference to Nevada state code, which stipulates that cities must file very skeletal plans with the state (compared to very comprehensive plans created in Louisville and Portland). The website has no calendar or news to inform the public. The site does provide links to CERT training, FEMA, and Citizen Corps. Information used for citizen preparedness is incredibly limited; indicating that families need 72-hour kits and plans but not describing contents or reasons why the kits are important. On a positive note, the website is connected to telephone alert system that serves all southern Nevada. The website serving the Las Vegas community can be described as very limited. Information is sparse, transparency is almost non-existent, and dedicated public interaction with emergency management seems to be dismally, if not a distant secondary concern to security. Overall, the website contributes far less to emergency management concerns compared with other cities.

\section{Oklahoma City}

The website maintained by the Oklahoma City Emergency Management Office offers the least amount of information, transparency, and dedicated effort of any city in 
this study. Oklahoma City, Oklahoma is a community of 580,000 citizens, which makes it the least populated city, four thousand people less than Portland (U.S. Census Bureau, 2012). The first, and only, category that is fulfilled by the Oklahoma emergency website involves contacts and feedback. On the mail page, the agency presents an address, phone number and email in which citizens are invited to make comments and suggestions (Okc.gov).

As an extension of the police department, it is obvious that emergency management holds an obscured secondary position to security concerns. The website offers no plans, calendars, alerts, or news. Very basic information on tornados, floods, chemical spills, explosions, lightning, and winter storms is provided, but limited response and preparedness details are available. The real depth of emergency management information and transparency is divided between the Oklahoma State Emergency Office and the Oklahoma City-County Health Department. Respectively, these two websites do offer similar level of detail to Louisville, including; emergency plans, contact information, calendars, alerts, news, and information on what citizens can do. Emergency management in Oklahoma City provides a basic website that helps citizens connect to more informed websites created by the state and health departments. As local citizens, these linked resources don't help build an understanding of local concerns, responsibilities and activities. Rather than having informed citizens familiar with local command and control structures, public works priorities and health concerns; the community in Oklahoma City has the potential to become very chaotic during a disaster. Overall, the emergency management website offers very little local information and transparency to which the efforts of mitigation and preparedness could be built upon.

\section{Conclusion}

In many communities, the website that emergency managers maintain may be the only interface they have with the general public. The brief exploration of four cities that are comparable to Portland have illuminated a very wide range of content. At one end of the spectrum Portland and Louisville present sites that communicate a great deal of 


\section{Public Participation in Emergency Management}

information including emergency plans, calendars, alerts, news and agency contacts. The presence of these items allows the public to glean a very thorough understanding of both emergency management and their personal role in government's attempts to mitigate, prepare, respond and recovery from disasters. The other end of the spectrum represents emergency management offices, which have minimally followed the FEMA definition for information provisions, as follows:

"The amount of public involvement will vary by project and applicant. Adequate public involvement is determined by various factors which include but are not limited to size of population affected, dollar amount of project, geographic area size, and potential for controversy" (U.S. Depart of Homeland Security, New Orleans).

The wide range informational elements present a problem for the average citizen, who may have to engage multiple authorities to gain basic emergency management information. A worse scenario, citizens looking for information get confused and discouraged by poorly maintained and populated websites, adding to the forces already promoting their disengagement from mitigation and preparedness. The PBEM offers citizens not only a plethora of information, but importantly they are presented in many different formats. With a single click of a mouse, a user can contact local authorities, find the next emergency management community activity, or request a presentation for their organization or business. Although this study would contend that providing information is not nearly enough to facilitate greater public participation in mitigation and preparedness, it is a very necessary requirement. With that in mind, local communities may look to the PBEM website as a successful example of how to communicate information, transparency, and dedication to public outreach in reaching emergency management goals.

\section{Project Impact Portland, Oregon}

Project Impact initiated a small revolution in the way the emergency managers conducted their duties and engaged the public, and Portland is evidence of this (Project Impact Guide, 1997). It took approximately two years, but in 1999, Multnomah County 
and Portland signed a Project Impact Partnership Agreement (FEMA, 1999). Present at the ceremony were representatives from local government, community groups, businesses and nonprofit organizations. Within this initial agreement, the partners prioritized five immediate activities: establish a flood hazard community rating system, developed business and industry continuity plans, provide flood hazard information for homeowners and business, created primary school based educational programs, and finally form neighborhood emergency response teams. It is obvious that some of these initiatives were successful implemented in Portland, the fact that this researcher is also a Neighborhood Emergency Team member is evidence. Also evident is that PBEM is still developing the kind of partnerships that Project Impact called for, but with less assistance and collaborative benefits provided by the federal government.

\section{Conclusion}

The problems that emergency managers face in a community are those that can have dramatic impacts on all stakeholders, and thus should involve them. Portland, Oregon created its first dedicated emergency management office in 2003 amidst a major reorganization of FEMA under the Department of Homeland Security. While grant funding from DHS helped pay for and establish the PBEM, the agency's initial years were marred by lack of leadership and vacant partnerships. This was due in part to rigid frameworks, requirements, and organizational examples emerging from the federal government. Rather than deny the problems, the agency proactively engaged fellow agencies and the community at large to maximize its potential. The Portland Strategic Plan of 2010 presents a series of steps the agency is planning to take to make Portland a safer place, through greater public participation in mitigation and preparedness activities. Indeed, PBEM efforts are to be commended but it should be acknowledged that an even greater role for the general public are implementable. These include conducting general goal shaping workshops with the public; allowing neighborhood specificity in policy formation; conducting mitigation planning in a collaborative manner; and finally conducting tabletop exercises with the community to bring participation to fruition. 
This appendix put Portland on a continuum of cities that meet minimal levels of public engagement, providing information. Websites represent a powerfully accessible tool for emergency managers to not only inform the community, but also directly involve them. As was demonstrated, emergency management websites have a very wide range of success in elements such as allowing feedback, providing access to city plans, updated calendars, operation alert systems, news and ways citizens can get involved. Portland and Louisville represent emergency managers who provided their communities with great sites. Finally, this appendix established precedents of federal emergency management programing that emphasized devolution, local judgment, and community engagement. Project Impact, while short lived, empowered communities like Portland and fortified their local foundations, the effects of which are still visible today. 